\title{
AVALIAÇÃO DA EFICÁCIA DE UM PROTOCOLO DE EXERCÍCIOS FÍSICOS BASEADO NO MÉTODO PILATES NAS VARIÁVEIS DOR LOMBAR, FLEXIBILIDADE E FORÇA MUSCULAR EM PROFISSIONAIS DE ENFERMAGEM COM LOMBALGIA CRÔNICA IDIOPÁTICA
}

Tese apresentada à Escola de
Enfermagem de Ribeirão Preto da
Universidade de São Paulo para
obtenção do título de Doutora em
Ciências junto ao Programa de Pós-
Graduação em Enfermagem
Fundamental.

Área de Concentração: Enfermagem Fundamental

Linha de pesquisa: Saúde do Trabalhador

Orientadora: Profa. Dra. Maria Helena Palucci Marziale 
Autorizo a reprodução ou divulgação total ou parcial deste trabalho, por qualquer meio convencional ou eletrônico, para fins de estudo e pesquisa, desde que citada a fonte.

FICHA CATALOGRÁFICA

Sebastião-Franco, Barbara Aparecida

Avaliação da eficácia de um protocolo de exercícios físicos baseados no método Pilates nas variáveis dor, flexibilidade e força muscular em profissionais de enfermagem com lombalgia crônica idiopática. Ribeirão Preto, 2010.

183 p. : il.

Tese de Doutorado apresentada à Escola de Enfermagem de Ribeirão Preto/ USP. Área de concentração: Enfermagem Fundamental.

Orientadora: Marziale, Maria Helena Palucci.

1.Equipe de enfermagem. 2.Dor lombar. 3.Limitação da mobilidade. 4. Força muscular. 5. Técnicas de exercício e de movimento. 
SEBASTIÃO-FRANCO, Barbara Aparecida

Avaliação da eficácia de um protocolo de exercícios físicos baseado no método Pilates nas variáveis dor, flexibilidade e força muscular em profissionais de enfermagem com lombalgia crônica idiopática

Tese apresentada à Escola de Enfermagem de Ribeirão Preto da Universidade de São Paulo para obtenção do título de Doutor em Ciências junto ao Programa de Pós-Graduação em Enfermagem Fundamental.

Aprovado em ....................

Banca Examinadora

Prof. Dr. Instituição:

Julgamento: Assinatura:

Prof. Dr. Instituição:

Julgamento: Assinatura:

Prof. Dr. Instituição:

Julgamento: Assinatura:

Prof. Dr. Instituição:

Julgamento: Assinatura:

Prof. Dr. Instituição:

Julgamento: Assinatura: 


\section{Dedícatóría}

À Minha Mãe querida Ruth P. Pacola (in Memorian) que me Criou, me deu Oportunidades e me Ensinou a Trithar pelo árduo Caminho da Honestidade e Seriedade durante Toda a sua Vida.

"Mãe! Se te quís com todos os extremos, hoje te quero muito mais ainda; pois mais amamos quanto mais sofremos e a minha dor vai-se tornando infinda". 


\section{Agradecimentos}

$\mathcal{A}$ Deus, por manter-me firme e objetiva diante das dificuldades e das frustrações,

$\mathcal{A}$ minha orientadora Maria Helena Palucci Marziale pela confiança e paciência,

À CAPES pela oportunidade,

Aos profissionaís de enfermagem dessa Instituição pela participaçãa voluntária, colaboração e confiança no meu trabalho,

Às Pós-Graduandas Claudia Ríos Cataño dessa Escola e Ana Teresa Mancini Pimenta da Faculdade de Medicina de Ribeirão Preto dessa Instituição pela ajuda e companheirismo, À Profa. Dra. María Lúcía do Carmo C. Robazzi pela delícadeza com a qual nos auxilia,

$\mathcal{A}$ seus pós-graduandos que sempre me ofereceram ajuda e amizade,

Às parceiras de estudo Môníca Chiodi e Lísandra Martíns pelo companheirismo,

$\mathcal{A}$ todos os funcionários dessa Instituição que sempre me receberam e me trataram com carinho e profissionalismo,

Às minhas irmãs Maria Ríta e Regina que foram mais do que mães nessa jornada,

Ao meu marido Luiz Gustavo pela paciência e tolerância,

À minha fitha amada Luiza que foi gerada, nascida e já crescida nesse percurso,

$\mathcal{A}$ todos aqueles que de um modo ou de outro colaboraram para a realização dessa pesquisa. 
"Nenhum proveito se tira da ígnorância, porque até para perguntar é preciso saber." 


\section{RESUMO}

SEBASTIÃO-FRANCO, B.A. Avaliação da eficácia de um protocolo de exercícios físicos baseados no método Pilates nas variáveis dor lombar, flexibilidade e força muscular em profissionais de enfermagem com lombalgia crônica idiopática. 2010. 183 p. Tese (Doutorado) - Escola de Enfermagem de Ribeirão Preto, Universidade de São Paulo, Ribeirão Preto, 2010.

Pesquisadores de várias partes do mundo têm destacado os trabalhadores de enfermagem como um grupo de risco aos distúrbios osteomusculares, com destaque para a lombalgia como um dos fatores associados a prejuízos na execução da atividade laboral. Exercícios físicos são indicados nesses casos e dentre os indicados, destacam-se os baseados no método Pilates, por ativarem os mecanismos de controle neuromuscular e à sua efetividade no alívio da dor e melhora da função de indivíduos com lombalgia crônica não específica. A hipótese testada nesse estudo foi a de que os exercícios físicos baseados no método Pilates são mais efetivos no tratamento da lombalgia quando comparados aos exercícios convencionais de alongamento e fortalecimento. O objetivo da pesquisa foi comparar a efetividade de um protocolo de exercícios físicos baseado no método Pilates, considerando as variáveis dor lombar, flexibilidade de coluna cervical, tronco e quadril e força de glúteos, com outro protocolo contendo exercícios de alongamento e fortalecimento convencionais em profissionais da enfermagem com lombalgia crônica idiopática. Trata-se de um estudo de intervenção, controlado e não-randomizado com análise quantitativa dos dados do qual participaram 19 trabalhadores de enfermagem (enfermeiros, técnicos e auxiliares de enfermagem) de um hospital universitário do interior do estado de São Paulo. A coleta de dados foi realizada no período de setembro de 2009 a junho de 2010 por meio de aplicação de três instrumentos (pré-avaliação, formulário de dados pessoais e questionário Oswestry) e dois testes físicos (fleximetria e dinamometria). Os participantes foram divididos em dois grupos: um grupo controle (GC), o qual foi submetido ao protocolo de exercícios convencionais de alongamento e fortalecimento e o Grupo Pilates (GP), submetido ao protocolo de exercícios físicos baseado no método Pilates. Os dados foram analisados por meio dos softwares Statistical Package for the Social Science (SPSS), versão 15.0 for Windows e o statistical Analysis System (SAS), versão 9. Os exercícios físicos baseados no método Pilates obtiveram eficácia significativa na melhora da força de glúteo máximo direito e esquerdo ( $p<0,01$ e $p=0,04$, respectivamente). Numa análise intra grupo, o GC apresentou uma melhora significativa da amplitude de tronco $(C s=0,91-p<0,01)$ quando comparado ao GP após a intervenção. Com relação a dor lombar, ambos protocolos apresentaram melhora clínica. Verifica-se que o método Pilates de exercícios mostrou-se superiormente eficaz na melhora da força glútea quando comparado aos exercícios convencionais. Conclusão: O método Pilates apresenta aspectos incentivadores quando comparado aos programas de exercícios convencionais, além de peculiaridades, como número reduzido de repetições, trabalho do corpo como um todo e princípios que devem ser aplicados durante a execução do método, os quais determinam disciplina e consciência corporal. Tal fato pode proporcionar uma maior adesão nas atividades físicas ministradas para os trabalhadores de enfermagem em expedientes de trabalho.

Palavras-chave: Equipe de enfermagem. Dor lombar. Limitação da mobilidade. Força muscular. Técnicas de exercício e de movimento. 


\title{
ABSTRACT
}

\author{
SEBASTIÃO-FRANCO, B.A. Efficacy assessment of physical exercises \\ protocol based on the Pilates method for the variables lumbar pain, \\ flexibility and muscular strength in a group of nursing porfessionals with \\ chronic idiopathic low back pain. 2010. 183 p. Thesis (Doctorate) - University \\ of São Paulo - Ribeirão Preto Nursing School, Ribeirão Preto, 2010.
}

Researchers from many countries have pointed nursing professionals as a risk group to osteomuscular disorders, with emphasis to lombalgy as one of the factors associated to impairment in the execution of laboral activities. Among the physical exercises indicated in these cases those based on the Pilates method stand out for the capability of activating neuromuscular control mechanisms, effectiveness to relieve pain and improvement of functioning of individuals with non-specific chronic low back pain. The hypothesis tested in the present study is that physical exercises based on the Pilates method are more effectivein the treatment of low back pain when compared to conventional stretching and strengthening exercises. The objetive of the present study was to compare the effectiveness of a physical exercises protocol based on the Pilates method, considering the variables low back pain, cervical spine, trunk and hips flexibility and gluteous strength, to another with conventional stretching and strengthening exercises in a group of nursing professionals with chronic idiopathic low back pain. It is a controlled non-randomized study with quantitative data analysis in which 19 nursing professionals participated (nurses, technicians and auxiliary nurses) from a university hospital in São Paulo state, Brazil. Data collection was conducted between September 2009 and June 2010 through application of three instruments (preassessment, personal data form and Oswestry questionnaire) and two physical tests (fleximetry and dynamometry). Participants were divided in two groups: a control group (CG), which was submitted to a conventional stretching and strengthening physical exercises protocol, and the Pilates Group (PG), submitted to the physical exercises protocol based on the Pilates method. Data was analyses through softwares Statistical Package for the Social Science (SPSS), version 15.0 for Windows and statistical Analysis System (SAS), version 9. Physical exercises based on the Pilates Method obtained significant efficacy in the improvement of strength of right and left gluteous maximus ( $p<0,01$ e $p=0,04$, respectively). In an intragroup analysis, CG present a significant improvement of trunk amplitude $(C s=0,91-p<0,01)$, when compared to $P G$ after intervention. Concerning low back pain, both protocols presented clinical improvement. The Pilates method shows superior efficacy in the improvement of gluteous strength when compared to conventional exercises. Conclusion: The Pilates Method presents motivating aspects when compared to conventional exercises, besides particularities, such as number of repetitions, work the body as a whole and principles which sholud be applied during the execution of the method, which determine corporal discipline and consciousness. This could provide a greater adhesion to physical activities offered to nursing professionals during work time.

Keywords: Nursing staff. Low back pain. Mobility limitation. Muscular strength. Exercise and movement techniques. 


\title{
RESUMEN
}

\author{
SEBASTIÃO-FRANCO, B.A. Evaluación de la eficiencia de un protocolo de \\ ejercicios físicos basados en el método de Pilates en las variables de \\ dolor lumbar, flexibilidad y fuerza muscular em profesionales de \\ enfermería con lumbalgia crónica idiopática. 2010. 183 p. Tesis (Doctorado) \\ - Escuela de Enfermería de Ribeirao Preto, Universidad de Sao Paulo, \\ Ribeirao Preto, 2010.
}

Investigadores destacan a los trabajadores de enfermería como un grupo de riesgo en problemas osteomusculares, con destaque en la lumbalgia, siendo uno de los factores asociados a perjuicios en la actividad laboral. Ejercicios físicos son indicados, destacándose los basados en el método Pilates, por activar los mecanismos de control neuromuscular, su efectividad en el alivio del dolor y de mejorar la función de individuos con lumbalgia crónica no específica. La hipótesis testada fue que los ejercicios físicos basados en el método de Pilates son más efectivos en el tratamiento de lumbalgia cuando comparados con ejercicios convencionales de alongamiento y fortalecimiento. El objetivo fue comparar la efectividad de un protocolo de ejercicios físicos basados en el método Pilates, considerando las variables de dolor lumbar, flexibilidad de la columna cervical, tronco, cadera, y fuerza de los glúteos, con otro protocolo de ejercicios de alongamiento y fortalecimiento convencionales en profesionales de enfermería con lumbalgia crónica idiopática. Se trata de un estudio de intervención, controlado y no randomizado con análisis cuantitativo, con la participación de 19 trabajadores de enfermería (enfermeros, técnicos y auxiliares de enfermería) de un hospital universitario del interior del estado de Sao Paulo. La colecta de datos fue realizada en el periodo de septiembre 2009 a junio 2010 por medio de la aplicación de tres instrumentos (preevaluación, formulario de datos personales y cuestionario de Oswestry) y dos testes físicos (fleximetría y dinamometría). Los participantes fueron divididos en dos grupos: un grupo control (GC) sometido al protocolo de ejercicios convencionales de alongamiento y fortalecimiento y el grupo Pilates (GP), sometido al protocolo de ejercicios basados en el método Pilates. Los datos fueron analizados por medio de los software Statistical Package for the Social Science (SPSS), versión 15.0, y el statistical Analysis System (SAS), versão 9. Los ejercicios físicos basados en el método Pilates obtuvieron eficiencia significativa en la mejora de la fuerza del glúteo máximo derecho e izquierdo $(p<0,01$ e $p=0,04)$. En el análisis intra grupo, o GC presentó una mejora significativa en la amplitud del tronco $(\mathrm{Cs}=0,91-\mathrm{p}<0,01)$ cuando comparado al GP después de la intervención. Con relación al dolor lumbar, ambos protocolos presentaron mejora clínica. Se verificó que el método Pilates, mostró ser superior y eficaz para mejorar la fuerza del glúteo comprado con los ejercicios convencionales. Conclusión, el método Pilates presenta aspectos que incentivan cuando es comparado con otros programas de ejercicios convencionales, además de las peculiaridades, como el número reducido de repeticiones, trabaja el cuerpo como un todo, los principios aplicados durante la ejecución del método, son los que determinan disciplina y consciencia corporal. Tal hecho puede proporcionar una mejor adhesión en las actividades físicas dirigidas a los trabajadores de enfermería.

Palabras-clave: Grupo de Enfermería. Dolor en la Región lumbar, Limitación el Movilidad, Fuerza Muscular, Técnicas por Movimiento e de ejercicios. 


\section{LISTA DE FIGURAS}

Figura 1- Coluna vertebral em vista anterior, lateral esquerda e posterior.

Figura 2a- Vértebra lombar típica - vista anterior

Figura 2b- Vértebra lombar típica - vista posterior

Figura 3a- Reeducação respiratória com a mão esquerda sobre o tórax e a direita sobre o abdômen.

Figura 3b- Reeducação respiratória com braços ao longo do tronco.

Figura 4 Fortalecimento de glúteo máximo - ponte.

Figura 5a- Abdominal com braços cruzados no peito.

Figura 5b- $\quad$ Abdominal com braços elevados atrás da cabeça.

Figura 6a- $\quad$ Alongamento de IT (isquiotibiais) com o membro contralateral direito flexionado.

Figura 6b- Alongamento de IT (isquiotibiais) com o membro contralateral direito estendido.

Figura 7a- Posição inicial - gato.

Figura 7b- Extensão de perna e braço contralateral - fortalecimento de tronco.

Figura 8- $\quad$ Fortalecimento de ombros - execução

Figura 9a- Posição inicial para extensão de tronco.

Figura 9b- Extensão de tronco.

Figura 10a- Postura inicial.

Figura 10b- Flexão de membros inferiores com inclinação anterior de tronco.

Figura 11a- Postura inicial.

Figura 11b- Inclinação da coluna cervical....................................... 54

Figura 11c- Flexão da coluna cervical 
Figura11d- Extensão da coluna cervical

Figura 12a- Alongamento de adutores com os braços posicionados ao longo do tronco.

Figura 12b- Alongamento de adutores com os braços alongados e elevados acima da cabeça em "V".

Figura 13a- Respiração com a mão esquerda sobre o tórax e a direita sobre o abdômen.

Figura 13b- Respiração com as duas mãos posicionadas ao longo do tronco.

Figura 14a- Ponte - posição inicial.

Figura 14b- Ponte - execução do exercício.

Figura 15a- Círculo com uma perna - posição inicial.

Figura 15b- Círculo com uma perna - posição final

Figura 16-

Hundred modificado.

68

Figura 17- Single leg streigth

Figura 18-

Swimming (nadando).

69

Figura 19a-

postura de gato

70

Figura 19b-

Formação da prancha após a postura de gato

Figura 20a-

Push up - postura inicial

71

Figura

20b,c,d.

Push up - execução

71

Figura 21a-

Standing footwork - posição inicial

72

Figura 21b-

Standing footwork - execução

72

Figura 22a-

Mermaid - posição inicial.

Figura 22b-

Mermaid - execução

73

Figura 23- $\quad$ Fluxograma para seleção da amostra e o número final de participantes que concluíram o estudo. Ribeirão Preto - SP, 2010. $(n=19)$.

Figura 24a,b- Flexímetro (ICP)...... 
Figura 25a,b- The Lafayette Manual Muscle Test System (MMT) - Modelo 01163

Figura 26- $\quad$ Fluxograma para descrição dos procedimentos realizados no estudo da pré-avaliação à reavaliação. Ribeirão Preto - SP, 2010. $(n=19)$.

Figura 27a- Primeira vértebra cervical (Atlas) - vista superior com processo transverso e forame transverso.

Figura 27b- Primeira vértebra cervical (Atlas) - vista inferior com faceta articular para dente do atlas.

Figura 28a- Áxis com o dente do áxis.

Figura 28b- Áxis.

Figura 29- Vértebra cervical típica

Figra 30a- $\quad$ Teste de flexibilidade da coluna cervical - posição inicial........

Figura 30b- Teste de flexibilidade da coluna cervical - posição final.

Figura 31a-

Tórax.

96

Figura 31b-

Abdômen ou cavidade abdominal....

96

Figura 31c-

Pelve.

96

Figura 32a-

Teste de flexibilidade de tronco -

98

Figura 32b- Teste de flexibilidade de tronco - fim.

98

Figura 33a- inferior direito - início.

Teste de flexibilidade de quadril realizada com membro

Figura 33b-

inferior direito - fim.

Figura 34a,b- Músculo glúteo máximo.

100

Figura 35a-

Teste de força muscular de glúteo máximo esquerdo posicionamento inicial.

Figura 35b-

Teste de força muscular de glúteo máximo esquerdo execução.

Participantes do estudo e seus respectivos tempos de

Figura 36- cumprimento do protocolo de exercícios. Ribeirão Preto SP, 2010. $(n=19)$. 


\section{LISTA DE TABELAS}

Tabela 1. Distribuição dos profissionais de enfermagem participantes do estudo, segundo os aspectos individuais e sóciodemográficos. Ribeirão Preto - SP, 2010. $(n=19)$.

Tabela 2. Distribuição dos profissionais de enfermagem participantes do estudo, segundo os aspectos profissionais. Ribeirão Preto - SP, 2010. $(n=19)$

Tabela 3. Distribuição dos profissionais de enfermagem participantes do estudo, segundo aspectos relacionados ao trabalho. Ribeirão Preto - SP, 2010. ( $n=19)$.

Tabela 4. Médias dos valores obtidos do Questionário Oswestry incapacidade para a dor lombar - antes e após a intervenção a partir dos escores brutos do Instrumento. Ribeirão Preto - SP, 2010. $(n=19)$

Tabela 5. Distribuição dos profissionais de enfermagem participantes do estudo segundo os escores do Questionário Oswestry incapacidade para a dor lombar antes e após a intervenção nos dois grupos. Ribeirão Preto - SP, 2010. $(n=19)$

Tabela 6. Distribuição dos profissionais de enfermagem participantes do estudo segundo os itens das 5 primeiras escalas contidas no Questionário Oswestry (dor, cuidados pessoais, levantar objetos, caminhar e sentar) antes e após a intervenção nos dois grupos. Ribeirão Preto - SP, 2010. (n $=19)$.

Tabela 7. Distribuição dos profissionais de enfermagem participantes do estudo segundo os itens das 5 últimas escalas contidas no Questionário Oswestry (ficar em pé, dormir, vida sexual, vida social e locomoção) antes e após a intervenção nos dois grupos. Ribeirão Preto - SP, 2010. $(n=19)$.

Tabela 8. Associação intra grupo das variáveis incapacidade funcional e o tipo de postura predominantemente adotada na rotina de trabalho diário antes e após a intervenção. Ribeirão Preto - SP, 2010. ( $n=19)$

Tabela 9. Correlação entre as variáveis incapacidade funcional e o tipo de postura predominante adotado na rotina de trabalho diário antes e após a intervenção. Ribeirão Preto - SP, 2010. $(n=19)$. 
Tabela 10. Médias das amplitudes de movimentos articulares mensuradas nos profissionais de enfermagem participantes do estudo antes e após as intervenções. Ribeirão Preto SP, 2010. $(n=19)$.

Tabela 11. Média das forças musculares mensuradas nos profissionais de enfermagem participantes do estudo antes e após as intervenções. Ribeirão Preto - SP, 2010. $(n=19)$.

Tabela 12. Medidas das forças musculares de glúteo máximo direito e esquerdo $(\mathrm{Kg})$ antes e após a intervenção e a diferença dos valores dessas medidas antes e após a intervenção.

Ribeirão Preto - SP, 2010. $(n=19)$

Tabela 13. Resultados do modelo de efeitos mistos para a variável Força de Glúteo máximo Direito. Ribeirão Preto - SP, 2010. $(n=19)$.

Tabela 14. Resultados do modelo de efeitos mistos para a variável Força de glúteo máximo esquerdo. Ribeirão Preto - SP, 2010. $(n=19)$. 


\section{LISTA DE GRÁFICOS}

Gráfico 1 Correlação entre as variáveis incapacidade funcional e postura predominante na rotina de trabalho diário. Ribeirão Preto - SP, 2010. $(n=19)$..

Gráfico 2 Dispersão e correlação entre as variáveis incapacidade funcional e amplitude de flexoextensão da coluna cervical antes e após a intervenção. Ribeirão Preto - SP, 2010. $(n=19) \ldots \ldots$.

Gráfico 3 Dispersão e Correlação entre as variáveis incapacidade funcional e amplitude de flexoextensão do tronco antes e após a intervenção. Ribeirão Preto - SP, 2010. $(n=19)$

Gráfico 4 Correlações entre as variáveis incapacidade funcional e tempo de tratamento. Ribeirão Preto SP, 2010. $(n=19)$.

Gráfico 5 Comparação da força do glúteo máximo direito, por grupo, antes e após a intervenção. Ribeirão Preto $S P, 2010 .(n=19)$

Gráfico 6 Comparação da força do glúteo máximo esquerdo, por grupo, antes e após a intervenção. Ribeirão Preto - SP, 2010. $(n=19)$ 


\section{LISTA DE ABREVIATURAS E SIGLAS}
AVD
Atividades de Vida Diária
LER
Lesões por Esforços Repetitivos
DORT
Distúrbios Osteomusculares Relacionadas com o Trabalho
UTI
Unidade de Terapia Intensiva
SNC
Sistema Nervoso Central
ADM
Amplitude de Movimento
ASTFM
Área de Secção Transversa das Fibras Musculares
ACSM
American College of Sports Medicine
ABP
Associação Brasileira de Pilates
CME
Central de Materiais e Esterilização
VGRF
Reação de Força em uma Plataforma Vertical
CIF
Classificação Internacional de Funcionalidade
$\mathrm{HC}$
Hospital das Clínicas
FMRP Faculdade de Medicina de Ribeirão Preto
USP Universidade de São Paulo
RH Recursos Humanos

FAEPA Fundação de Apoio ao Ensino, Pesquisa e Assistência

CLT Consolidação das Leis trabalhistas

SESMT Especializado em Segurança e Medicina do Trabalho

CER Centro de Reabilitação

SAMSP Serviço de Atendimento Médico de Saúde do Pessoal

TCLE Termo de Consentimento Livre e Esclarecido

ODI Oswestry Disability Index

ICP Instituto Code de Pesquisa

MMT Manual Muscle Test

FAEPA Fundação de Apoio ao Ensino, Pesquisa e Assistência

Cs

Correlação de spearman 


\section{SUMÁRIO}

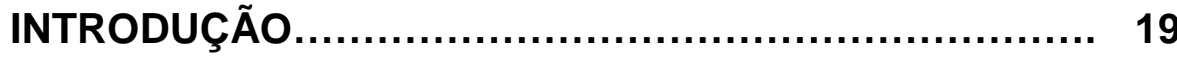

HIPÓTESES DO ESTUDO............................................... 26

3 OBJETIVOS.

Lombalgia 30

Descrição do protocolo de exercícios de alongamento e fortalecimento convencionais.

O método Pilates de exercícios.

Princípios fundamentais do método Pilates

Descrição do protocolo de exercícios baseados no método Pilates.

MATERIAL E MÉTODOS

Delineamento do estudo. 75 Instrumentos de medidas

Protocolos de intervenção.

Procedimentos para a realização da pesquisa. 88 
6.5 Incapacidade funcional devido à dor lombar...................... 119

6.5.1 Relação da incapacidade funcional devido à dor lombar com as posturas adotadas na rotina de trabalho.

6.6 Amplitude de movimento articular.

6.7.1 Comparação da força do glúteo máximo direito e esquerdo, por grupo, antes e após a intervenção.

APÊNDICES APÊNDICE A - Termo de consentimento livre e esclarecido.

APÊNDICE B - Pré- avaliação 174

APÊNDICE C - Formulário de dados pessoais. 175

APÊNDICE D - Protocolo 1: Exercícios físicos baseados no método Pilates.

APÊNDICE E - Protocolo 2: Exercícios de alongamento e fortalecimento convencionais.

ANEXOS

ANEXO A - Folha de aprovação do Comitê de Ética em Pesquisa.

ANEXO B - Questionário Oswestry para avaliação da dor lombar. 


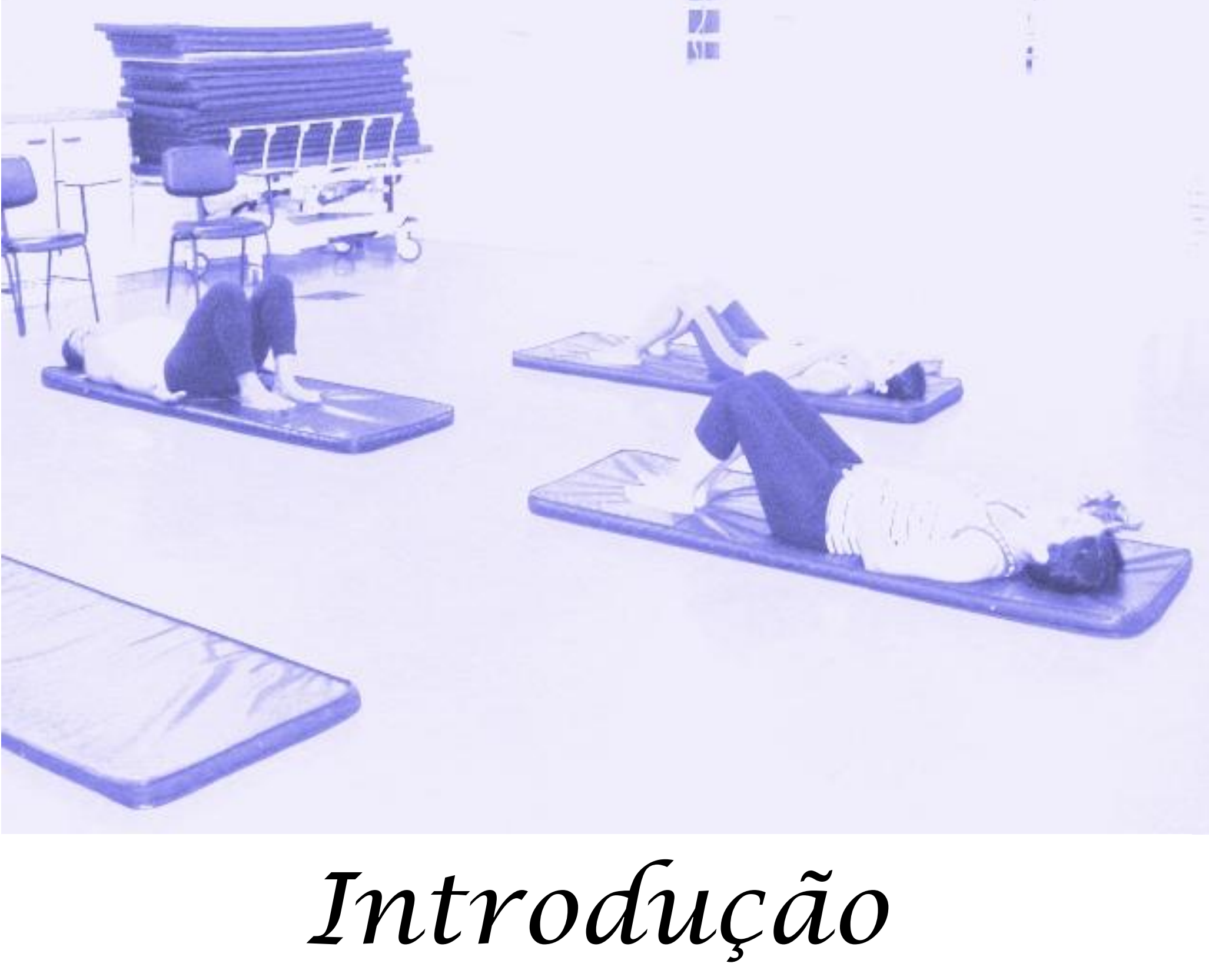




\section{INTRODUÇÃO}

A enfermagem é responsável pelo maior contingente da força de trabalho dos estabelecimentos hospitalares, com responsabilidade pela assistência e gestão nas 24 horas. Os trabalhadores de enfermagem estão expostos às inadequadas condições de trabalho neste ambiente (NASCIMENTO, 2003), dentre elas destaca-se a exposição aos fatores biológicos, físicos, químicos e organizacionais (SANTOS, 2001).

No Brasil, o trabalho de enfermagem é realizado, muitas vezes, sob condições precárias de recursos humanos e materiais, baixos salários e ambiente insalubre, dividido por tarefas e com extensas horas dedicadas ao trabalho que, na maioria das vezes, não oferece, sequer, local apropriado ao descanso. A enfermagem como prática social, por sua vez, atende às exigências assim definidas, reproduzindo ações complementares à prática médica (DAL PAI; SCHRANK; PEDRO, 2006). As condições inadequadas de trabalho oferecidas pelas instituições de saúde e as peculiaridades do trabalho de enfermagem tem sido responsáveis pelo adoecimento desses profissionais, o que resulta em prejuízo para as instituições empregadoras, para os próprios trabalhadores e para o governo (MARZIALE, 2001).

Num estudo realizado para analisar os afastamentos de curta duração dos profissionais de enfermagem de um hospital universitário, constatou-se que as doenças osteomusculares aparecem em segundo lugar (13,4\%), após as doenças do aparelho respiratório $(18,2 \%)$ dentre àquelas que mais produzem afastamentos entre os profissionais de saúde (REIS; MORO; CONTIJO, 2003). 
Gurgueira; Alexandre; Corrêa, (2003) ao classificar os setores mais acometidos na área da enfermagem, relatam que os profissionais que atuam em unidades de internação e atendem pacientes com alto grau de dependência física são os mais acometidos pelas afecções musculoesqueléticas, dentre eles aqueles que trabalham em setores como Unidades de Terapia Intensiva (UTI), Cirurgia do Trauma, Emergência Clínica, Ortopedia, Traumatologia, Neuroclínica e Neurocirurgia.

Pesquisadores e organizações de várias partes do mundo têm destacado a equipe de enfermagem como grupo de risco em relação ao desenvolvimento de distúrbios osteomusculares (JOSEPHSON et al., 1997). Entre esses distúrbios destacam-se as lombalgias (ALEXANDRE; ANGERAMI; MOREIRA, 1996; SMEDLEY et al., 1998; PINHO et al., 2001).

Dados internacionais mostram, por meio de estudo realizado na Inglaterra, que no transcorrer de um ano em um único distrito de saúde, funcionários da enfermagem perderam 668 dias de trabalho devido às dores nas costas. Segundo estimativa, 40.000 enfermeiros faltam, a cada ano, do serviço nesse país, tendo também como justificativa as dores nas costas (RAISTRICK, 1981; ALEXANDRE; BENATTI, 1998).

Murofuse e Marziale (2005) em estudo sobre os atendimentos efetuados aos profissionais de enfermagem em unidades de saúde de Minas Gerais constataram que, de 6070 atendimentos realizados, $85,3 \%$ foram prestados ao trabalhador do sexo feminino e $14,7 \%$, do sexo masculino. Tal evidência reflete o fato histórico de que a força do trabalho de enfermagem configura-se eminentemente feminina. 
Murofuse e Marziale (2005) ao avaliar as 6070 licenças médicas de trabalhadores de 23 unidades de saúde de Minas Gerais constataram que os trabalhadores de enfermagem do sexo feminino, que são a maioria dos registros de afastamento, tiveram menor atendimento devido às LER/DORT quando comparados aos indivíduos do sexo masculino, com $14,7 \%$ dos atendimentos.

Gurgueira; Alexandre; Corrêa, (2003) ao descreverem as regiões corporais acometidas pelas algias e lesões, constataram que as lombalgias, lesões em membros superiores, joelhos e região cervical, bem como as dores miofasciais e dores generalizadas estão presentes em trabalhadores da área da saúde, entre eles, os enfermeiros.

Em um estudo realizado por Costa; Vieira; Sena, (2009), verificou-se que dentre os motivos dos afastamentos de trabalho dos profissionais de enfermagem, as doenças do sistema osteomuscular e conjuntivo compõem $23,5 \%$ das doenças registradas entre as mulheres e $28,6 \%$ entre os homens.

Gurgueira; Alexandre; Corrêa, (2003) ao investigarem os sintomas musculoesqueléticos apresentados por trabalhadoras de enfermagem, constataram que a dor lombar foi o distúrbio osteomuscular mais relatado, tanto no último ano (59\%), quanto na última semana $(31,4 \%)$. Nesse mesmo estudo, a dor lombar também foi a queixa mais freqüente utilizada para justificar a ausência no trabalho e a procura de auxílio médico. Quanto às atividades realizadas julgadas como causas da dor lombar relatada pelas trabalhadoras, $87,6 \%$ das auxiliares de enfermagem relataram a movimentação de pacientes e $49,5 \%$, o transporte dos mesmos. 
As lombalgias são comuns na população em geral em torno dos 45 anos de idade e compreende, por volta de, $70 \%$ dos acometimentos da coluna vertebral (RYDEARD; LEGER; SMITH, 2006), no entanto, muitas vezes esta síndrome está relacionada às atividades laborais desenvolvidas pelos indivíduos (PONTE, 2005).

Diversos são os recursos que os profissionais da área da saúde, dentre eles, os fisioterapeutas, lançam mão para o tratamento da lombalgia. Segundo Sherman et al., (2010), medicações, exercícios, programas educativos, autocuidado, melhora no estilo de vida, terapias manuais, complementares, medicina alternativa, tratamentos minimamente invasivos e cirurgias são alguns deles, mas existem poucas evidências surpreendentes que subsidiam a eficácia da maioria desses tratamentos.

Andrade; Araújo; Vilar, (2005), ao analisar a eficácia de uma técnica de exercícios denominada "Escola da Coluna" em pacientes com lombalgia crônica, constataram que grande parte dos estudos indicou como resultados a melhora da dor, da mobilidade da coluna e da incapacidade funcional para realizar determinadas atividades diárias como caminhar, vestir-se e curvar-se (LIMA-COSTA; BARRETO; GIATTI, 2003), mas esses resultados foram observados apenas a curto e médio prazos. Tal fato ressalta a ineficácia de alguns métodos de tratamento em função do tempo de intervenção e da durabilidade proporcionada na melhora da dor.

Considerando estudos realizados com aplicações de programas de exercícios físicos, alguns deles, sem êxito; outros com eficácia a curto e a médio prazos para a lombalgia e considerando as diversas causas osteomusculares que ocasionam essa moléstia, entre elas, o desequilíbrio das 
relações musculares conforme relatado em estudos já realizados (SILVA et al., 2004; GONÇALVES e BARBOSA, 2005; KAWANO et al., 2008); tem-se que a prática de exercícios físicos regulares podem exercer efeito de analgesia por proporcionar aumento da flexibilidade e da força muscular em determinados grupos musculares, auxiliando no tratamento para essa síndrome.

$\mathrm{Na}$ presente pesquisa, duas propostas de intervenção foram feitas, sendo uma composta por exercícios baseados no método Pilates e outra composta por exercícios de alongamento e exercícios de fortalecimento convencionais. Decidiu-se verificar a eficácia da primeira intervenção em relação à segunda, pois se acredita que os exercícios baseados no método Pilates poderão favorecer a adoção de posturas físicas adequadas na execução das atividades laborais dos profissionais de enfermagem, proporcionando maior controle motor durante os movimentos e o repouso, maior flexibilidade e melhora da força muscular e, conseqüentemente, melhor qualidade de vida no trabalho dos profissionais de enfermagem.

Dentre os vários programas de exercícios físicos, destaca-se, neste estudo, o método Pilates que foi criado pelo alemão Joseph Humbertus Pilates. Esse método consiste em uma série de exercícios baseados em movimentos progressivos que o corpo é capaz de executar. Durante a I Guerra Mundial, Pilates iniciou o uso das molas nas camas de hospitais desenvolvendo um sistema que veio a inspirá-lo para a criação de seus equipamentos e de seu método que viriam posteriormente (RYDEARD; LEGER; SMITH, 2006).

Aliando a eficácia desse método com os aspectos neuromusculares ocasionados na dor lombar, considera-se que os exercícios baseados no método Pilates poderão oferecer melhora efetiva com relação aos exercícios 
convencionais já utilizados no tratamento dessa moléstia. Acredita-se que os exercícios baseados no método Pilates, por apresentarem aspectos desafiadores para quem os pratica, vários níveis de dificuldade a partir de um mesmo exercício, entre outras peculiaridades, acabam por oferecer um componente incentivador na prática de atividade física, qualidade essa não observada em outras modalidades de exercícios físicos. 

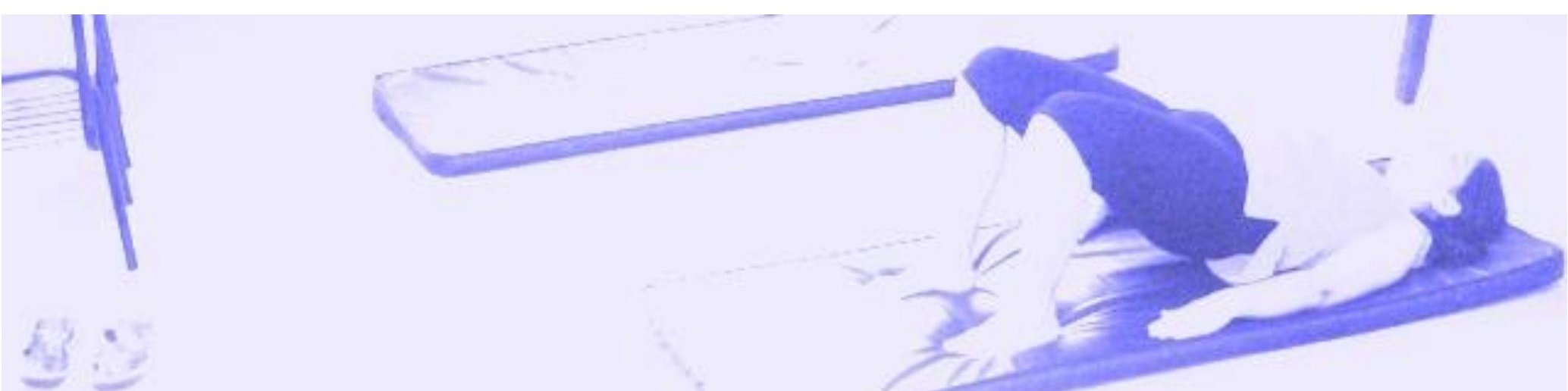

Hipótese do estudo 


\section{HIPÓTESE DO ESTUDO}

Exercícios físicos baseados no método Pilates são mais efetivos no tratamento da lombalgia quando comparados aos exercícios convencionais de alongamento e fortalecimento. 


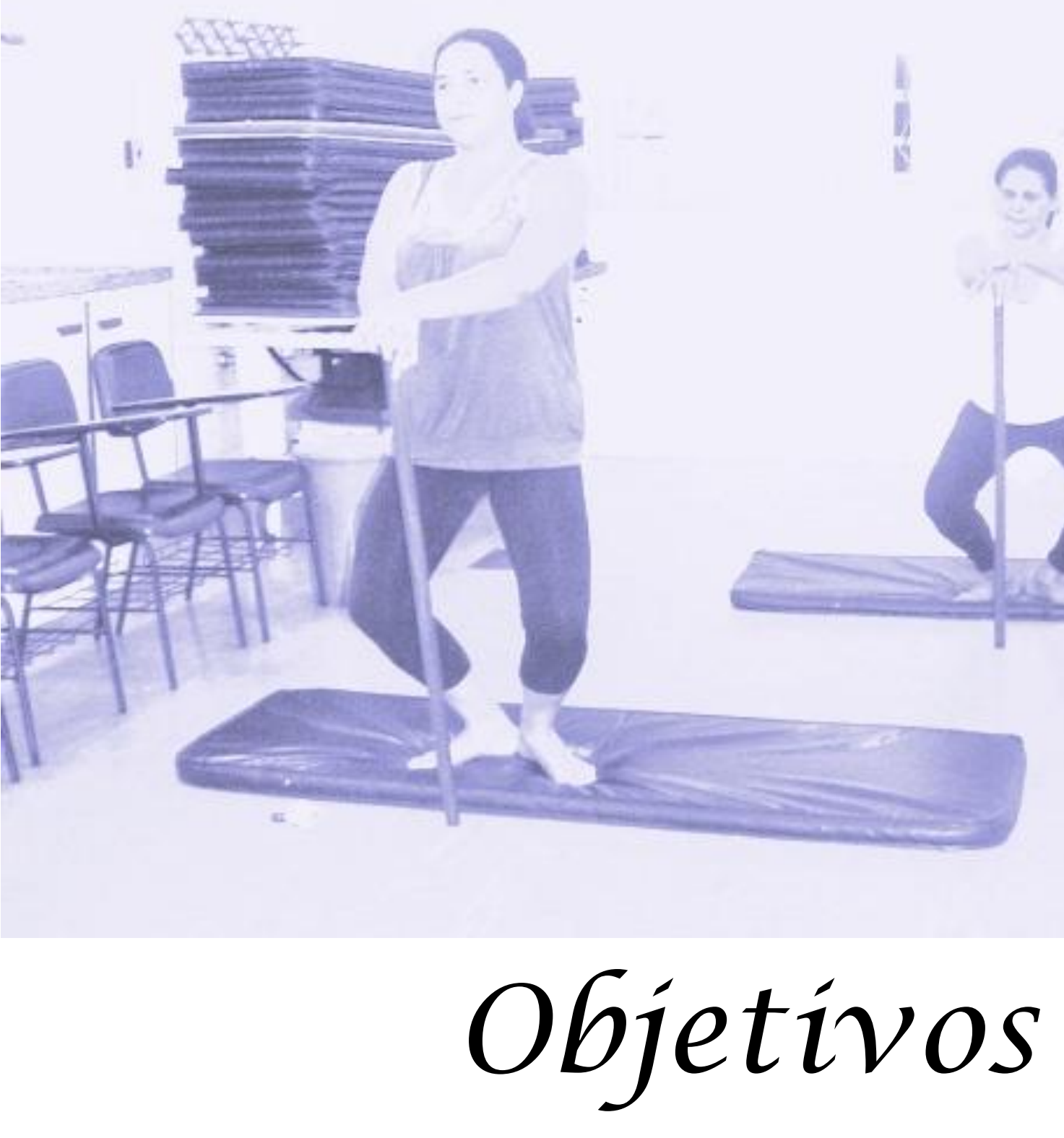




\section{OBJETIVOS}

\subsection{Objetivo Geral}

Comparar a efetividade de um protocolo de exercícios físicos baseado no método Pilates nas variáveis dor, flexibilidade e força com outro protocolo contendo exercícios de alongamento e fortalecimento convencionais aplicados em profissionais da enfermagem com lombalgia crônica idiopática.

\subsection{Objetivos Específicos}

- Caracterizar os participantes do estudo segundo os aspectos sóciodemográficos, profissionais, do trabalho e hábitos pessoais;

- Avaliar a incapacidade funcional provocada pela dor lombar antes e após a aplicação dos protocolos nos dois grupos;

- Avaliar a flexibilidade da coluna cervical, tronco e quadril antes e após a aplicação dos protocolos nos dois grupos;

- Avaliar a força do glúteo máximo antes e após a aplicação dos protocolos nos dois grupos;

- Associar as variáveis dor lombar, flexibilidade e força de glúteo máximo;

- Associar as variáveis tipo de postura mais adotada na rotina de trabalho e tempo de tratamento devido a dor lombar. 


\section{REFERENCIAL TEÓRICO}

\subsection{Lombalgia}

A lombalgia é definida como um sintoma referido na altura da cintura pélvica. O seu diagnóstico pode ser considerado simples, pois geralmente 0 quadro clínico da lombalgia é constituído por dor, incapacidade de se movimentar e trabalhar. A lombalgia caracteriza-se por dor na região dorsal, entre o último arco costal e a prega glútea mais especificamente, na região da coluna lombar, seguimento este que suporta a maior carga e grande parte do peso corporal (BERNARD,1993; GRIEVE, 1994; BRAZIL, 2004).

\subsubsection{Aspectos anatômicos e funcionais da dor lombar}

O conhecimento da anatomia da coluna e de sua fisiologia é de grande importância para se compreender a etiopatogenia da dor lombar. Além das vértebras e dos músculos, a coluna depende do funcionamento dos discos intervertebrais e dos ligamentos, tanto para a sustentação quanto para a mobilização (ABREU et al., 2007).

Em se tratando da localização anatômica, a lombalgia é percebida na região lombar e/ou sacral (Figura 1) que é localizada entre os limites superior, por uma linha transversa imaginária que passa pelo processo espinhoso da última vértebra torácica; inferior, por uma linha transversa imaginária que passa pelas articulações sacrococcígeas posteriores; lateral, por linhas verticais tangenciais às bordas laterais do músculo elevador da espinha continuando por 
linhas passando pelas espinhas ilíacas póstero-superiores e inferiores (MERSKEY e BOGDUK ,1994).

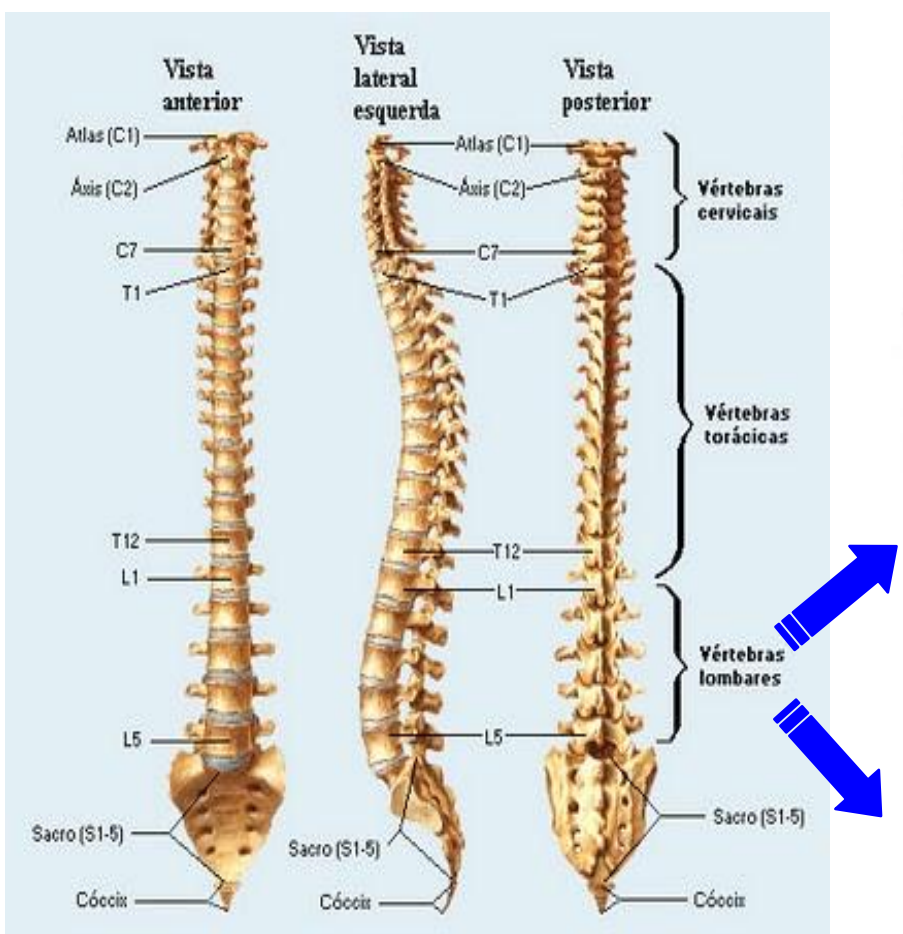

Fonte: Ossos da coluna vertebral.

Figura 1- Coluna vertebral em vista anterior, lateral esquerda e posterior.

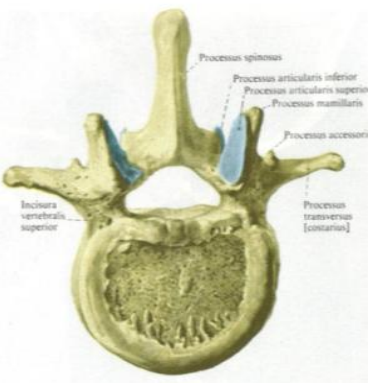

Fonte: Spalteholz-Spanner (1988, p.42) Figura 2a - Vértebra lombar típica - vista anterior

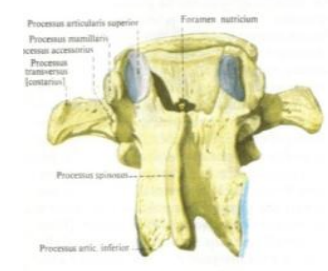

Fonte: Spalteholz-Spanner (1988,p.42) Figura $2 \mathrm{~b}$ - Vértebra lombar típica - vista posterior

Funcionalmente, a coluna lombar pode ser dividida em compartimento anterior, médio e posterior; cada compartimento constitui uma unidade mecânica funcional. O compartimento anterior é constituído pelos corpos vertebrais (Figuras 2a,b) e pelo disco intervertebral, que é adaptado para a absorção de choques e para o suporte de pesos. O compartimento médio é formado pelo canal raquidiano e pelos pedículos. O compartimento posterior protege posteriormente os elementos neurais e é responsável pelo direcionamento das unidades funcionais nos movimentos de flexão anterior, extensão, flexão lateral e rotação (IMAMURA; KASIYAMA; IMAMURA, 2001). 
Porto (2000) admite que a principal causa da lombalgia é a alteração do disco intervertebral, que se torna incapaz de amortecer as cargas que Ihe são transmitidas, mas sabendo-se que a parte central do disco não possui inervação sensitiva, acredita-se que a dor só surge quando alterações discais atingem as lamelas superficiais e o ligamento posterior que são estruturas ricamente inervadas.

A carga que a coluna lombar suporta está relacionada ao alinhamento da coluna vertebral; com o envelhecimento, ocorre perda da mobilidade das articulações da coluna vertebral, diminuição na potência muscular e ocorrência de hipotrofia dos músculos abdominais, com o predomínio do iliopsoas e os paravertebrais lombares sobre a musculatura ântero-lateral do abdômen. Tal fato provoca estruturação dos componentes da coluna lombar na posição de hiperlordose, configurando hiperextensão do conjunto lombossacro (ABREU et al., 2007).

Na prática clínica diária, observa-se que o grau de lordose lombar é variável durante a vida. Normalmente, existe boa mobilidade lombar na infância e adolescência, enquanto na idade adulta, com o aparecimento de fatores de risco como a gravidez, o sedentarismo, a obesidade e a osteoporose, a coluna lombar apresenta redução da mobilidade. A ação dos músculos iliopsoas, na idade adulta, passa a exercer flexão da pelve sobre os quadris, substituindo a ação dos abdominais (ABREU et al., 2007).

Assim sendo, músculos essencialmente flexores da coxa sobre a pelve aumentam sua força, quando comparados com os abdominais, configurando 0 desequilíbrio entre os músculos lordogênicos e antilordogênicos. A identificação do momento em que esse desequilíbrio se estabelece deverá ser 
fator decisivo na profilaxia da estruturação da coluna lombar em hiperextensão, ou seja, em hiperlordose (ABREU et al., 2007).

Essa perda da mobilidade da coluna lombar em razão do desequilíbrio muscular pode ser causa de aumento da pressão nas articulações interfacetárias, que levaria à artrose, sendo reconhecida como síndrome facetária. A profilaxia do desequilíbrio muscular lombar é, em última análise, elemento fundamental na redução dos índices de lombalgia na população em geral (ABREU et al., 2007).

A estabilidade da coluna vertebral pode ser definida como a habilidade da articulação em retornar ao seu estado original após sofrer uma perturbação. Uma proposta inovadora foi feita com o intuito de estabelecer esse equilíbrio através de um modelo que incorpora três subsistemas: passivo, ativo e neural (PANJABI a,b, 1992).

O subsistema passivo é composto por estruturas ósseas, articulares e ligamentares, ele contribui para o controle próximo ao final da amplitude articular onde são desenvolvidas forças reativas que resistem ao movimento. Entretanto, em torno da posição neutra da articulação, ele não oferece nenhum suporte estabilizador significativo (PANJABI a,b, 1992).

O subsistema ativo contempla as estruturas musculares quando desempenha suas funções contráteis. Este, diferentemente do primeiro, atua na obtenção mecânica da estabilidade, mesmo a partir da posição neutra, pois é capaz de modular sua resistência ao longo de toda a amplitude de movimento; o subsistema neural é aquele que monitora e regula de forma contínua as forças ao redor da articulação (PANJABI a,b, 1992). 
Lesão nos subsistemas passivo e/ou ativo levam a aumentos não fisiológicos na amplitude da zona neutra (PANJABI b,1992; PANJABI, 2003). Por outro lado, a atividade muscular é capaz de minimizá-las e mesmo restaurar os limites fisiológicos após lesão ou degeneração das estruturas passivas, o que representa papel fundamental na busca da estabilidade (PANJABI, 2003).

O grande número de músculos que cruza a coluna pode atuar no aumento de sua rigidez estrutural, contribuindo em sua estabilização. Nesse contexto, grupamentos musculares específicos desempenham papéis distintos no contexto da obtenção de estabilidade (BERGMARK, 1989; RODGES, 2004).

Outro aspecto relevante a ser abordado é que os músculos do tronco são categorizados em dois grandes grupos funcionais: os músculos locais e os globais (BERGMARK, 1989). Junto aos últimos incluem-se os grandes e superficiais músculos do tronco que não possuem ligações diretas nas vértebras e aqueles que cruzam diversos segmentos, como o grande dorsal, reto abdominal e porções dos eretores espinhais (BERGMARK, 1989; COMERFORD; MOTTRAM, 2001; HODGES, 2004).

Em contrapartida, os músculos locais seriam os pequenos músculos e determinadas porções profundas de outros que têm ligações diretas nas vértebras. Considera-se que os músculos "globais" são os responsáveis por gerar os torques necessários para as movimentações da coluna e tronco, controlar sua orientação, balancear as cargas externas e as transferir do tórax à pelve, minimizando-as sobre a coluna e seus componentes (BERGMARK, 1989; COMERFORD; MOTTRAM, 2001; HODGES, 2004). 
Entretanto, para os referidos autores, apesar desses músculos (globais) serem fundamentais para a estabilidade da coluna, não são capazes de realizar o "ajuste fino" dos movimentos intervertebrais, como o controle dos movimentos intersegmentares específicos e das forças de cisalhamento. Para isso se faz necessária a ação dos componentes do outro grupo (locais).

Admite-se que os ditos músculos "locais" controlam a rigidez e a relação intervertebral, além da postura dos segmentos lombares, apesar de não serem efetivos no controle da orientação vertebral (BERGMARK, 1989; COMERFORD; MOTTRAM, 2001; RODGES, 2004). Dentre outros não citados, incluem também nesse grupo a porção profunda do oblíquo interno, o multífido e o transverso abdominal, os quais têm sido amplamente investigados na ultima década (HODGES, 1999; 2003; 2004).

Devido à especialização dos componentes do subsistema ativo com ações locais e globais, e à existência de diversos "níveis" de requerimento de estabilidade, uma coordenação interdependente adequada na ativação dos músculos do tronco é requerida para que se possam desempenhar suas funções (HODGES, 1999; RODGES, 2004; COMERFORD; MOTTRAM, 2001). Para explicar a forma como o subsistema neural controla todo esse mecanismo, os autores se munem do pressuposto da existência de uma "representação interna" da dinâmica corporal, ou seja, modelos abstratos construídos pela experiência nos quais se tem informação sobre as interações entre as forças internas e externas (COMERFORD; MOTTRAM, 2001; RODGES, 2004).

Diante de perturbações previsíveis, baseando-se no modelo interno disponível, o Sistema Nervoso Central (SNC) define previamente as respostas 
musculares a serem dadas. Assim, um mecanismo de ajuste antecipatório feedforward seria o responsável por essa modulação. Além disso, consideram que em situações nas quais não há previsibilidade da perturbação, o sistema responde à posteriori e em resposta às desestabilizações. Através das informações obtidas pelos receptores periféricos e mecanismos reflexos, o sistema age em busca da retomada do equilíbrio articular, exemplo clássico de mecanismo por feedback (COMERFORD; MOTTRAM, 2001; HODGES, 2004).

Ao analisar a atuação desses mecanismos e seus grupos musculares relacionados (globais e locais), acredita-se que os exercícios baseados no método Pilates conseguem contemplar essa musculatura de forma a acionar ambos grupos musculares por meio da ativação do power house (casa de força). Essa "casa de força" é composta por vários músculos, sendo eles locais e globais e é denominada também como Core, segundo Pilates - cerne do corpo para o qual são direcionadas todas as ações musculares periféricas (MUSCOLINO; CIPRIANI, 2004).

Evidências científicas permitem afirmar que a lombalgia não ocorre apenas por fatores biológicos, mas outros fatores também podem estar envolvidos na determinação dessa patologia, sendo eles individuais e do ambiente em que se vive e trabalha. Alterações dos mecanismos neuromusculares, como os descritos anteriormente, que afetam a estabilidade da musculatura do tronco e a eficiência dos movimentos pode ser um fator desencadeante para a lombalgia e não somente a falta de alongamentos ou fortalecimentos musculares que envolvam essa região (LONG, 1999; RATHMELL, 2008). 
Outras causas as quais podem trazer a lombalgia como manifestação e incômodo são as doenças sistêmicas como metástases tumorais, mieloma múltiplo, leucemia, anemia falciforme, espondilite anquilosante ou até mesmo manifestação clínica de doenças de órgãos localizados no abdômen, como úlcera péptica, colecistite, pancreatite, apendicite retrocecal, aneurisma da aorta, inflamações pélvicas, endometriose, doenças da próstata. (STUBBS; BUCKLE; HUDSON, 1983; BARROS FILHO, 1995; BARROS FILHO; LECH, 2001).

Esses mesmos autores citados anteriormente relatam que as doenças da articulação do quadril e da articulação sacroilíaca, como as doenças degenerativas, as doenças da coluna lombar, como espondilolistese, artrose, degeneração discal e fraturas, também causam dor lombar. Porto (2000) ainda acrescenta que processos inflamatórios, degenerativos, por alterações mecânicas da coluna vertebral, como má postura, escoliose, má formações e sobrecargas na musculatura lombar, também levam à apresentação desse sintoma.

A lombalgia mecânico-postural, a qual nos atemos no presente estudo, também denominada lombalgia inespecífica, representa, no entanto, grande parte das algias de coluna referidas pela população. Nela geralmente ocorre um desequilíbrio entre a carga funcional, que seria o esforço requerido para atividades do trabalho e da vida diária, e a capacidade funcional, que é o potencial de execução para essas atividades (DEYO,1988; CAILLIET, 2001).

Na lombalgia mecânico-postural, a dor não apresenta irradiação importante, a intensidade da dor é variável, desde uma sensação de desconforto até uma dor lancinante, quase sempre há transtorno funcional, 
impedindo o paciente de se apoiar, trabalhar ou repousar. Em alguns casos há bloqueio funcional, ficando o paciente em uma posição rígida, sem condições de exercer qualquer atividade. É comum a presença de rigidez matinal que melhora com a movimentação. Mudanças de posição, ato de sentar, deambular, tossir, espirrar e efetuar pequenos esforços provoca dor. Observase limitação da mobilidade da coluna, dor a palpação da região lombar, podendo haver uma área extremamente sensível (PORTO, 2000).

Comumente a lombalgia divide-se em aguda e crônica. A lombalgia aguda é a dor que está presente por três meses ou menos. Os episódios de dor aguda costumam ocorrer em pacientes com idade em torno de 25 anos e em $90 \%$ dos casos desaparecem em 30 dias com ou sem tratamento medicamentoso, fisioterapêutico ou mesmo por meio do repouso. A lombalgia crônica é a dor persistente durante três meses, no mínimo, o que corresponde a $10 \%$ dos pacientes acometidos por lombalgia aguda recidivante. Esse tipo de lombalgia é mais comum em pacientes de 45 a 50 anos. (ROSENTHAL, 1994; MENDES, 1999).

Os principais fatores responsáveis pela cronicidade das dores lombares são problemas psicológicos, baixo nível de escolaridade, trabalho pesado ou em postura sentada, levantar grandes quantidades de peso, sedentarismo, acidentes de trabalho, dirigir veículos, horas excessivas de trabalho, gravidez, ferimentos e tabagismo (MENDES, 1999). Em se tratando da presente pesquisa, acredita-se que as posturas adotadas nas rotinas de trabalho diário podem ser um fator desencadeante ou intensificador para a dor lombar.

Alguns estudos constataram que é alta a prevalência de lombalgia e que 60 a $80 \%$ dos indivíduos sofreram ou sofrerão algum dia com essa moléstia 
(KELSEY et al, 1984; BUCKLE, 1987). Estima-se que o gasto anual relacionado a esse problema (custos médicos e indenizações) foi em torno de 20 bilhões de dólares durante a década de 90 e a previsão para esta é de que esses gastos superem 50 bilhões de dólares (FRYMOYER e CATS-BARIL, 1991; NACHEMSON,1999).

De Vitta, (1996) ao realizar um estudo com o intuito de correlacionar a lombalgia com as variáveis tipo de ocupação, idade e sexo, traz que há uma maior prevalência dessa moléstia nas faixas etárias abaixo de 30 anos $(61,2 \%)$ e entre 31 a 40 anos (48,5\%) e uma menor prevalência na faixa entre 51 e 60 anos (25\%) e acima de 60 anos (13,6\%).

Estatísticas nacionais e de outros países mostram que a lombalgia é a causa mais freqüente de decréscimos permanentes ou temporários da capacidade laboral entre pessoas em idade produtiva (STUBBS; BUCKLE; HUDSON, 1983; DONZELLI et al., 2006) e pode estar associada com as posturas físicas de trabalho, particularmente ao levantar e movimentar pacientes (RYDEARD et al., 2006).

A dor lombar é uma das alterações musculoesqueléticas mais comuns nas sociedades industrializadas, afetando $70 \%$ a $80 \%$ da população adulta em algum momento da vida (HODGES, 2004), tendo predileção por adultos jovens, em fase economicamente ativa (CECIN et al., 1991; DE VITTA, 1996), sendo uma das razões mais comuns para aposentadoria por incapacidade total ou parcial (NACHEMSON, 1999).

Em relação à prevalência sexual e etária, estudos demonstram que é mais comum a dor lombar em mulheres que em homens e que esta patologia 
acomete geralmente mais indivíduos na idade produtiva em média dos 25 aos 60 anos (NIEMAN, 1999; TEIXEIRA et al., 2002).

Outro aspecto bastante relevante levantado no estudo de Silva, (2004), é com relação aos serviços de atenção básica em saúde que devem estar preparados para diagnosticar e tratar o problema da lombalgia crônica, bem como estarem aptos para identificar suas causas afim de serem estabelecidas estratégias de prevenção adequadas a cada caso.

\subsection{Exercícios de alongamento e resistidos}

Tanto em humanos quanto em animais, dependendo da intensidade, duração e freqüência, os exercícios resistidos e de alongamento ativam mecanismos hipertróficos. No entanto, não se sabe qual é a resposta do músculo esquelético a esta combinação, tanto para potencializar o treinamento desportivo como para acelerar o processo de reabilitação (SECCHI et al., 2008).

Quando um músculo perde sua flexibilidade normal, ocorre uma alteração na relação comprimento-tensão, incapacitando-o de produzir um pico de tensão adequado, o que desenvolve fraqueza com retração muscular. 0 encurtamento muscular pode ser decorrente de diversos fatores, tais como alinhamento postural incorreto, imobilização do músculo, fraqueza muscular e envelhecimento (MORENO et al., 2007).

Tem-se que os exercícios de alongamento podem e devem ser praticados por favorecerem a flexibilidade e a amplitude articular, bem como promover a manutenção dos níveis de amplitude articular já atingidos, mas 
estudos se divergem ao afirmar que esta prática de exercícios gera força muscular e estabilidade lombo-pélvica, fatores os quais favorecem a melhora da dor lombar (GOSSMAN et al, 1982).

O alongamento muscular é freqüentemente efetuado nas práticas desportivas, com o objetivo de aumentar a flexibilidade muscular e a amplitude articular, assim como diminuir o risco de lesões e, possivelmente, melhorar o desempenho atlético (SAFRAN; SEABER; GARRET, 1989). Já foi demonstrado que o treinamento de flexibilidade pode melhorar a performance nos exercícios de força envolvendo o ciclo alongamento/encurtamento do músculo em exercício (BARBANTI, 1998).

A maioria dos autores que realizou pesquisas com humanos demonstrou a efetividade das técnicas de alongamento estático passivo, dinâmico ou por Facilitação Neuromuscular Proprioceptiva (BANDY; IRON; BRIGGLER, 1997). A técnica de alongamento estático tem sido utilizada por ser considerada bastante eficiente para produzir aumento agudo na amplitude de movimento articular (BEHM et al., 2004; DAVIS et al., 2005). Por esse motivo, inúmeros profissionais prescrevem exercícios de alongamento por meio dessa técnica durante o trabalho de aquecimento (NELSON; KOOKKONEN; ARNALL, 2005).

Estudos experimentais publicados, realizados em sua maioria com animais, demonstraram que 0 alongamento ativo excêntrico seria o mais indicado para promover o alongamento muscular, pois é o que mais rapidamente estimula adaptações no comprimento do músculo, aumentando, então, sua flexibilidade e podendo também causar mudanças nos níveis de geração de força (GOLDSPINK; SCUTT; LOUGHNA, 1992). Baseando-se ainda no estudo anterior e no de Bandy; Iron; Briggler, (1997), conclui-se que 
uma duração 30 segundos seria o tempo ideal para que se obtenha ganhos de amplitude num exercício de alongamento.

Em se tratando do tempo de estímulo e do número de repetições realizadas nos alongamentos ativos, tem-se que, segundo Viveiros et al., (2004) tanto o número de séries como o tempo de duração do estímulo influenciaram os valores de flexibilidade pós-exercício de forma aguda. A maior alteração, porém, ocorreu por conta do tempo de duração do estímulo. O efeito do número de séries parece ficar subordinado ao tempo de duração do estímulo do alongamento. Quanto às respostas aos efeitos do alongamento em longo prazo, a literatura é escassa de dados ao discutir esse aspecto (HORTOBÁGYI et al., 1985; WORRELL; SMITH; WINEGARDER, 1994).

Um estudo recente realizado com o objetivo de analisar a durabilidade dos ganhos da flexibilidade após seis semanas de aplicação da técnica de alongamento isoladamente ou associada ao aquecimento muscular e avaliar qual entre duas técnicas seria mais eficaz em relação à manutenção da flexibilidade e por quanto tempo, teve-se que o programa com alongamento estático foi efetivo no aumento da ADM (amplitude de movimento) articular de joelho, mas a associação deste com o aquecimento profundo não levou a um maior ganho de flexibilidade. Como já esperado, houve retorno da flexibilidade apresentada após o treinamento, em relação à primeira medida em ambos os grupos até 72 horas (LIMA et al., 2006).

Em se tratando deste mesmo estudo, os autores citados sugerem que os benefícios de um treino com exercícios de alongamento estático de isquiotibiais em longo prazo (seis semanas) em indivíduos insuficientemente ativos, sem patologias musculoesqueléticas, existem, porém assim que se interrompe este 
treinamento os benefícios vão deixando de existir se não for passada nenhuma orientação ao indivíduo.

Essa mesma pesquisa relata a importância desses estudos e a aplicabilidade dos resultados obtidos nos mesmos na prescrição de exercícios de alongamento. Outra afirmativa a cerca dos resultados desse estudo é a necessidade da prática diária de exercícios para a manutenção ou desenvolvimento da flexibilidade, pois os efeitos agudos tardios após 24 horas apresentam tendência ao retorno dos valores iniciais, mesmo com variações no número de séries ou no tempo de duração do estímulo.

Coutinho et al., (2004) mostraram que sessões de alongamento mantidas por 40 minutos, realizadas três vezes por semana no músculo sóleo de rato, foram suficientes para aumentar o comprimento muscular, o número de sarcômeros em série e a área de secção transversa das fibras musculares (ASTFM) de músculos não encurtados.

Fronteira; Dawson; Slovik, (2006) relataram em seu estudo que clinicamente, tem sido proposto que, para ocorrer aumentos mais significativos de ADM, o alongamento deve ser realizado cinco vezes por semana. Entretanto, duas a três sessões semanais são suficientes para gerar ganhos de ADM (amplitude de movimento). Após o ganho, uma sessão de alongamento semanal é eficiente para sua manutenção.

A respeito dos tipos de alongamento, a presente pesquisa se ateve em dar enfoque apenas ao alongamento ativo, pois segundo Achour Jr., (1999), esse é determinado pelo maior alcance do movimento voluntário utilizando-se da contração dos agonistas e relaxamento dos antagonistas e foi esse o utilizado na presente pesquisa. A respeito dos outros tipos os quais alguns 
deles já foram relatados anteriormente como o passivo, o estático, o ativopassivo e o ativo assistido e o balístico, esses não receberam enfoque na presente pesquisa.

De acordo com os estudos supracitados, percebe-se que ainda existe uma enorme celeuma no que tange os benefícios do alongamento, tanto isoladamente como também associado à outra atividade física. Percebe-se que os estudos ainda se divergem quanto à aplicabilidade dessa prática, mas embora com poucas evidências a respeito de sua prática de melhor eficácia, esta atividade ainda parece ser uma modalidade de exercício físico bastante praticada, não só na comunidade atlética, mas entre as pessoas comuns e sedentárias.

A respeito dos exercícios resistidos, o posicionamento do American College of Sports Medicine (ACSM) demonstra a importância da força e da potência muscular. O treinamento dessas capacidades mostra-se efetivo na melhoria de várias atividades funcionais e no aumento da força e hipertrofia muscular (KRAEMER et al., 2002).

A força muscular é definida por vários autores, dentre eles, Barbanti (1997) como sendo a capacidade de exercer tensão muscular contra uma resistência, envolvendo fatores mecânicos e fisiológicos que determinem a força em algum movimento particular. Para Guedes (1997), força é a capacidade de exercer tensão muscular contra uma resistência, superando, sustentando ou cedendo à mesma.

O treino de força induz alterações no sistema nervoso central, o qual pode aumentar o número de unidades motoras recrutadas, alterar a freqüência de disparos dos motoneurônios, melhorar a sincronia da unidade motora 
durante determinado padrão de movimento e reduzir ou cancelar gradativamente os impulsos inibitórios permitindo que o músculo atinja níveis mais elevados de força (MCARDLE; KATCH; KATCH, 1998).

O exercício ativo resistido, no qual uma contração muscular dinâmica ou estática é resistida por força externa, aplicada mecânica ou manualmente, é um quesito imprescindível num programa de reabilitação, para se promover a saúde e o bem-estar físico e prevenir o risco de lesões. Ele restaura, melhora ou mantém a força, a potência e a resistência muscular contra a fadiga entre outros efeitos (BATTAGLINI et al., 2004).

A hipertrofia muscular é caracterizada pelo aumento da secção transversa do músculo. Trata-se do produto final ou resultante após a utilização de treinamentos especializados em força, ou seja, é uma adaptação fisiológica do músculo, sendo mais pronunciada após períodos prolongados desta forma de treinamento. A hipertrofia não deve ser conceituada como sendo uma valência ou qualidade física, pelo fato de ser uma supercompensação de um treinamento específico de uma qualidade física (CHIESA, 2003).

Segundo Monteiro; Simão; Farinatti, (2005), o treinamento de força é prescrito em função da combinação de diversas variáveis. Dentre elas podemse citar o número de séries, os intervalos de recuperação e a quantidade, tipo e ordenação dos exercícios escolhidos. A forma pela qual essas variáveis são manipuladas resulta em efeitos diferenciados no aprimoramento da força e hipertrofia muscular.

Para Daher et al., (2005), a força é necessária para uma boa aparência, é imprescindível para um bom desempenho na execução de qualquer outra 
atividade física, é altamente considerada em uma prova de aptidão física e atua como profilaxia para prevenir algumas doenças ortopédicas.

Em se tratando de pausas realizadas entre as repetições, elas podem representar uma variável importante na elaboração do programa de treinamento, podendo exercer influência direta nas adaptações fisiológicas e no desempenho do indivíduo (KRAEMER et al., 2002; KRAEMER; RATAMESS, 2004; SEBASTIÃO, 2007). Estudos realizados revelam que pausas de 30, 60, 90 e 120 segundos podem provocar respostas hormonais, cardiovasculares e metabólicas com alterações significativas (FLECK, 1988; HÄKKINEN; PAKARINEN, 1993; KRAEMER et al., 1990; KRAEMER et al., 1993; ABDESSEMED et al., 1999).

A prescrição do treinamento de força torna-se imprescindível para distintas populações como, por exemplo, atletas, indivíduos que apresentam lesões ortopédicas, idosos, ou mesmo àqueles praticantes saudáveis que visam à promoção da saúde (POLLOCK , 1998; EVANS, 1999).

Os programas de treinamento resistidos podem ser realizados sem 0 uso de aparelhos, sendo a intensidade dos exercícios determinada pela própria resistência corporal (FLECK; KRAEMER, 2002; DOWSHEN, 2001; FAIGENBAUM, 2003; CARVALHO, 2004). Com o intuito de tornar a prática de exercícios físicos uma rotina efetiva e sem grandes investimentos em acessórios, aparelhos ou instrumentos, a presente pesquisa propôs a aplicação de dois protocolos de exercícios os quais se utilizam apenas da carga corporal para exercer resistência e promover modificações mecânicas e metabólicas no organismo. 


\subsubsection{Descrição do protocolo de Exercícios de Alongamento e fortalecimento convencionais}

1. Reeducação respiratória

Os exercícios respiratórios são, geralmente, eleitos para iniciarem uma prática de atividade física, independente da técnica utilizada, proporcionam ao indivíduo uma melhora da percepção corporal e da ventilação pulmonar dentre outros benefícios (PRADO et al., 2004).

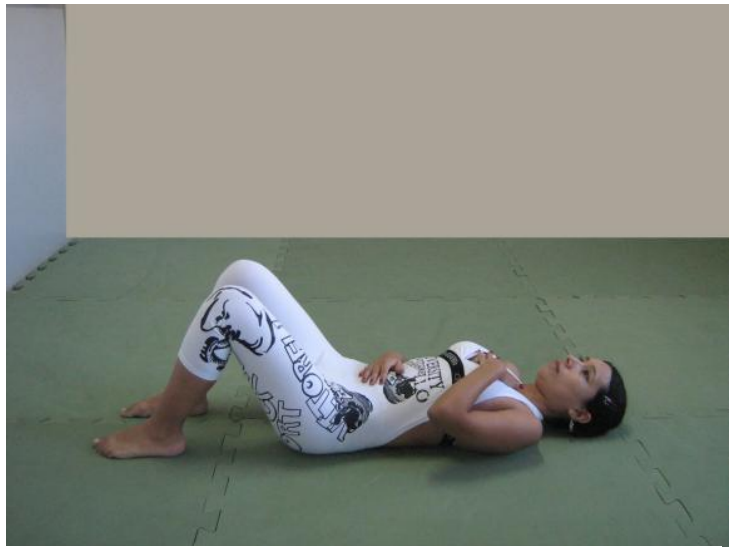

Figura 3a - Reeducação respiratória.

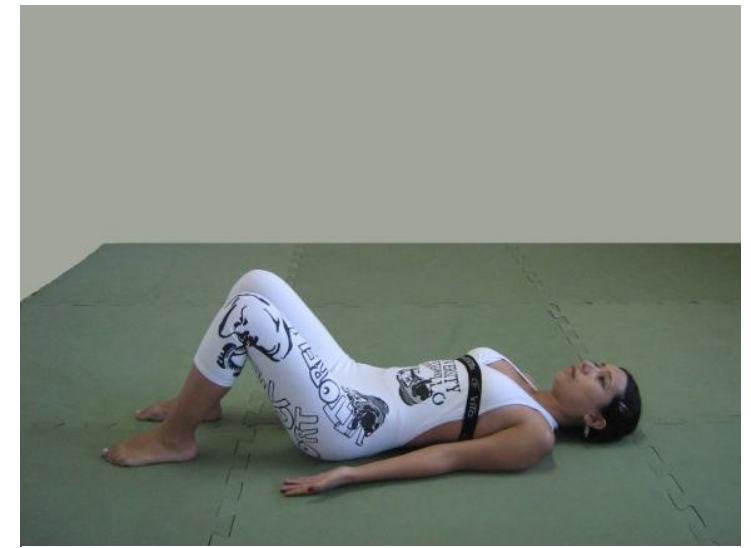

Figura 3b - Reeducação respiratória com braços ao longo do tronco.

2. Fortalecimento de glúteos

Esse exercício é executado exatamente como o segundo exercício do protocolo de exercícios baseados no método Pilates (vide descrição da Articulating sholder Bridge).

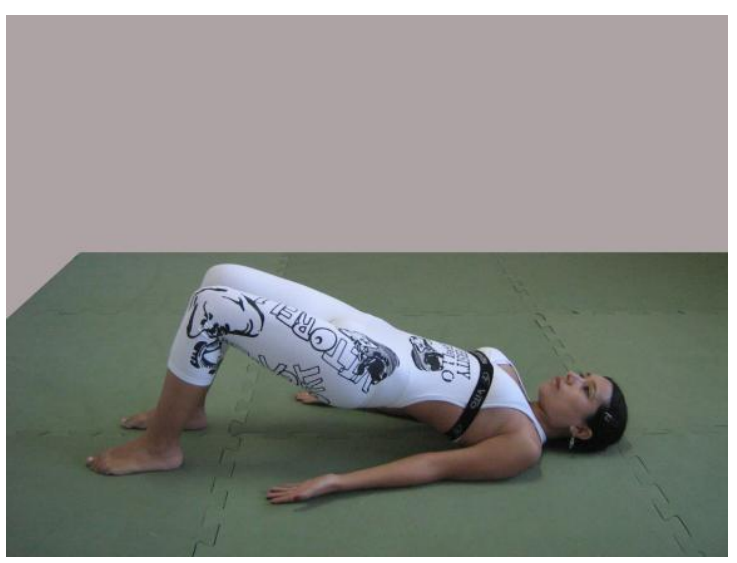

Figura 4- Fortalecimento de glúteo máximo. 


\section{Abdominais}

Segundo Kisner, (1992), neste exercício, o voluntário deve se posicionar em decúbito dorsal com joelhos flexionados e pés apoiados no chão com a coluna lombar retificada e apoiada na mesma superfície. Deve se começar com uma inclinação posterior da pelve, em seguida, deve-se elevar a cabeça do chão, o que provoca uma contração estabilizadora dos músculos abdominais. Esse movimento deve ser progredido com a elevação do tórax até que as escápulas deixem o solo.

Nas primeiras 10 sessões, foi orientado ao voluntário para que ele mantivesse os braços cruzados no peito (Figura 5a), e, a partir da 11aㅗ , que os braços fossem elevados atrás da cabeça com as mãos apoiadas sob a nuca com uma palma da mão sobreposta a outra de modo que os cotovelos permanecessem abertos (Figura 5b). Dessa forma, estabeleceu-se um grau de dificuldade maior para o fortalecimento dos abdominais.

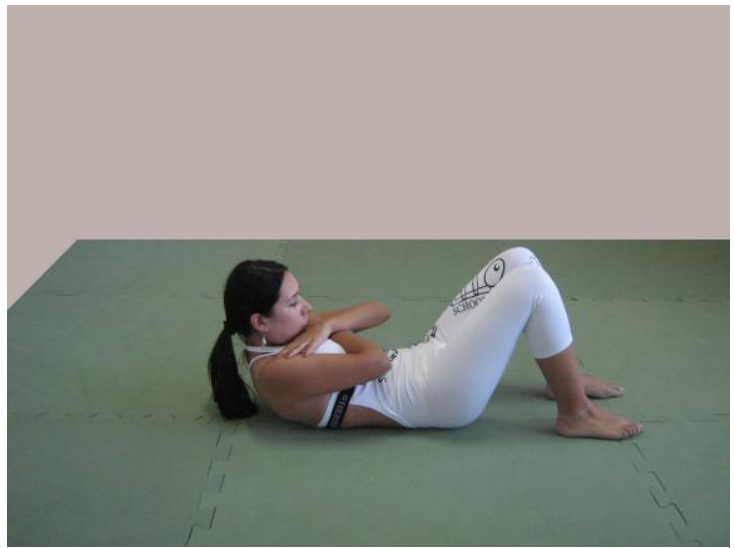

Figura $5 \mathrm{a}$ - Abdominal com braços cruzados no peito.

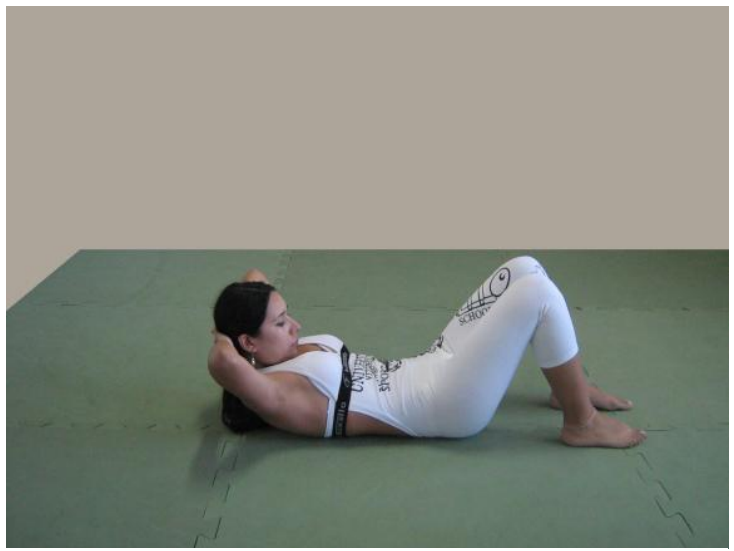

Figura 5b - Abdominal com braços elevados atrás da cabeça. 
4. Alongamento de Isquiotibiais (IT)

$\mathrm{Na}$ presente pesquisa, optou-se em, inicialmente, realizar os exercícios para alongamento dos isquiotibiais com a perna contralateral flexionada (Figura 6a), enquanto a perna alongada era elevada estendida na direção do tronco. Embora nessa posição, a flexibilidade da coluna lombar soma-se à amplitude de flexão do quadril fazendo com que os isquiotibiais pareçam mais longos do que realmente o são (KENDALL; McCREARY; PROVANCE, 1995), trata-se de uma postura mais confortável para manter o membro inferior estendido. Posteriormente, quando o participante já havia realizado as 10 primeiras sessões, ele deveria manter as duas pernas estendidas (Figura 6b).

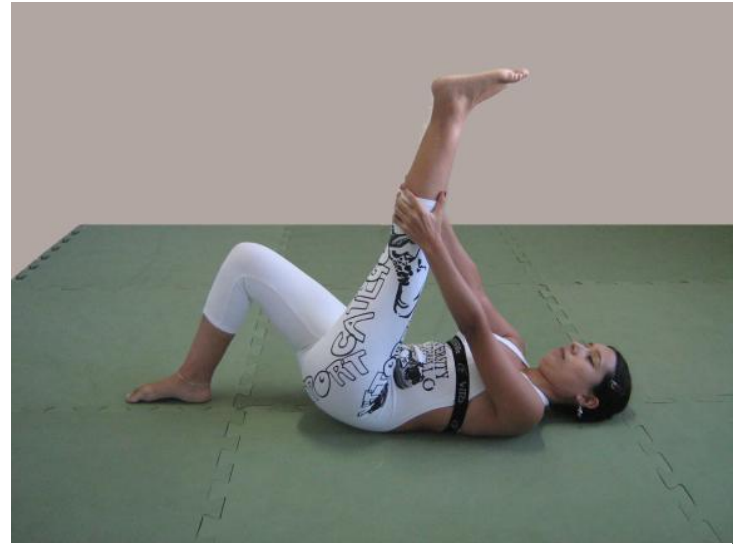

Figura 6a - Alongamento de IT com o membro contralateral direito flexionado.

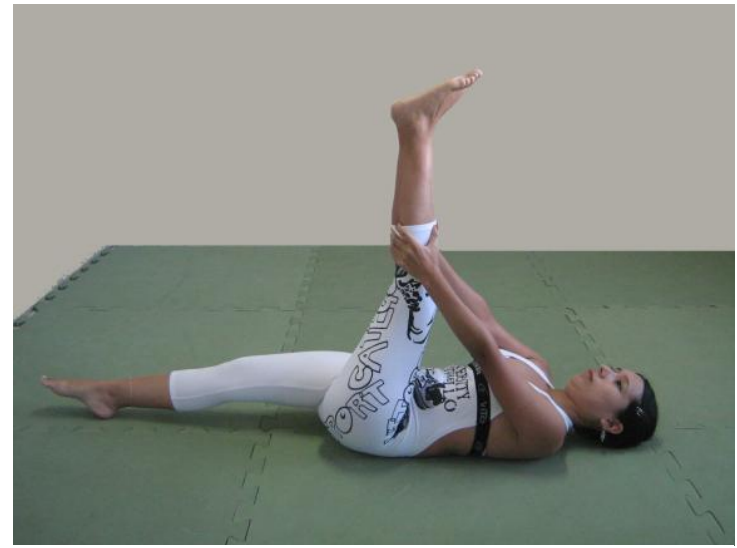

Figura 6b - Alongamento de IT com o membro contralateral direito estendido.

\section{Fortalecimento de tronco}

Nesse exercício, o voluntário deveria ficar em posição de "gato" com as mãos espalmadas apoiando o chão (Figura 7a). O participante era instruído pelo autor do estudo a realizar uma retroversão pélvica antes de estender o membro inferior. Este devia ser alongado posteriormente de forma que se alinhasse ao quadril e o braço contralateral estendido à frente simultaneamente 
à extensão da perna atrás (Figura $7 \mathrm{~b}$ ). Da mesma forma que a perna era estendida até a altura do quadril, o braço deveria elevar-se até a altura do ombro sem que houvesse envolvimento do músculo trapézio (KISNER, 1992).

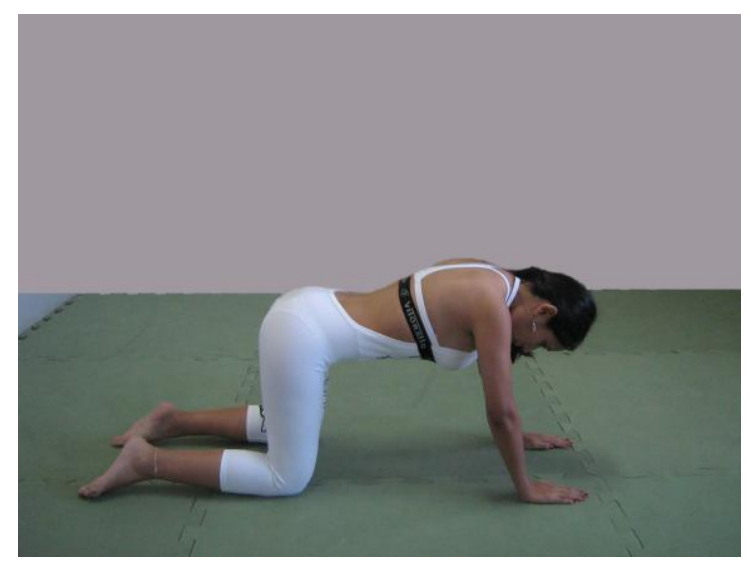

Figura 7a - Posição inicial - gato.

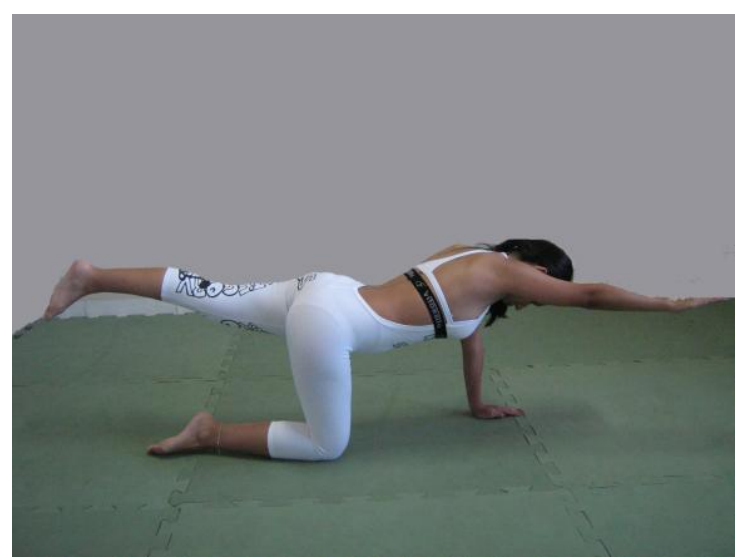

Figura $7 \mathrm{~b}$ - Extensão de perna e braço contralateral (fortalecimento de tronco).

6. Fortalecimento de ombros

Inicialmente, o voluntário deve se posicionar em decúbito ventral com as mãos espalmadas no chão na mesma direção dos ombros. Os joelhos e os dorsos dos pés apoiados no chão. $O$ ângulo do quadril com as coxas deve ser um pouco maior que $90^{\circ}$, o abdômen deve estar bem contraído. O exercício ocorre com uma flexão do antebraço em direção ao chão (Figura 8). Posteriormente, o participante passa a realizar esse mesmo movimento apenas com apoio nas mãos e nos antepés, o que torna o exercício com um grau de dificuldade maior (PENTEADO, 2010). 


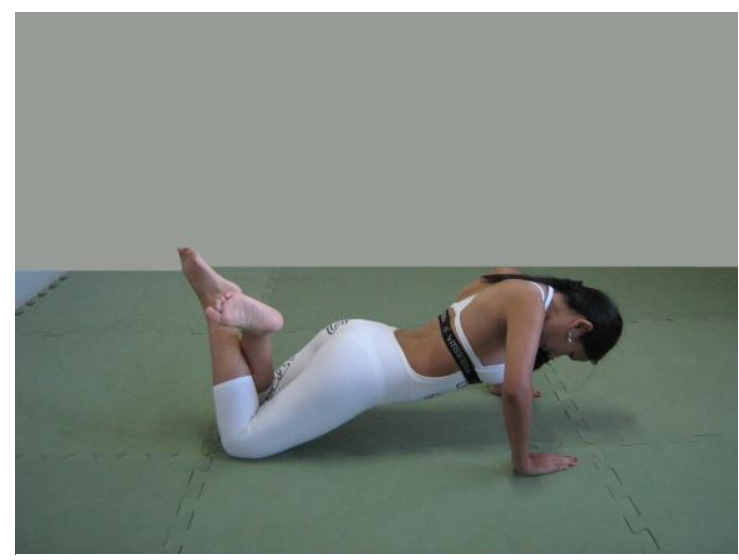

Figura 8 - Fortalecimento de ombros execução.

7. Alongamento de tronco anterior

O participante deve se posicionar em decúbito ventral com as mãos apoiadas no chão na direção ou acima dos ombros (Figura 9a). Em seguida, o indivíduo deve elevar o seu tórax da superfície de apoio mantendo a pelve em contato com a mesma. Ao empurrar o chão com as mãos, o voluntário deve empurrar seus ombros para baixo com o intuito de deprimir as escápulas (Figura 9b). Trata-se de uma flexão em decúbito ventral que também alonga os músculos flexores de quadril e fortalece os extensores de tronco (KISNER, 1992).

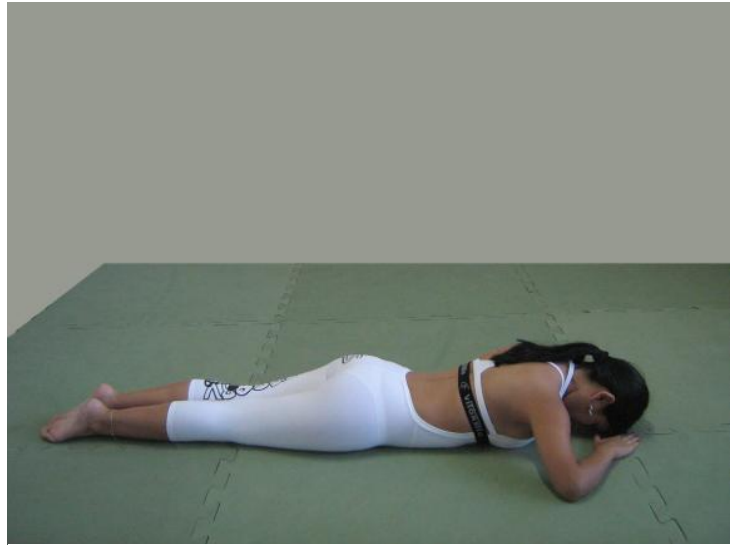

Figura 9a - Posição inicial.

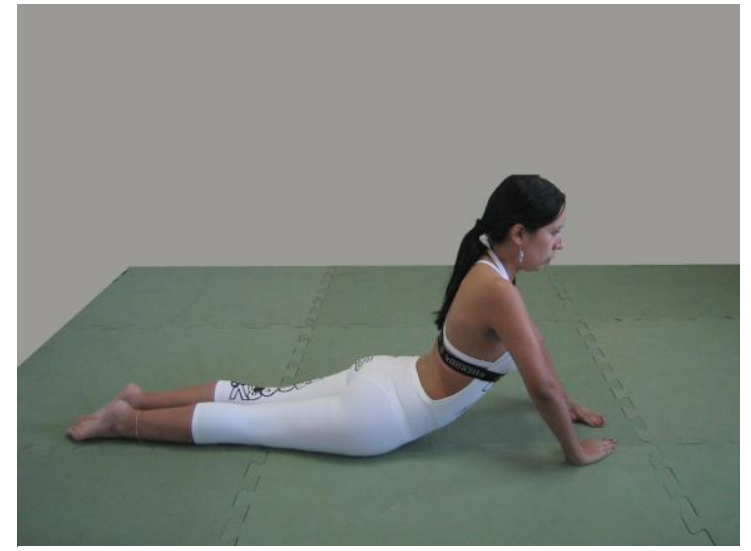

Figura 9b - Extensão de tronco. 
8. Fortalecimento de quadríceps com Inclinação anterior de tronco

Segundo estudo de Silva et al., (2004), este exercício pode ser executado na posição ortostática, pés afastados a uma distância igual à largura do quadril (Figura 10a), o voluntário deve realizar uma flexão de quadril e de joelhos, enquanto o tronco deve realizar uma inclinação anterior simultânea à flexão de quadril e joelhos com manutenção da musculatura abdominal contraída (Figura 10b).

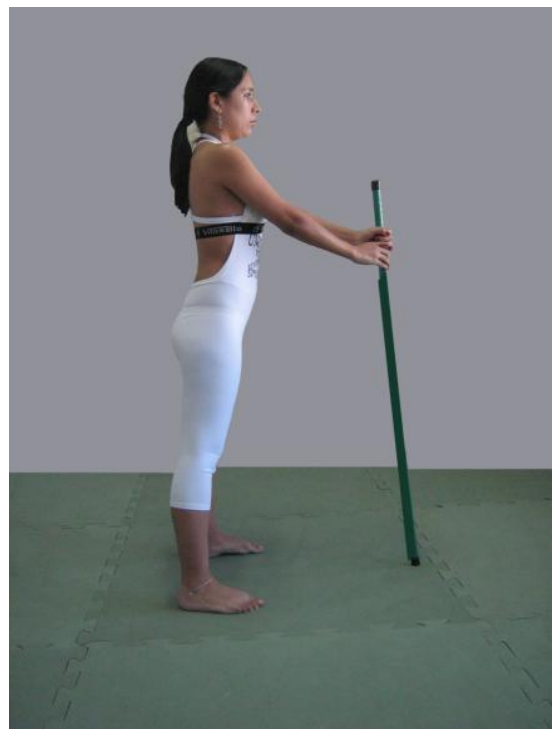

Figura 10a - Postura inicial.

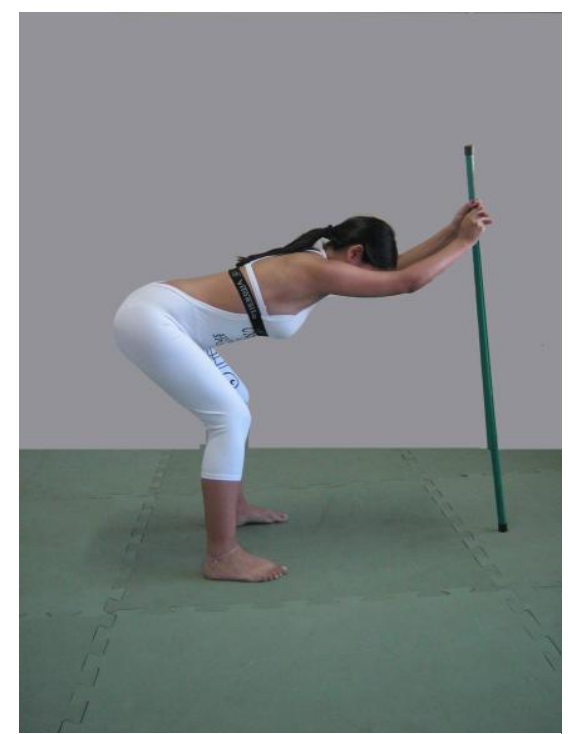

Figura 10b - Flexão de membros inferiores com inclinação anterior de tronco.

9. Alongamento cervical (inclinação, rotação, flexão e extensão)

Essa série de alongamentos cervicais foi realizada com o participante em pé, pernas levemente afastadas na largura do quadril e joelhos semiflexionados (Figura 11a).

Com a cabeça e olhos horizontalizados, o participante deve ativamente inclinar sua cabeça para um dos lados com o auxílo da mão do mesmo lado em que a cabeça se inclina. Deve-se manter esse alongamento por 30 segundos 
(Figura 11b). O movimento deve ser realizado em três repetições mantendo o mesmo tempo de manutenção do alngamento de 30 segundos e o exercício deve ser repetido para o outro lado.

Em seguida, com as mãos sobrepostas e posicionadas abaixo do occiptal, o participante deve realizar ativamente uma flexão cervical (Figura 11c), de forma que ele não deposite o peso de seus membros superiores sobre a nuca, mas tracione esta para cima, afim de que o movimento proporcione uma flexão da cabeça em direção ao peito.

No movimento de extenção cervical, os braços devem ser posicionados ao longo do tronco com as palmas das mãos direcionadas para frente, afim de que os ombros mantenham-se estabilizados. Em seguida, com a boca fechada, o abdomem contraído e o quadril posicionado em postura neutra, o participante deve realizar uma extensão cervical (Figura 11d). O voluntário deve ser orientado a manter-se imóvel da cintura para baixo com o intuito de que ele não projete o quadril anteriormente nem flexione os joelhos. No movimento de rotação da cabeça, este deve ocorrer em três repetições para cada lado, também com manutenção do alongamento de 30 segundos. 


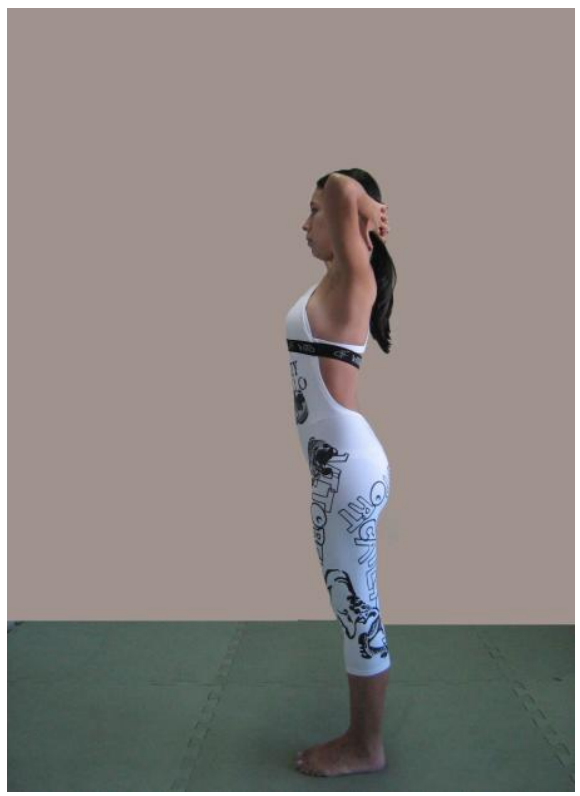

Figura 11a - Postura inicial.

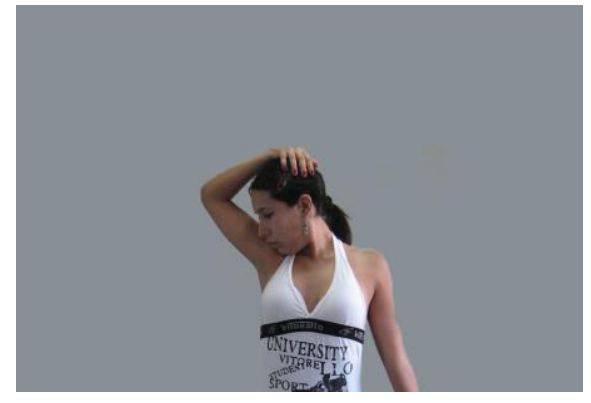

Figura 11b - Inclinação da coluna cervical.

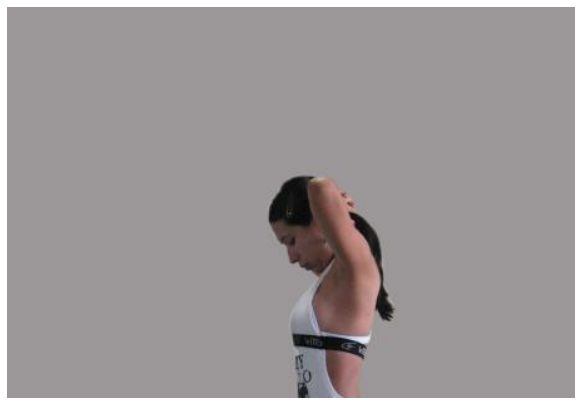

Figura 11c - Flexão da coluna cervical.

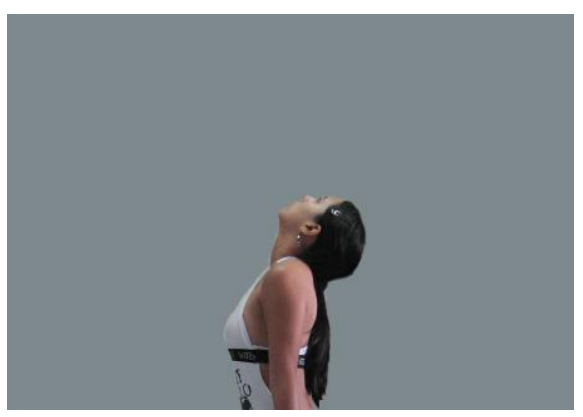

Figura 11d - Extensão da coluna cervical. 
10. Alongamento de Adutores de quadril

Com o participante em decúbito dorsal, joelhos flexionados e coxas abduzidas; os pés devem estar com as plantas posicionadas uma contra a outra. Até a $10^{\mathrm{a}}$ sessão, o voluntário deve realizar a postura de alongamento com os braços aduzidos e estendidos ao longo do tronco (Figura 34a), a partir da $11^{\text {a }}$ sessão, os braços sobem com uma flexão de ombros acima da cabeça, afim de exigir um alongamento de músculos peitorais (Figura 34b) (SÖLVEBORN, 2004).

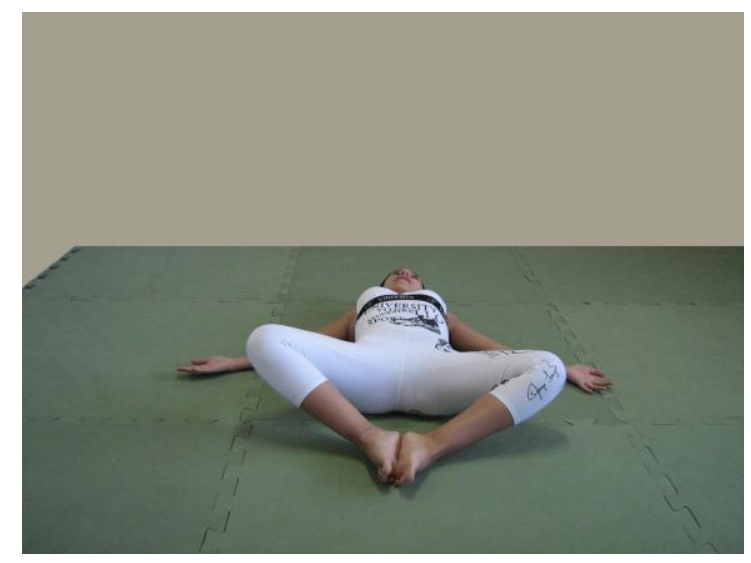

Figura 12a - Alongamento de adutores com os braços alongados e posicionados ao longo do tronco.

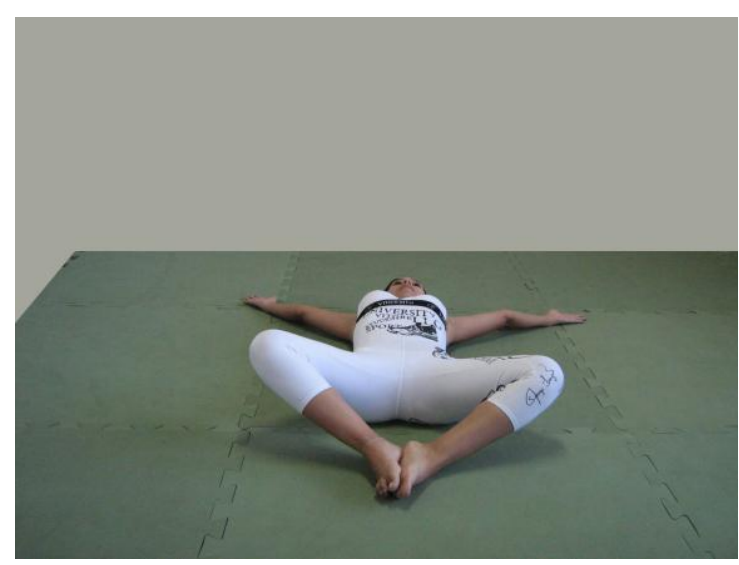

Figura 12b - Alongamento de adutores com os braços alongados e elevados acima da cabeça em "V". 


\subsection{O método Pilates de exercícios}

Tradicionalmente, tem-se enfatizado a importância dos exercícios contínuos para a promoção da saúde. Entretanto, nos últimos anos também tem se demonstrado a necessidade do treinamento contra-resistido para proporcionar efeitos benéficos sobre a aptidão muscular (força e resistência), metabolismo, função cardiovascular, fatores de risco e bem estar (POLLOCK et al., 1998) e Pilates tem se demonstrado um método de exercícios que atua no condicionamento dessas variáveis acima citadas.

O método Pilates é popular há décadas entre bailarinos e comunidade da área da saúde; é o único capaz de treinar a conscientização entre corpomente e o controle dos movimentos e da postura. Mecanismos especializados promovem a oportunidade de treinar movimentos padronizados posturais. A demanda neuromuscular do tradicional método de Pilates pode ser bastante alta, no entanto, a modificação do método pode ser necessária para a aplicação de intervenção fisioterapêutica (RYDEARD et al., 2006).

Praticantes descrevem Pilates como o único método para condicionamento físico que faz uso da combinação de exercícios de alongamento, fortalecimento e respiratórios o qual desenvolve a musculatura do tronco e restaura o equilíbrio muscular do sistema musculoesquelético. Joseph Hubertus Pilates desenvolveu o método há mais de 85 anos na Alemanha com o intuito de tratar suas próprias moléstias como a asma e a má postura e o colocou em prática inicialmente para tratar doentes e acidentados da primeira guerra mundial (SMITH; SMITH, 2005).

O mesmo autor citado anteriormente relata que Pilates era extremamente consciente sobre a influência negativa dos hábitos modernos 
sobre a coluna vertebral, a postura e a respiração. Ele provou diversas condutas de tratamento que incluíam Yoga, auto-defesa, controle de peso e ginástica os quais, posteriormente o subsidiaram para a criação do seu método que teve inicialmente a terminologia de "Contrologia" ou controle da consciência muscular.

Pilates foi difundido nos Estados Unidos a partir de 1923 e, atualmente, existem cerca de 300 centros especializados do método Pilates nesse país. Foi durante a década de 90 que o método começou a ser praticado pelos primeiros adeptos do método no Brasil (RYDEARD et al., 2006).

Numa perspectiva clínica, Pilates compõem-se de movimentos concêntricos, excêntricos, isométricos e co-contrações os quais são produzidos por meio de sinergismos musculares. Pilates enfatiza a estabilidade lombopélvica, a precisão, a mobilização segmentar da coluna vertebral, a mobilização e a estabilização da articulação de ombros, cotovelos, quadril, joelhos e tornozelos, a coordenação e o equilíbrio. A respiração através da expansão ântero-posterior, látero-lateral e superior e inferior da caixa torácica, inspirando e expirando é facilitada por meio dos movimentos naturais da coluna vertebral, dos braços e das pernas, sempre evitando a manobra de valsalva (SMITH; SMITH, 2005).

Dentre as formas de treinamento contra resistência, o método Pilates surgiu como forma de condicionamento físico particularmente interessado em proporcionar bem-estar geral ao indivíduo, sendo assim capaz de proporcionar força, flexibilidade, boa postura, controle, consciência e percepção do movimento (BLUM, 2002). 
Baseando-se em princípios da cultura oriental, sobretudo relacionados às noções de concentração, equilíbrio, percepção, controle corporal e flexibilidade, e da cultura ocidental, destacando a ênfase relativa à força e ao tônus muscular, o Pilates configura-se pela tentativa do controle o mais consciente possível dos músculos envolvidos nos movimentos. A isto se convencionou chamar de "contrologia" (MUSCOLINO e CIPRIANI, 2004). Assim, o método Pilates se baseia em fundamentos anatômicos, fisiológicos e cinesiológicos e é compreendido em seis princípios fundamentais: Respiração, Concentração, controle, centralização, precisão e fluidez de movimento (LANGE et al., 2000; LATEY,2001; CRAIG, 2004; MUSCOLIN; CIPRIANI, 2004; SEGAL; HEIN; BASFORD, 2004).

\subsubsection{Princípios fundamentais do método Pilates}

a) Respiração

Segundo Craig (2004), Joseph Pilates afirmava que freqüentemente respira-se errado, usando apenas uma fração da capacidade do pulmão. Por isto, Pilates em seu trabalho enfatizava a respiração como o fator primordial no início do movimento, fornecendo a organização do tronco pelo recrutamento dos músculos estabilizadores profundos da coluna na sustentação pélvica e favorecendo o relaxamento dos músculos inspiratórios e cervicais.

Esse mecanismo pôde ser descrito sincronicamente por meio do ciclo respiratório proposto pelo método o qual ocorre na seguinte ordem cronológica: 1) Inspiração torácica; 2) Expiração do tórax superior; 3) Expiração do tórax inferior e 4) Expiração abdominal. Este ciclo deve ser sincronizado ocorrendo 
ao mesmo tempo da ação muscular, favorecendo o incremento da ventilação pulmonar, a melhora da oxigenação tecidual, conseqüentemente a captação de produtos metabólicos associados à fadiga (GALLAGHER; KRYZANOWSKA, 2000; CRAIG, 2004; DALTRO; FERNANDES, 2004).

b) Concentração

A Concentração é necessária durante todo o exercício. Todos os movimentos são realizados conscientemente utilizando a inteligência, a intuição, a imaginação, a vontade e a memória configurando-se num diálogo interno. A concentração é voltada para cada parte do corpo, com o intuito de que o movimento seja desenvolvido com a maior eficiência possível. Qualquer membro ou parte do corpo é importante e nenhum movimento é ignorado. A atenção dispensada na realização do exercício é destacada ao aprendizado motor, que é o grande objetivo da técnica (LATEY, 2001).

c) Controle

Inicialmente, Joseph Pilates denominou o método "Controlgy" - A Arte da contrologia. Controle é definido a partir do discernimento da atividade motora, na execução do exercício enquanto ocorre mobilização de agonistas primários numa ação específica. A coordenação é a integração da atividade motora de todo o corpo visando um padrão suave e harmônico de movimento. É importante a preocupação com o controle de todos os movimentos a fim de aprimorar a coordenação motora, evitando contrações musculares inadequadas ou indesejáveis. O uso contínuo da Contrologia aumenta a oferta normal e natural de sangue puro e rico que vai fluir e circular pelo cérebro correspondente a novas áreas cerebrais antes adormecidas (PILATES, 2010).

d) Centralização 
Em se tratando da centralização, a este princípio, Pilates o denominou de powerhouse (centro de força) ou core. Segundo Muscolino e Cipriani (2004), embora este seja o ponto focal para o controle corporal, o próprio Joseph Pilates nunca definiu exatamente quais são os parâmetros e quais as estruturas que constituem o powrehouse. Para Pilates, trata-se exatamente do ponto que cruza uma linha imaginária que passa pela metade superior e a metade inferior do corpo e que cruza do lado direito ao esquerdo do corpo;

Segundo Latey (2001), o powerhouse é constituído pelas quatro camadas abdominais: o reto do abdômen, oblíquos interno e externo, transverso do abdômen; eretores profundos da espinha, extensores, flexores do quadril juntamente com os músculos que compõe o assoalho pélvico. Este centro de força forma uma estrutura de suporte, responsável pela sustentação da coluna e órgãos internos. O fortalecimento desta musculatura proporciona a estabilização do tronco e um alinhamento biomecânico com menor gasto energético aos movimentos.

e) Precisão

A precisão é de fundamental importância na qualidade do movimento, sobretudo, ao realinhamento postural do corpo. Consiste no refinamento do controle e equilíbrio dos diferentes músculos envolvidos em um movimento (MUSCOLINO; CIPRIANI, 2004).

f) Fluidez

Quanto a fluidez no movimento, esse princípio se refere à maneira como a qual o exercício deve ser realizado. A maneira controlada e contínua deve exibir qualidade de fluidez e leveza, que absorvam os impactos do corpo com o solo e que se faça uso da inércia, contribuindo para a manutenção da saúde do 
corpo. Esse princípio deve ser aplicado não apenas na execução de cada exercício, mas na transição entre um e outro, ao contrário dos movimentos truncados, pesados, que criam choques no solo, levam ao desperdício de energia ao tornar os tecidos propensos ao desgaste prematuro (MUSCOLINO; CIPRIANI, 2004).

Os exercícios baseados no método Pilates, os quais ativam os mecanismos de controle neuromuscular, são efetivos no decréscimo da dor e melhoram a função de indivíduos com lombalgia crônica não específica. Esses benefícios também podem proporcionar alívio de dores crônicas (RYDEARD et al., 2006), assim como a lombalgia em profissionais de enfermagem, objetivo do presente estudo.

Estudos minuciosos a respeito dos tipos de exercícios para prevenção de lombalgia trazem que a função do multífido, músculo relacionado à extensão de tronco, está prejudicada em pacientes com lombalgia (ALARANTA et al.,1993; PARKKOLA; RYTOKOSKI; KORMANO, 1993) e por outro lado, a função dos flexores de tronco parece não apresentar alteração em pacientes com a mesma moléstia (FLICKER et al., 1993). Sendo assim, existem evidências convincentes de que a realização de um programa de exercícios com ênfase no fortalecimento da musculatura extensora do tronco restaura a função da coluna lombar e previne o surgimento de lombalgia (KOLYNIAK et al., 2004), dessa forma, o presente estudo teve como proposta de intervenção a aplicação de dois protocolos de exercícios: um baseados no método Pilates (APÊNDICE 1) e outro com exercícios convencionais de alongamento e fortalecimento (APÊNDICE 2). Ambos os protocolos, embora diferentes 
tecnicamente, apresentam exercícios para os mesmos grupos musculares e são propostos para serem executados em posturas bem semelhantes.

Em decorrência de estudos realizados a respeito dos tipos de exercícios mais indicados para a prevenção de lombalgia (CUNNINGHAN e KELSEY, 1984), optou-se no presente estudo em elaborar os protocolos com o intuito de enfatizar exercícios de extensão e mobilização de tronco sem deixar de lado os exercícios abdominais e com isso promover aumento da força muscular, da flexibilidade e do controle postural, os quais contribuirão para a melhora da dor lombar e para o desempenho de sua função no trabalho.

Em uma pesquisa realizada, comparou-se a eficácia de duas técnicas de exercícios em pacientes com lombalgia crônica idiopática. Um protocolo de exercícios baseado no método Pilates e outro baseado na Escola da Coluna. Verificou-se nessa pesquisa que a aplicação do método Pilates é uma alternativa válida para pacientes que sofrem com essa patologia. Embora as duas técnicas mostraram-se eficientes na melhora da dor nesses pacientes, Pilates estimula o interesse dos pacientes e os envolve durante a prática (CUNNINGHAN e KELSEY, 1984).

Reconhecendo, dessa forma, a grande demanda física do profissional de enfermagem que atua na assistência, a prática de exercícios baseada no método Pilates poderá favorecer os aspectos neuromusculares desse trabalhador, colaborando assim para um melhor preparo físico e emocional do mesmo e assim esperar que, com o aumento da flexibilidade e do fortalecimento muscular, esse profissional poderá lidar melhor com as conseqüências de suas cargas físicas de trabalho no que tange os aspectos 
osteomusculares, tendo como diminuição os afastamentos causados por esse tipo de moléstia.

\subsubsection{Descrição do protocolo de exercícios baseados no método Pilates}

\section{Breathing (Respiração)}

De acordo com o descobrimento de Joseph H. Pilates, o homem respira de forma incorreta freqüentemente, usando apenas uma fração da capacidade pulmonar. Quando ainda bebê, usa a respiração abdominal e a eficaz respiração diafragmática para relaxar (CRAIG, 2004).

A respiração é fundamental no método Pilates para que haja uma execução ideal e recrutamento da musculatura profunda. Ao se iniciar no método, o praticante deve aprender como respirar corretamente por meio da inspiração e expiração profunda e completa. Além disso, a busca do recrutamento do músculo transverso abdominal deve ocorrer através da expiração forçada, a fim de dar suporte para todo o grupo abdominal e estabilização de coluna lombar e pelve, favorecendo o relaxamento dos músculos inspiratórios e cervicais (PILATES, 2010).

Pilates ensina a respiração lateral. Trata-se de um tipo de respiração que se evita a expansão do abdômen. O objetivo é usar os músculos torácicos e costais para promover a expansão lateral da caixa torácica e criar espaço para os pulmões se insuflarem. A razão para não expandir o abdômen com ar é a de que ao alongar o músculo inferior do abdômen, a região lombar fica sem suporte, desprotegida (PILATES, 2010). 
Por ter sofrido muito com a asma, Pilates descobriu o poder da respiração diafragmática ao enviar o ar para a caixa torácica. Ele falava sobre "espremer" todos os átomos de ar puro dos pulmões e sobre a importância de ter uma boa inspiração e expiração. Não se sabe como a respiração diafragmática de Pilates interfere nas doenças como asma e enfisema, contudo, após uma aula do método, alguns de seus alunos, que respiravam com dificuldade, obtinham grande melhora (CRAIG, 2004).

Optou-se por iniciar a sessão com o exercício respiratório (Figura 13 a,b), pois segundo Pilates (2010), o exercício respiratório, dentre as inúmeras funções e benefícios, é um exercício preparatório para os outros que o sucederão; eles ativam a musculatura do dorso, preparando-o e promovendo a estabilização do mesmo para os próximos exercícios. Na Figura 13a, uma mão sobre o tórax (esquerda) e a outra sobre o abdômen (direita) foi utilizada nas 10 primeiras sessões a fim de que o participante entendesse o movimento respiratório, depois, nas próximas 10 sessões, os braços foram posicionados ao longo do tronco, conforme mostra a Figura 13b.

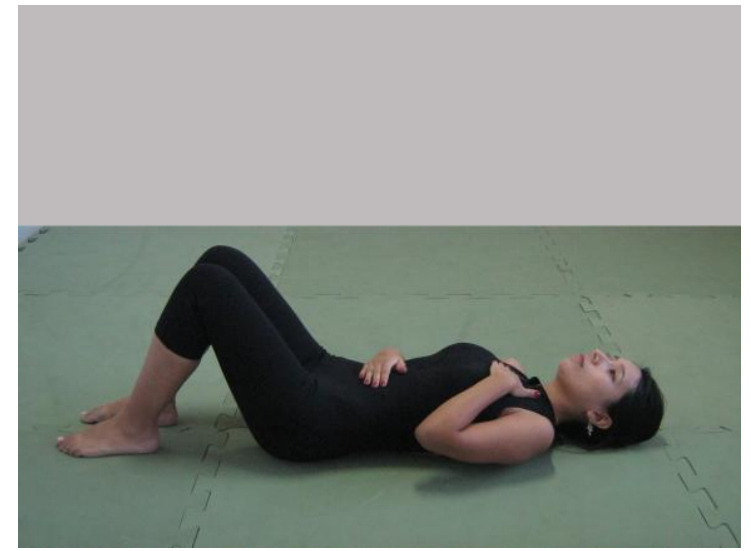

Figura 13a - Respiração com a mão esquerda sobre o tórax e a direita sobre o abdômen.

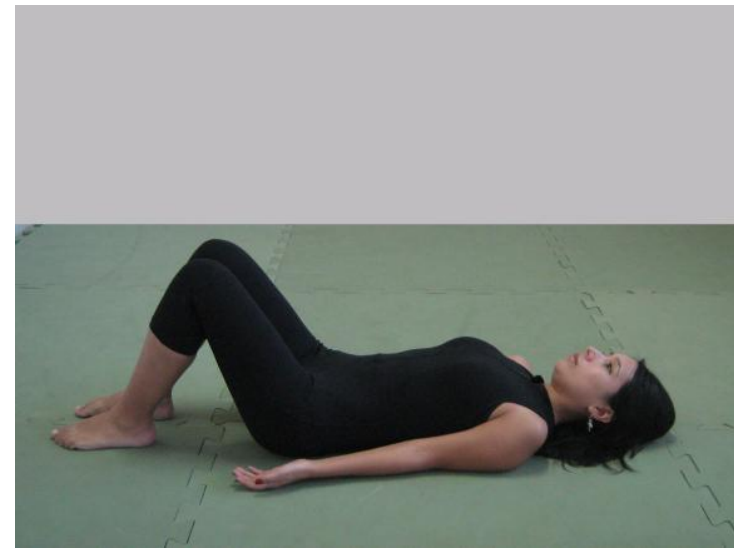

Figura 13b - Respiração com as duas mãos posicionadas ao longo do tronco. 


\section{Articulating sholder Bridge (Ponte)}

A articulating sholder bridge ou ponte articulada (Figura 14 a,b) recebe essa denominação por executar a elevação do quadril como se cada vértebra de extremidade distal para proximal saísse do chão ponto a ponto a partir de uma retroversão pélvica até que o quadril se alinhe com as coxas em extensão como se formasse o desenho de uma ponte (Figura 14b). O retorno do exercício é realizado de forma inversa, sendo que a partir dessa posição, as vértebras vão se alinhando no chão de proximal para distal até que a pelve assuma novamente uma postura neutra no chão (CHENG E ISACOWITZ, 2003).

O voluntário deve se posicionar em decúbito dorsal com os joelhos flexionados e pés paralelamente posicionados e apoiados no solo. A ponte deve ser feita com o paciente pressionando a parte superior da coluna torácica contra o solo, sem que haja elevação dos calcanhares (KISNER, 1992).

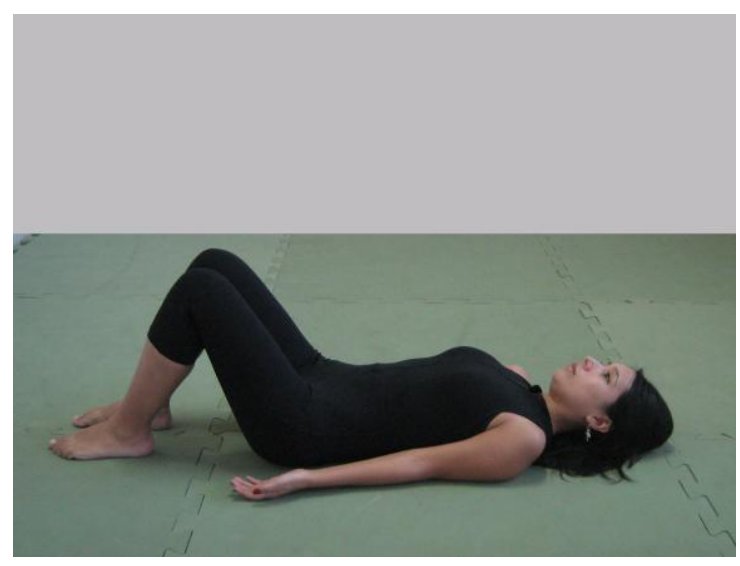

Figura 14a - Ponte - posição inicial.

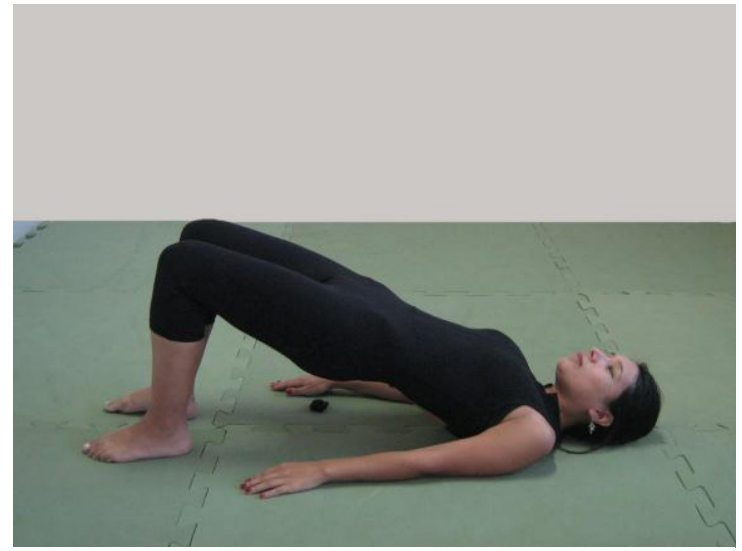

Figura 14b - Ponte - execução do exercício. 


\section{Single Leg Circles (Círculo com uma perna)}

Trata-se de um exercício que tem como objetivo desafiar seu executor ao exigir uma estabilização de tronco e pelve enquanto alonga e fortalece 0 membro inferior que executa um movimento circular. Recrutar a "casa de força" e aplica uma dinâmica oposição, alongando acima e abaixo da pelve igualmente; cria-se uma base estável de suporte para que ocorra o movimento do membro. Os movimentos circulares do membro inferior direcionados para cima promovem um desafio para a coordenação e uma habilidade para a integração do core (Figura 15 a,b) (PILATES, 2010).

Na presente pesquisa, a perna contralateral à execução do movimento, (a perna direita conforme as Figuras $15 \mathrm{a}, \mathrm{b}$ ), permaneceu flexionada durante as 10 primeiras sessões a fim de se obter uma maior estabilização do quadril durante o giro da perna esquerda.

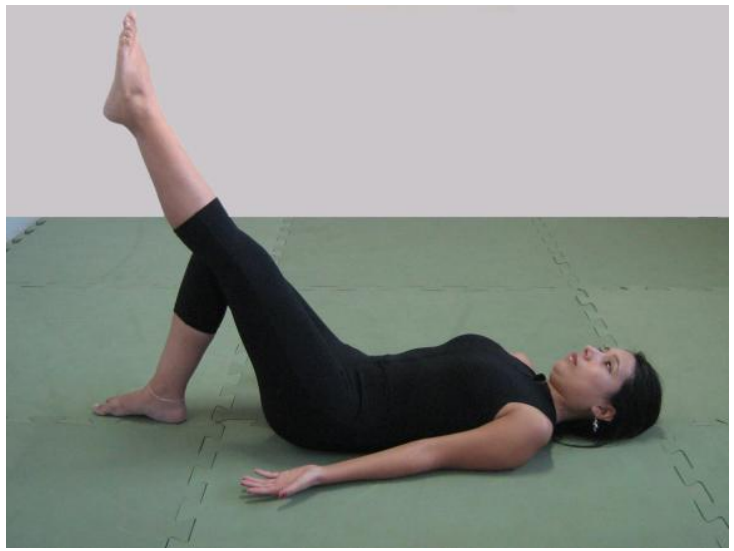

Figura 15a - Círculo com uma perna posição inicial.

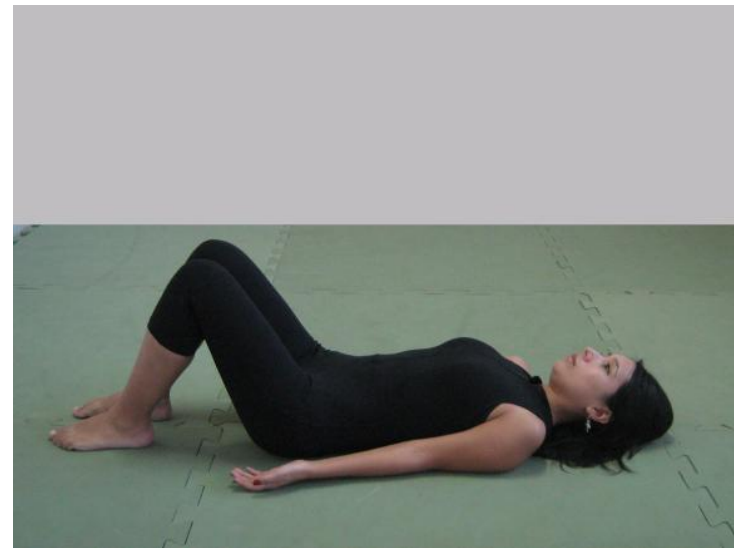

Figura 15b - Círculo com uma perna posição final. 


\section{Hundred (Cem)}

Segundo Sacco et al., (2005), o Hundred é um exercício recomendado para o fortalecimento dos músculos abdominais, glúteo máximo e reto femoral, auxiliando na estabilização da pelve. No solo, o exercício original se inicia com o sujeito em decúbito dorsal, com flexão de $90^{\circ}$ de quadril, joelho flexionado a $90^{\circ}$, tornozelo em extensão, ombro a $90^{\circ}$ de flexão, cotovelos estendidos, antebraços em pronação e punho neutro. A execução do movimento consiste em extensão do quadril (de $90^{\circ}$ para $20^{\circ}$ de flexão), extensão total de joelhos, extensão do ombro (de $90^{\circ}$ de flexão para a posição neutra de $0^{\circ}$ ), flexão de coluna cervical a $40^{\circ}$, flexão de coluna torácica a $25^{\circ}$. Os membros inferiores ficam em rotação lateral durante a extensão. A manutenção da pelve neutra e das escápulas estabilizadas é de grande importância para a execução correta do exercício.

A importância deste exercício específico do método Pilates, inserido no contexto de benefícios, é a estabilização da coluna lombar, o treino de força, da flexibilidade e da propriocepção e a reeducação postural, ou seja, a ativação do powerhouse durante esse exercício pode proporcionar diversas ações positivas para o organismo como um todo tendo como foco principal sempre, a saúde e o bem estar do aluno/paciente. No total, são acionados, em torno de, 90 músculos neste exercício, dependendo da posição adotada para a execução (MUSCOLINO; CIPRIANI, 2004). 


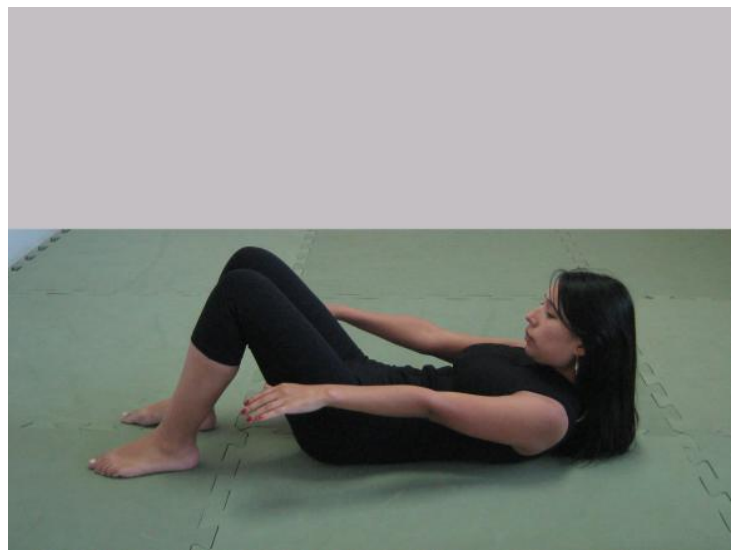

Figura 16 - Hundred modificado com os pés no chão paralelos e levemente afastados.

$\mathrm{Na}$ presente pesquisa, optou-se em iniciar o exercício com os pés apoiados no solo até que o participante obtenha maior força abdominal (Figura 16). A partir da $11^{\text {a }}$ sessão, os voluntários passaram a executar o exercício com as pernas elevadas e paralelas ao solo, estando os joelhos flexionados a $90^{\circ}$

\section{Single leg stretch (Alongamento de uma perna)}

Trata-se de um exercício desafiador para o fortalecimento dos músculos abdominais e o treino da coordenação (Figura 17). Esse exercício deve ser executado em posição neutra, em decúbito dorsal. Deve-se inspirar profundamente e recrutar a musculatura abdominal; expirar profundamente e flexionar cada perna, alternadamente acima do peito, fazer uma inspiração e enquanto expirar, em seguida, estender a perna contralateral lentamente, permanecendo a outra no ar. Logo em seguida, repita o movimento alternando a perna e repetindo simultaneamente ao movimento o mesmo exercício respiratório. A coluna lombar deve permanecer bem posicionada no chão enquanto se executa o exercício. 


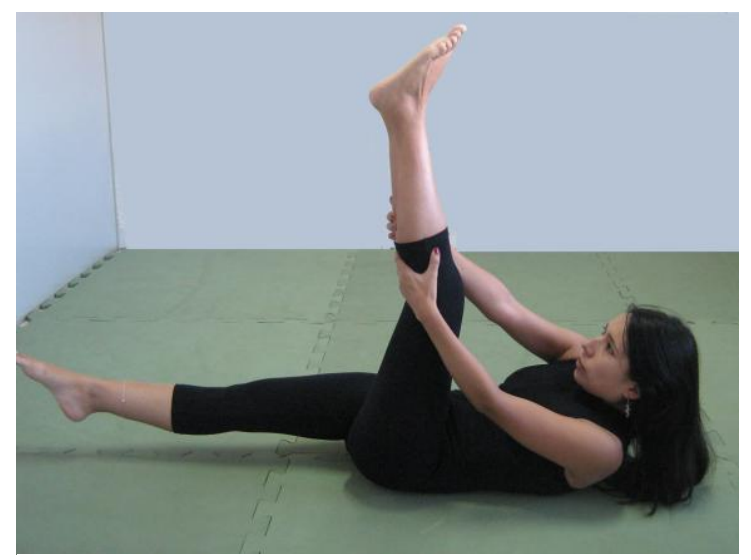

Figura 17 - Single leg streigth.

\section{Swimming (Nadando)}

Um estudo realizado por Sekendiz et al., (2007) mostraram que o exercício swimmng do método Pilates proporcionou aumento de força e resistência nos músculos do tronco em mulheres saudáveis.

Neste estudo, adaptou-se a oscilação entre braços e pernas opostas para oscilação, apenas, das pernas, enquanto os braços permaneciam alongados à frente (Figura18).

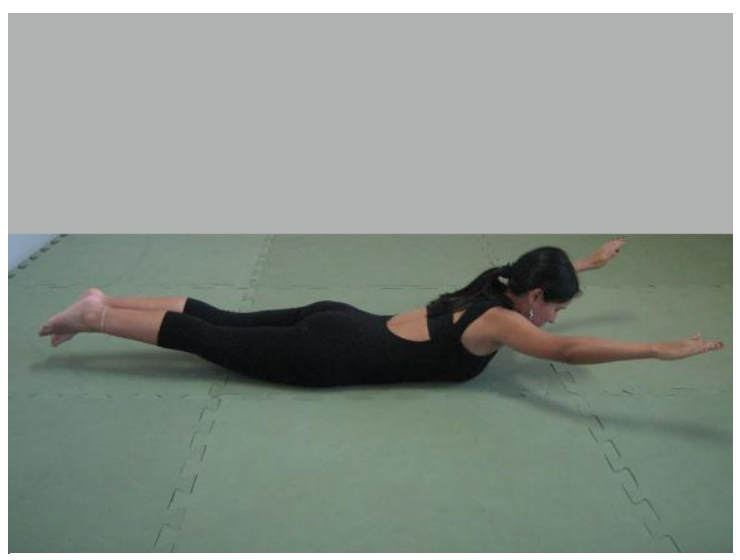

Figura 18 - Swimming (nadando). 


\section{Cat (gato)}

Neste exercício, o indivíduo deve se posicionar em decúbito ventral, com apoio em mãos, joelhos e dorso dos pés. Os quadris devem estar flexionados a noventa graus com as coxas e estas a noventa graus com as pernas (postura adaptada com seis apoios) (Figura 19a). Os ombros, cotovelos e punhos devem ficar posicionados verticalmente na mesma direção. Em seguida, com o tronco bem estabilizado apoiado nas mãos, deve-se conciliar a extensão de uma perna com o braço contralateral estendendo à frente (Figura 19b). Deve haver um alinhamento do membro inferior, tronco e braço de modo que se estabeleça o desenho de uma "prancha". Ao se alongar perna e braço, deve-se realizar uma expiração e procurar manter o controle do core.

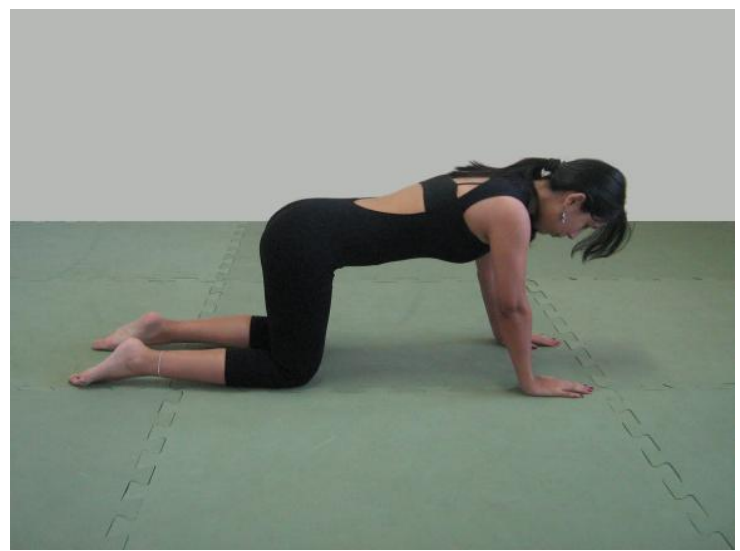

Figura 19a - postura de gato.

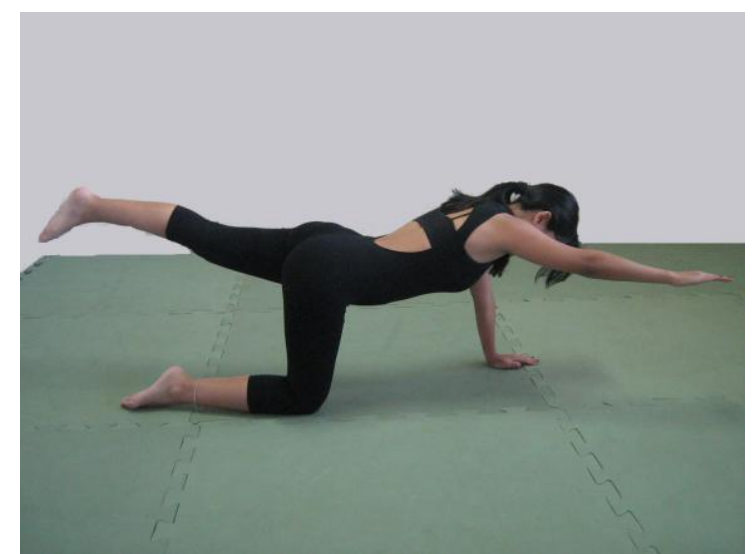

Figura 19b - Formação da prancha após a postura de gato.

8. Push Up (Empurrar para cima)

Ao inspirar, em posição ortostática, ombros alinhados (Figura 20a), os membros superiores devem se posicionados ao longo do tronco, em seguida, deve haver uma expiração juntamente com a flexão anterior de tronco e os 
braços acompanharem o enrolamento anterior de tronco permanecendo estes com os cotovelos na direção das orelhas; a seguir, quando as mãos alcançarem o chão (Figura 20b), deve-se caminhar com elas pra frente em três passadas largas, (Figura 20c), o abdômen deve se manter contraído e os ombros e escápulas estabilizados, até que o tronco chegue paralelo ao chão sustentado pelo antebraço em posição neutra (Figura 20d). Em seguida, devese trazer o abdômen na direção da pelve com uma inspiração e retornar lentamente à posição inicial (vertical) desenrolando o tronco até que o corpo volte para a postura ortostática.

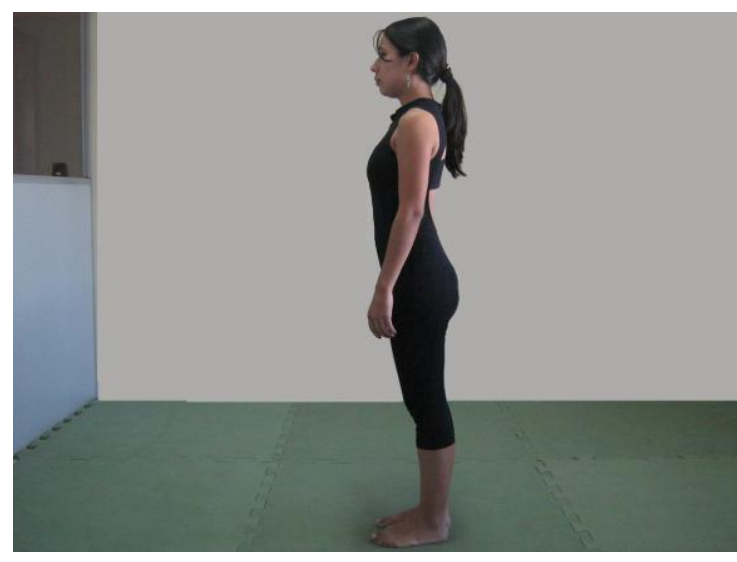

Figura 20a - Push up - postura inicial.

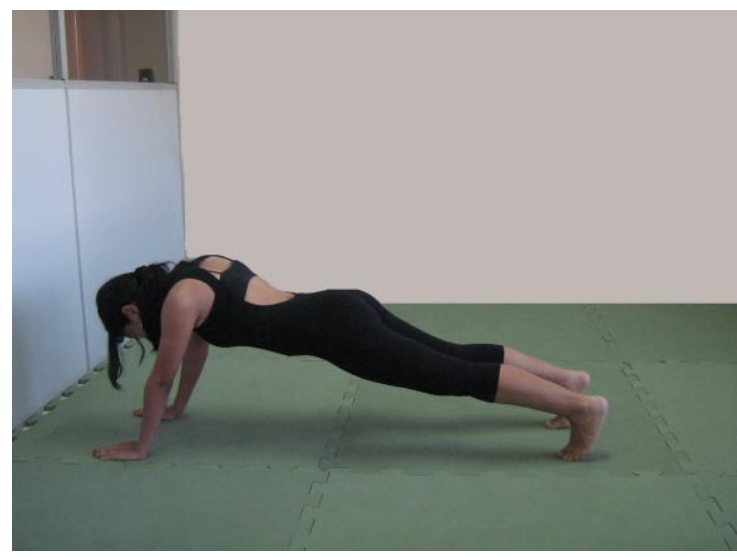

Figura 20c - Push up - execução

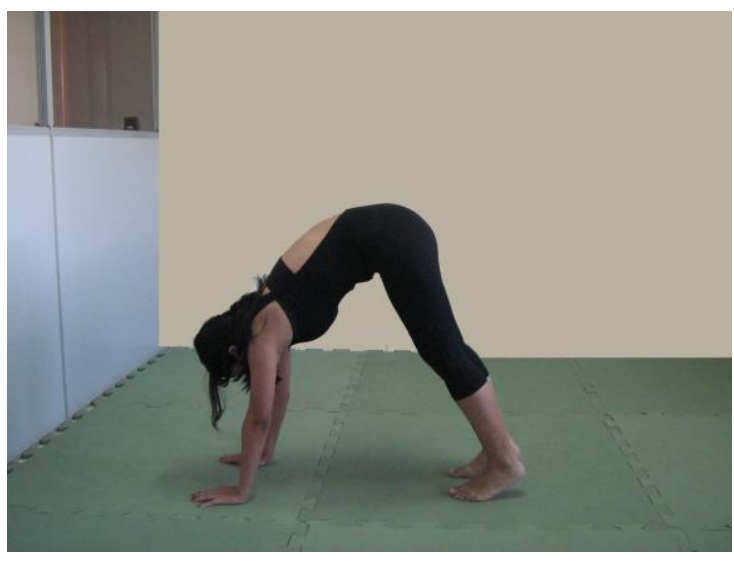

Figura 20b - Push up - execução

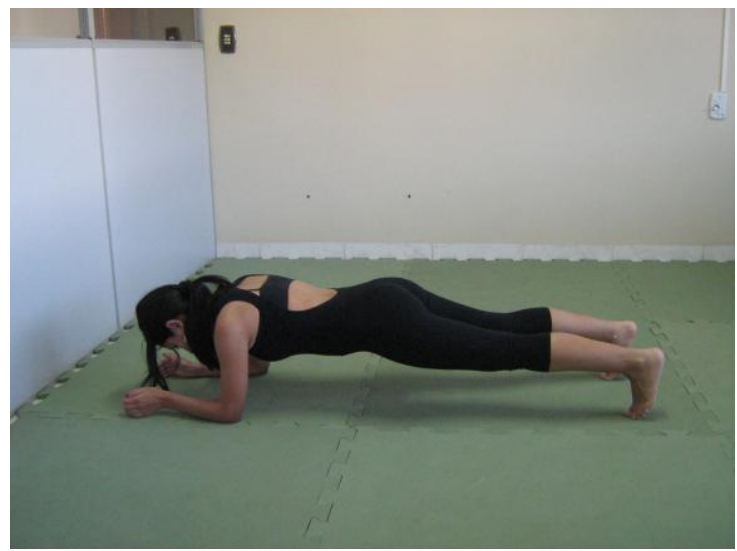

Figura 20d - Push up - execução 
9. Standing footwork (Trabalhando com os pés)

O objetivo desse exercício é o fortalecimento dos membros inferiores dos glúteos e do tornozelo. Segundo Craig (2004), os exercícios em pé trabalham os músculos dos membros inferiores diferentemente. Nesse exercício, o peso deve estar distribuído igualmente nas duas pernas e os joelhos devem estar alinhados com os pés. A respiração pode ser realizada de modo que quando se está em extensão de joelhos (no início do exercício), se realize uma inspiração (Figura 21a) e ao realizar a flexão de joelhos, faz-se a expiração (Figura 21b). Durante a flexão das pernas, os joelhos não devem ultrapassar a linha dos dedos verticalmente.

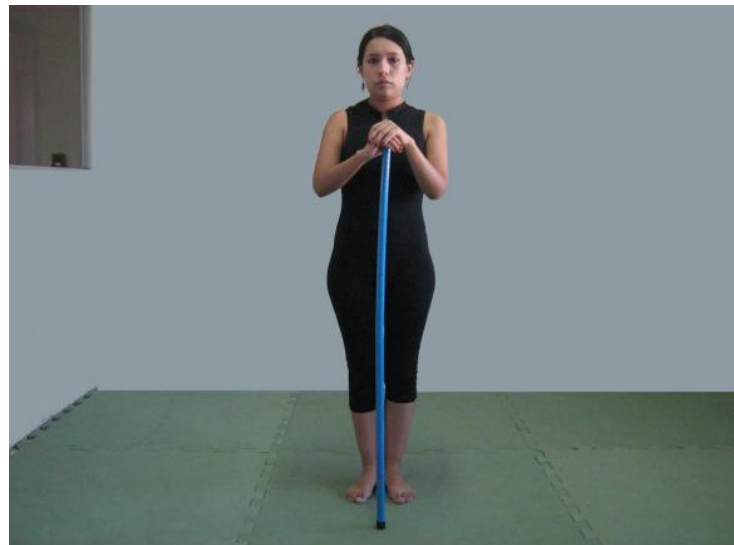

Figura 21a - Standing footwork - posição inicial.

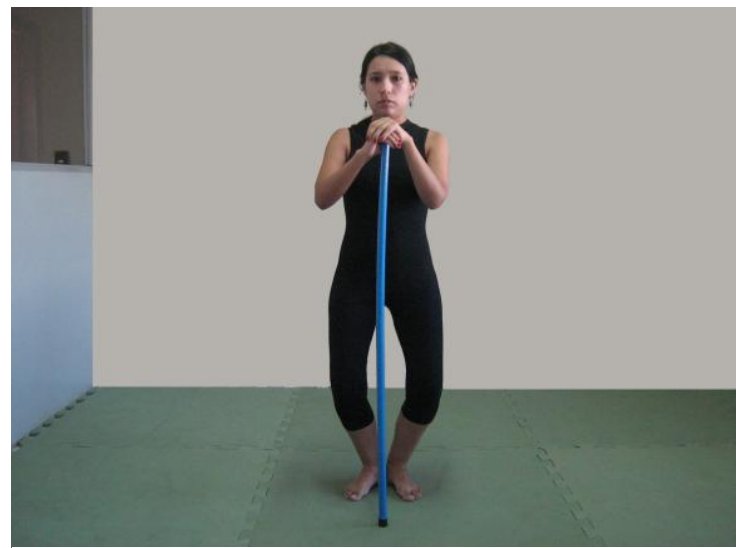

Figura 21b - Standing footwork execução.

\section{Mermaid (Sereia)}

O exercício mermaid permite uma estabilização dinâmica por meio de alongamento lateral de tronco e o fortalecimento dos abdominais profundos. Esse exercício é executado com o indivíduo sentado sobre os ísquios, com um quadril em rotação externa (perna da frente) e o outro com uma rotação interna (perna de trás), os joelhos permanecem flexionados de forma que as pernas 
desenham dois lados de um quadrado. O tronco deve permanecer alinhado e ereto com os braços posicionados ao lado do mesmo e os dedos das mãos alongados (PILATES, 2010) (Figura 22a).

No presente estudo, o movimento foi realizado de modo que o praticante realizasse uma dissociação das articulações do quadril e da cintura nesta posição, como se o tronco girasse como um espiral sobre a articulação do quadril. (Figura 22b).

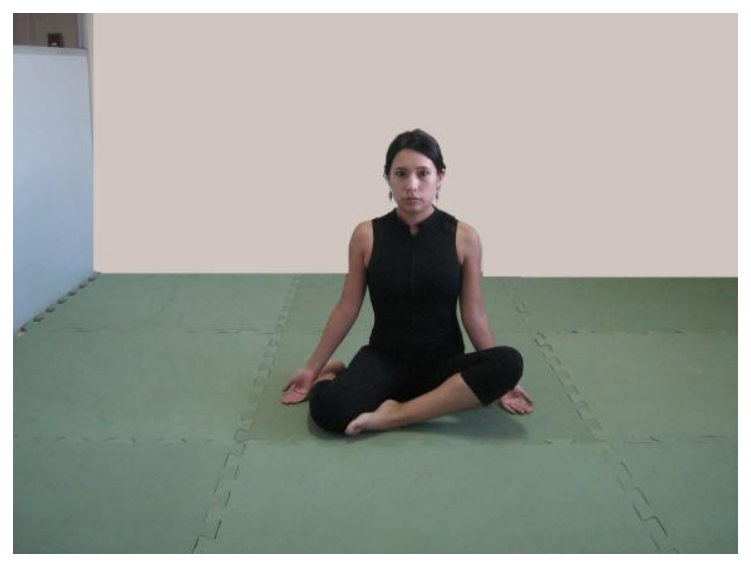

Figura 22a - Mermaid - posição inicial.

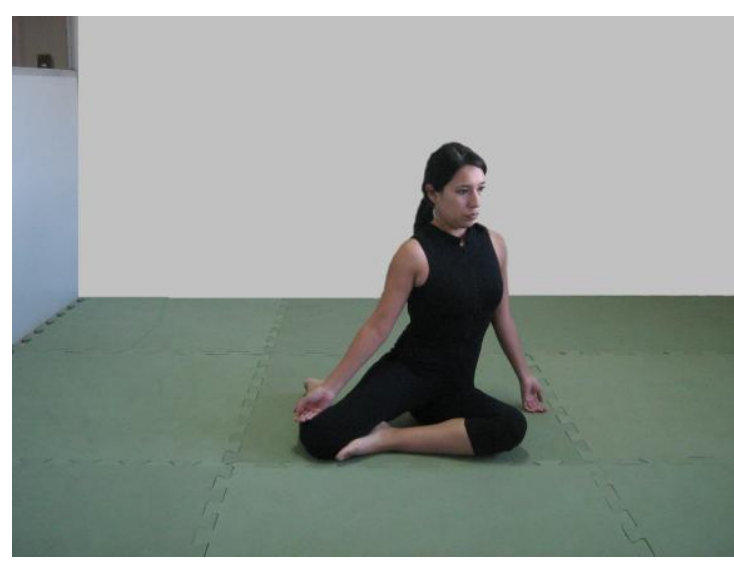

Figura 22b - Mermaid modificado execução. 


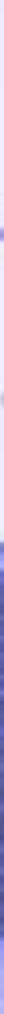

Material e Métodos 


\section{MATERIAL E MÉTODOS}

\subsection{Delineamento do estudo}

Trata-se de um estudo de intervenção, controlado e não-randomizado (HENNEKENS E BURING, 1987; ESCOSTEGUY, 1999) com análise quantitativa dos dados. Nesse tipo de delineamento, a distribuição do fator de intervenção, geralmente, fica a cargo dos pesquisadores que realizam a intervenção; conseqüentemente, o estudo fica sujeito ao viés de indicação do tratamento (ESCOSTEGUY, 1999).

$\mathrm{Na}$ presente pesquisa, a intervenção foi realizada por meio de dois grupos: o grupo controle (GC), que recebeu uma intervenção com exercícios convencionais de alongamento e fortalecimento e o grupo pilates (GP), que recebeu intervenção com exercícios baseados no método Pilates (GP). O GP foi formado primeiro e, em seguida, o GC. Não houve randomização da amostra em função do valor inexpressivo e o surgimento lento de voluntários que foram se interessando pelo presente estudo.

\subsection{Local do estudo e Casuística}

O estudo foi realizado com os trabalhadores de Enfermagem de um hospital universitário do interior do estado de São Paulo e a coleta dos dados foi feita em um laboratório didático da Escola de Enfermagem de Ribeirão Preto da Universidade de São Paulo (EERP - USP). O referido laboratório tratava-se de um ambiente claro, arejado, climatizado e de fácil acesso. 
A população do estudo compreendeu todos os profissionais de enfermagem (enfermeiros, auxiliares e técnicos de enfermagem) atuantes na unidade Campus do Hospital das Clínicas da Faculdade de Medicina de Ribeirão Preto da Universidade de São Paulo (HCFMRP - USP) no período da coleta de dados, que não se encontravam de férias, afastamento ou licença maternidade e que procuraram o Serviço de Atendimento Médico de Saúde do Pessoal (SAMSP) no período de setembro de 2009 a abril de 2010 com queixa de dor lombar crônica.

De acordo com informações coletadas do Centro de Recursos Humanos do Hospital, em setembro de 2009 (período de início da coleta), a instituição contava com um quadro de 1447 trabalhadores de enfermagem, sendo 1225, com vínculo empregatício como servidor público e 222 contratados pela Fundação de Apoio ao Ensino, Pesquisa e Assistência (FAEPA). A equipe de enfermagem era composta por 327 enfermeiros, 982 auxiliares de enfermagem e 138 técnicos de enfermagem. Todos os trabalhadores eram contratados sob o regime de contrato Consolidação das Leis trabalhistas (CLT) vigente no país.

A coleta de dados foi realizada no período de setembro de 2009 a junho de 2010. Os sujeitos da pesquisa foram recrutados junto ao Centro de Reabilitação Lucy Montoro do Hospital das Clínicas ou diretamente do SAMSP. Os trabalhadores de enfermagem com diagnóstico médico de lombalgia foram convidados a participar do estudo através de cartazes que foram fixados dentro do SAMSP e em locais distintos do hospital.

Por meio dessas divulgações, os trabalhadores de enfermagem obtiveram informações sobre a presente pesquisa e, quando interessados, contatavam o responsável pelo estudo por telefone e já realizavam uma pré - 
avaliação. Em seguida, caso se adequassem aos critérios de seleção, os voluntários já agendavam a avaliação que era realizada nas dependências da Escola de Enfermagem de Ribeirão Preto.

Não houve cálculo amostral para o presente estudo em detrimento de não se conhecer a prevalência de funcionários que poderiam procurar 0 SAMSP naquele período com queixa de lombalgia. Dessa forma, foi utilizado um método não probabilístico do tipo amostragem acidental. Segundo Martins, (2002), com esse tipo de amostragem não é possível generalizar os resultados da amostra para a população, pois amostras não probabilísticas não garantem a representatividade da população.

Segundo o referido autor, a amostragem do tipo acidental é formada por aqueles elementos que vão aparecendo e que podem ser obtidos até completar o número desejado de elementos da amostra.

\subsection{Critérios de Seleção}

Critérios de Inclusão: Foram incluídos os profissionais de enfermagem de ambos os sexos que apresentavam lombalgia crônica num período superior a três meses e assinaram o TCLE - Termo de Consentimento Livre e Esclarecido - (APÊNDICE A). Os voluntários incluídos foram aqueles que trabalhavam no período de setembro de 2009 a junho de 2010, período estabelecido para a coleta de dados.

Critérios de Exclusão: Foram excluídas as grávidas; funcionários com história de cirurgia e/ou fratura na coluna vertebral; com diagnóstico de doença reumática ou desordens metabólicas; que realizaram tratamento 
fisioterapêutico no último ano e com evidência de comprometimento neurológico ou processo inflamatório agudo e àqueles afastados do trabalho no período da coleta dos dados.

\subsubsection{Amostra}

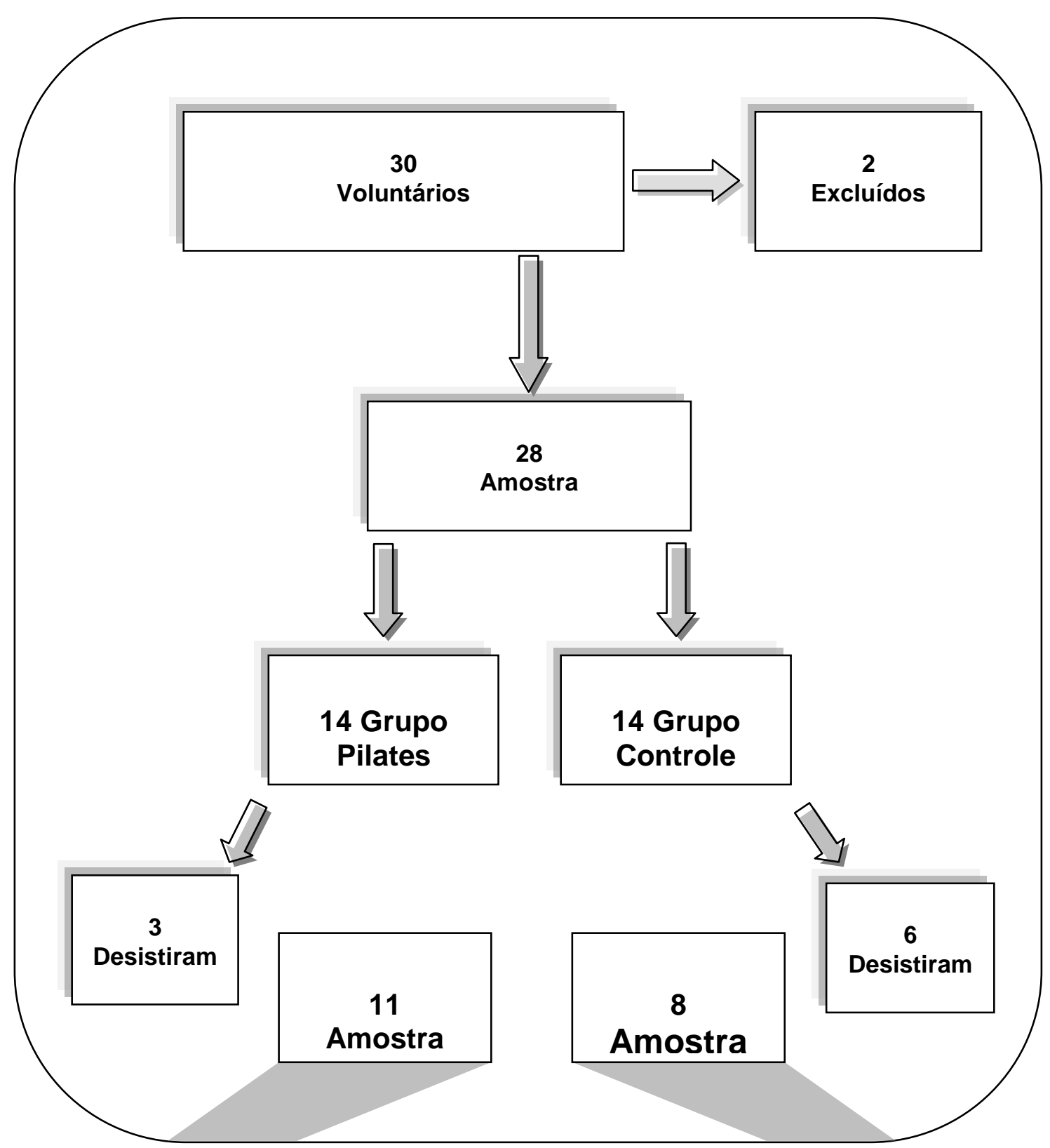

Figura 23 - Fluxograma para seleção da amostra e o número final de participantes que concluíram o estudo. Ribeirão Preto - SP, 2010. $(n=19)$ 
Conforme mostra a Figura - 23, trinta trabalhadores profissionais de enfermagem com lombalgia crônica idiopática diagnosticada no período de agosto de 2009 a abril de 2010 se interessaram em participar desta pesquisa após terem recebido atendimento médico pelo SAMSP. Estes entraram em contato com a pesquisadora responsável por meio de telefone e já realizaram a pré-avaliação para verificar se se adequavam aos critérios de inclusão do estudo. Desses, apenas dois voluntários foram excluídos e os 28 realizaram o pré- teste. Dentre esses 28 avaliados (pré-teste), 14 constituíram o grupo de intervenção com os exercícios baseados no método Pilates (GP) e 14 constituíram o grupo controle (GC) que realizaram exercícios de alongamento e fortalecimento convencionais. Dentre àqueles que compuseram o GP, três desistiram antes de realizarem cinco sessões e apenas onze concluíram às 20 sessões e a reavaliação (pós-teste).

Em se tratando do GC, dentre os 14 que constituíram a amostra inicial, seis desistiram antes de completar a quinta sessão e apenas oito realizaram as 20 sessões propostas pelo protocolo e o pós-teste. Sendo assim, dentre os 28 indivíduos que deram início à participação na presente pesquisa, apenas 19 o fizeram e chegaram até o final dos protocolos. O GC foi formado por $8(100 \%)$ participantes, um (12,5\%) do sexo masculino e 7 (87,5\%) do sexo feminino. 0 GP era formado por 11 voluntários, dentre esses um $(9,1 \%)$ do sexo masculino e $10(90,9 \%)$ do sexo feminino.

Em função do tempo e do número escasso de funcionários que procuravam a pesquisa, os primeiros voluntários foram indicados para o GP e quando esse grupo já era composto por 14 participantes, o outro grupo começou a ser formado, o GC. 
Após ter se formado o GP e ter iniciado as sessões de intervenção, o grupo controle (GC) já começava a se formar de acordo com a demanda dos novos interessados em participar da pesquisa. Essa distribuição foi realizada dessa forma, pelo fato de se perceber logo no início da coleta que os funcionários voluntários que aderiram à pesquisa, o faziam com o intuito de receber intervenção imediata.

Embora as intervenções ocorressem de forma concomitante durante certo período, preservou-se um período de dois meses e meio para a permanência de cada participante no estudo.

\subsection{Aspectos éticos}

O Projeto de Pesquisa foi aprovado pelo Comitê de Ética em Pesquisa do Hospital das Clínicas da Faculdade de Medicina de Ribeirão Preto - USP mediante atendimento à Resolução 196/96 sobre pesquisa envolvendo seres humanos do Conselho Nacional de Saúde/Ministério da Saúde (BRASIL, 2009) em sua $279^{\mathrm{a}}$ Reunião Ordinária realizada em 02/02/2009 sob Processo HCRP n¹2957/ 2008, (ANEXO A). Foi realizada uma concessão mediante ofício redigido pela responsável da pesquisa e enviada à direção da EERP-USP para a utilização do laboratório. A coleta de dados teve início em 02 setembro de 2009 e término em 30 de junho de 2010. 


\subsection{Instrumentos de medidas e protocolos de intervenção}

\subsubsection{Instrumentos de medidas}

Cinco instrumentos foram utilizados para o processo de pré-avaliação, avaliação (pré-teste) e reavaliação (pós-teste) dos participantes do estudo.

O primeiro instrumento utilizado na pré-avaliação (APÊNDICE B) consistia em um formulário construído pelo autor do estudo a partir dos critérios de seleção da pesquisa com o intuito de direcionar o primeiro contato com os interessados em participar do estudo para que fosse verificado se estes se adequavam ou não ao estudo. A aplicação desse instrumento foi feita por telefone durante o primeiro contato do interessado em participar da pesquisa com o pesquisador. $\mathrm{O}$ instrumento era composto por nove questões relativas à obtenção de dados sobre: identificação; sexo; situação gestacional, realização de cirurgias em coluna vertebral e/ou histórias de fraturas na coluna vertebral; diagnóstico de doenças reumáticas e/ou desordens metabólicas; presença de lombalgia crônica com irradiação periférica de dor por, pelo menos, três meses; prática de atividade física regular no último ano; realização de tratamento fisioterapêutico no último ano e evidência de comprometimento neurológico ou processo inflamatório agudo.

O segundo instrumento tratava-se de um formulário de identificação dados pessoais - (APÊNDICE C) elaborado pelo autor da pesquisa para caracterizar a população de trabalhadores de enfermagem (enfermeiros, técnicos e auxiliares de enfermagem) segundo os aspectos: 
- sociodemográficos e hábitos pessoais (questões de 1 a 8 ) nome, sexo, data de nascimento, peso, altura, hábito de fumar e tomar café;

- Aspectos profissionais (questões de 9 a 19) - meio de locomoção para o trabalho, duração do trajeto, profissão, setor que atua, horas trabalhadas por dia e por semana, em quantos locais trabalha, em qual(is) turno(s) trabalha, qual(is) a(s) postura(s) física mais adotada(s) na rotina de trabalho e qual a porcentagem do tempo - rotina de trabalho - permanecia nessa mesma postura.

Estes dois instrumentos de coleta de dados foram submetidos à avaliação aparente de conteúdo, sendo julgados como adequados e pertinentes ao estudo por cinco especialistas da área de fisioterapia.

O terceiro instrumento utilizado foi o questionário Oswestry para avaliação da dor lombar (ANEXO C). Esse questionário é dividido em sessões designadas para avaliar limitações em diversas atividades de vida diária como cuidados pessoais, levantar objetos, andar, sentar e viajar. Cada item contido em cada sessão é graduado de zero a cinco, sendo que o maior valor representa a pior condição (maior inabilidade) e o menor valor, a melhor condição física (menor inabilidade) (WALSH, 2008).

Dados na literatura têm apresentado escalas e questionários importantes para avaliar vários aspectos da dor lombar incluindo incapacidade percebida, qualidade de vida, intensidade, severidade e distribuição da dor, além do estado funcional (DEYO, 1994; NORDIN, 2003; OSTELO, 2005).

Atualmente, um grande número de estudos internacionais utiliza o Oswestry Disability Index (ODI). Este e o questionário de Roland- Morris tem se 
destacado como os mais comumente recomendados para mensurar condições específicas para desordens da coluna vertebral (VIGATTO; ALEXANDRE; CORREA, 2007).

O Oswestry Disability Index (ODI) foi primeiramente publicado em 1980 na versão 1.0. A versão 2.0 foi a modificação do ODI realizado pela Medical Research Council group no Reino Unido. Essa mesma versão 2.0 foi utilizada para a adaptação cultural (FAIRBANK, 2000).

Vigatto; Alexandre; Correa, (2007) realizaram a adaptação cultural do ODI para a língua portuguesa e avaliaram a confiabilidade e a consistência dessa versão brasileira. Nesse mesmo estudo, os autores concluíram que o processo de adaptação cultural foi bem sucedido e a adaptação do instrumento demonstrou apresentar excelentes propriedades psicométricas e confiabilidade na cultura brasileira.

Os dois instrumentos finais foram utilizados com o intuito de se obter dados objetivos e se tratavam de dois instrumentos de medida: O Flexímetro Code, para medir a amplitude articular das articulações da coluna cervical, tronco e quadril e o outro, o dinamômetro - The lafayette manual muscle test system, para medir a força de glúteo máximo direito e esquerdo.

Esse flexímetro (Figura 24 a,b) é desenvolvido e fabricado no Brasil sob patente do Instituto Code de Pesquisa (ICP). Esse equipamento consiste em um inclinômetro gravidade-dependente, cuja escala é de um grau, apresentando-se este preso por uma fita de velcro. Ao final de cada movimento, o aparelho deve ser reposicionado para que não haja alteração da medida em função do deslocamento da fita durante o movimento articular do avaliado. 


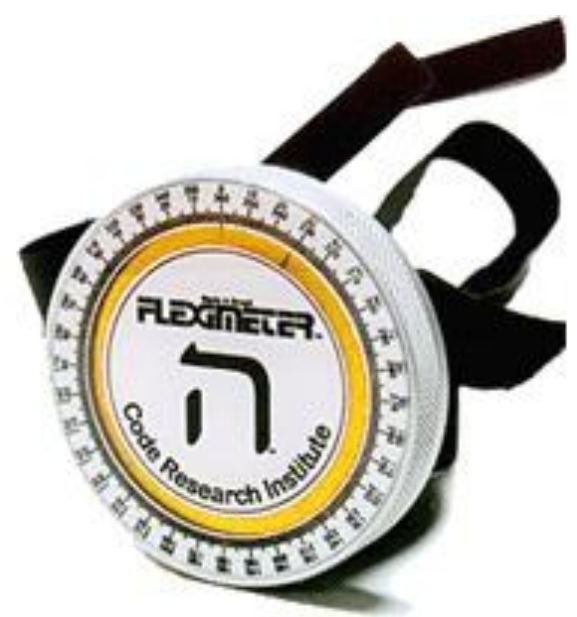

Fonte: Instituto Code de Pesquisa, (2008). Figura 24a - Flexímetro (ICP).

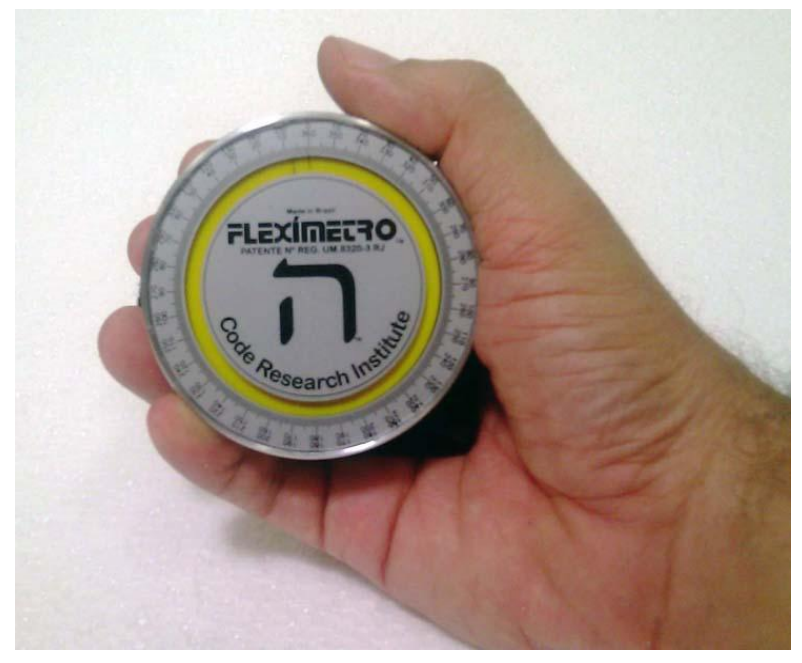

Fonte: Instituto Code de Pesquisa, (2008). Figura 24b - Flexímetro (ICP).

O teste de fleximetria foi aprimorado pelo ICP a partir do teste do flexômetro do LEIGHTON e deve ser utilizado com a intenção de se coletar informações a respeito do funcionamento articular do corpo humano para que se possa definir metas de ação sobre a performance demonstrada. O objetivo desse equipamento é determinar o grau de mobilidade articular em movimentos definidos utilizando uma escala em graus $\left(^{\circ}\right)$, a qual possui correspondência imediata com o ângulo descritor gerado pelo segmento corporal acionado (ICP, 2008).

Florêncio et al., (2010) num estudo realizado com o intuito de verificar a concordância entre as medidas de ADM (amplitude de movimento) cervical obtidas com o CROM e com o flexímetro e verificar a confiabilidade intra e interexaminadores de ambas as ferramentas, tiveram como resultado que 0 flexímetro é um instrumento cuja utilização pode ser também recomendada para a avaliação da amplitude cervical. 
O mesmo estudo também traz que, sendo o flexímetro mais barato e acessível, ele ainda pode ser utilizado para a avaliação de outros segmentos corporais, diferente do CROM, que possui uma excelente confiabilidade, mas não pode ser utilizado para outros fins. Além disso, ambas as ferramentas apresentaram confiabilidade intra e interexaminadores que variou entre moderada e excelente, o que comprova sua indicação para o uso na prática clínica.

Optou-se pela utilização do flexímetro na presente pesquisa pelo fato de este ser um instrumento simples, de manuseio fácil e de custo baixo com uma característica importante de oferecer um dado quantitativo e fidedigno.

O novo "Lafayette Manual Muscle Test System” (MMT) Modelo 01163 (Figura 25a,b), é um aparelho que deve ser acoplado na palma da mão com o objetivo de quantificar a força muscular excêntrica. Ao usar esse equipamento, o pico de força obtido por uma contração isométrica é mensurado quando o examinador aplica uma força contra o sujeito.

Quando comparado a outros equipamentos de diagnóstico (screening), o MMT tem grande vantagem por ser compacto, de fácil manuseio e de custo baixo. Um controle microprocessador é utilizado para armazenamento de valores de calibração e acumula dados automaticamente, resultando em fidedignidade, acurácia e leitura da força muscular estável.

O MMT modelo 01163 também apresenta menu interativo para apresentar uma grande demanda de opções como armazenamento de dados e apresenta o tempo dos testes que foram pré-estabelecidos. Ainda que fidedigno e versátil, o MMT é pequeno o suficiente para se adaptar confortavelmente na palma da mão. Seu design ergonômico permite que 
ambos, paciente e avaliador fiquem confortáveis durante o processo de avaliação (LAFAYETTE INSTRUMENT COMPANY, 2003).

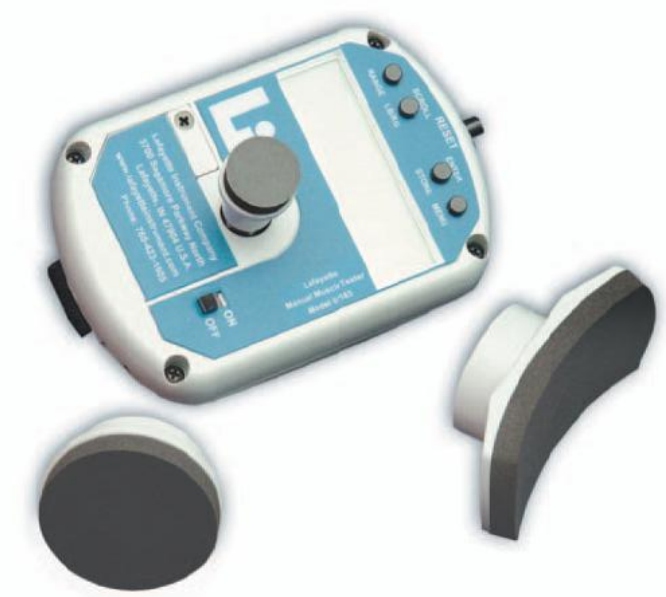

Fonte: Lafayette instrument Company (2003).

Figura 25a - The Lafayette Manual Muscle Test System (MMT) - Modelo 01163.

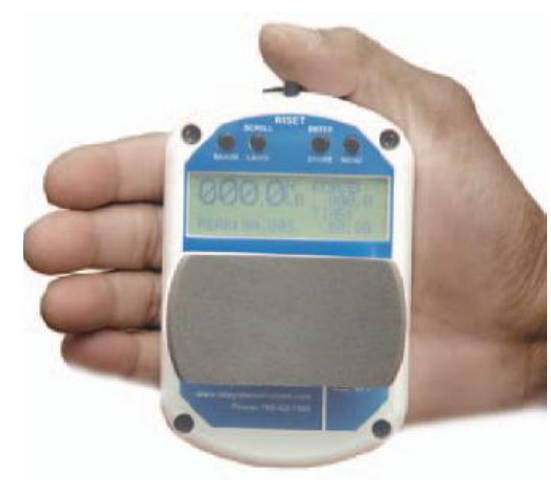

Fonte: Lafayette instrument Company (2003).

Figura 25b - The Lafayette Manual Muscle Test System (MMT) - Modelo 01163.

Um artigo realizado com o objetivo de descrever metodologias de testes musculares, definições de contrações musculares e discutir confiabilidades de testes musculares e aparelhos de dinamometria, Sisto; Dyson-Hudson, (2007) relataram que embora o MMT seja simples, de uso fácil e clinicamente prático e viável para aplicação, sua confiabilidade e sua aceitação são ainda pouco disseminados no que tange o aspecto de medição de força.

Dessa forma, mesmo pouco difundido, o MMT tem se destacado em pesquisas experimentais internacionais ao ser utilizado em experimentos com pré e pós teste com o intuito de oferecer dado quantitativo, fidedigno e de confiabilidade (MOSS e WRIGHT, 1993; LIEBLER et al., 2001; KLIGYTE; LUNDY-EKMAN; MEDEIROS,2003). 
Sendo assim, com o intuito de se obter um dado quantitativo na avaliação da força muscular de glúteo máximo na presente pesquisa, optou-se por utilizar o MMT modelo 01163. Por não exigir nenhum treinamento prévio para o manuseio do mesmo e a aquisição deste ser de fácil acesso em função do custo baixo. Acredita-se também que a inclusão desse instrumento de medida para a avaliação da força muscular em hospitais e clínicas de fisioterapia seja uma ferramenta de grande valia para quantificar déficits e ganhos de força em grupos musculares de seres humanos saudáveis ou debilitados.

\subsubsection{Protocolos de intervenção}

O Protocolo de exercícios físicos baseados no método Pilates (APÊNDICE D) foi elaborado pelo autor da pesquisa a partir dos objetivos e descrições de cada exercício do método. As adaptações e/ou alterações a partir da execução original foram realizadas com o intuito de que os exercícios se adequassem à população sedentária, embora alguns deles apresentassem uma evolução, em nível de dificuldade, eles foram realizados de maneira mais simples nas 10 primeiras sessões e, depois, partir da $11^{a}$ sessão, foram ministrados com um grau de dificuldade mais elevado.

Outro aspecto, que deve ser ressaltado, é com relação ao seguimento dos princípios do método Pilates durante a execução desse protocolo: dentre todos os princípios (respiração, concentração, controle, centralização, precisão e fluidez de movimento), apenas fluidez de movimento foi um princípio comprometido na sua aplicação em função de o protocolo não seguir uma 
seqüência original do método, pois os exercícios foram direcionados para grupos musculares específicos no tratamento da dor lombar.

Em se tratando do protocolo de exercícios físicos de alongamento e fortalecimento convencionais (APÊNDICE E), este também foi elaborado pelo autor da pesquisa a partir dos objetivos e descrições de cada exercício. Adaptações e/ou alterações também foram realizadas com o intuito de que os exercícios tornassem desafiadores para os praticantes com o passar do tempo.

Um aspecto importante que deve ser ressaltado nesse protocolo é com relação à ordem de execução dos exercícios, pois se privilegiou a realização dos exercícios de fortalecimento anterior aos de alongamento, acredita-se, segundo estudos publicados, que o alongamento que precede os exercícios resistidos não previne lesões e ainda pode danificar algumas estruturas musculotendíneas (HILYER et al., 1990; ROSÁRIO; MARQUES; MALUF, 2004).

Assim como no protocolo anterior, os exercícios também foram direcionados para grupos musculares específicos no tratamento da dor lombar, daí a semelhança de alguns exercícios, pois existem exercícios dentro do método de Pilates com denominações específicas que já são consagrados na prática de atividade física convencional.

\subsection{Procedimentos para a realização da pesquisa}

A pesquisa foi realizada em três etapas distintas após o voluntário ter realizado o primeiro contato com o pesquisador na pré-avaliação: avaliação (pré-teste), aplicação dos protocolos de exercícios e reavaliação (pós- teste). 
Pré- avaliação

Preenchimento do formulário para verificação da adequação do profissional aos critérios do estudo (realizado por telefone e pelo pesquisador responsável)

\section{FASE I}

Pré- teste

(realizado por um avaliador externo)

Leitura e

assinatura do

TCLE

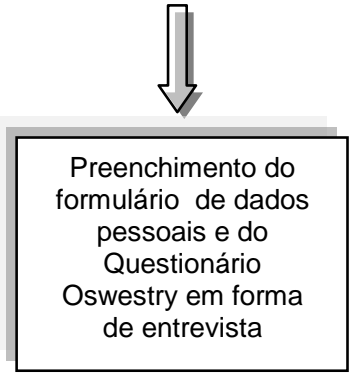

\begin{tabular}{|l|}
\hline Realização dos \\
dois testes \\
físicos: \\
Fleximetria e \\
Dinamometria \\
\end{tabular}

\section{FASE II}

\section{Aplicação dos Protocolos}

Exercícios físicos baseados no método Pilates Exercícios físicos de alongamento e fortalecimento convencionais

\section{FASE III}

\section{Pós- teste}

(realizado por um avaliador externo)
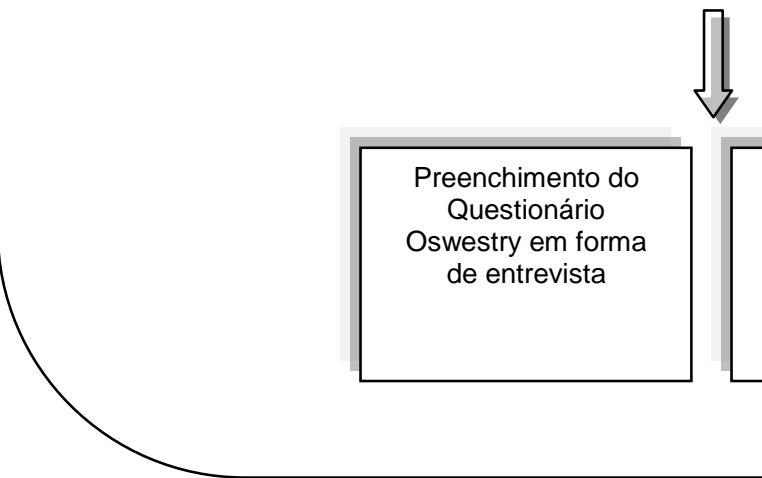

Realização dos dois testes físicos:

Fleximetria e

Dinamometria

Figura 26 - Fluxograma para descrição dos procedimentos realizados no estudo desde a préavaliação até a reavaliação. Ribeirão Preto - SP, 2010. $(n=19)$ 
Em setembro de 2009, após terem passado pela pré-avaliação, àqueles que obtiveram respostas negativas em todas as questões do formulário (APÊNDICE B) foram selecionados para participarem do estudo e realizarem o pré-teste. Este consistia em leitura e assinatura do TCLE (Termo de Consentimento Livre e Esclarecido) - (APÊNDICE A), ao preenchimento do formulário de dados pessoais (APÊNDICE C) e do Questionário Oswestry para avaliação da dor lombar (ANEXO C), ambos aplicados e preenchidos em forma de entrevista. Em seguida, o voluntário realizava os dois testes físicos, sendo um teste de amplitude articular, (teste de fleximetria) em coluna cervical, tronco e quadril e outro de força muscular em glúteos máximos.

As capacidades físicas, força muscular e flexibilidade, são componentes da aptidão física relacionada à promoção da saúde e seu desenvolvimento tem influência no desempenho das atividades cotidianas, além de evitar o aparecimento de alguns tipos de doenças degenerativas do sistema musculoesquelético (DAHER et al., 2005).

No presente estudo, essas capacidades funcionais foram avaliadas por meio de dois testes (fleximetria e dinamometria). Esses testes foram aplicados segundo as normas dos testes físicos de Kendall, (1995), padrão esse que também se basearam os criadores dos instrumentos utilizados na presente pesquisa (Flexímetro CODE e Dinamômetro Lafayette).

Para ambos os testes (força e fleximetria) foram realizadas três medidas com um intervalo de recuperação de 30 segundos entre elas. Anteriormente a cada teste, o voluntário foi orientado pelo examinador sobre que movimento realizar e como o fazer e durante o teste, um estímulo verbal era dado para que o participante chegasse até ao final da amplitude (caso do teste de fleximetria) 
e para que mantivesse a força isométrica até o tempo determinado para a medição da força que era de cinco segundos (tempo este calibrado para o teste de força). Os estímulos dados eram, respectivamente, "vai, vai, vai" e "força, força, força”, enquanto o examinador auxiliava o avaliado, fixando determinado segmento corporal que pudesse invalidar a prova.

O tempo despendido para se efetuar toda a avaliação (preenchimento de formulários e questionário) por meio de entrevista e realização dos testes físicos- fleximetria e dinamometria foi em torno de 45 minutos em média para cada participante do estudo.

Todo o processo de avaliação e reavaliação, com exceção da pré avaliação foi realizado por um avaliador externo, devidamente orientado e treinado pelo autor da pesquisa.

Os exercícios resistidos foram aplicados conjuntamente a outros de alongamento num protocolo de exercícios gerais (APÊNDICE E) com o intuito de simular uma prática comum de exercícios que são geralmente prescritos por fisioterapeutas em pacientes acometidos por dor lombar.

O protocolo de exercícios de alongamento e fortalecimento foi realizado de modo que os exercícios de alongamento fossem feitos em três repetições, com manutenção do estímulo de alongamento por 30 segundos e entre cada repetição havia uma pausa de 30 segundos. Já os exercícios de fortalecimento foram realizados em uma série contendo 10 repetições utilizando apenas a carga e as alavancas corporais para promover resistência e não havia pausa entre cada repetição.

O protocolo de exercícios de Pilates não conta com a mesma forma de aplicação, pois segundo Sacco et al., (2005), essa técnica conta com uma 
particularidade em se tratando da forma de execução, pois Pilates trabalha executando o exercícios em poucas repetições e com fluidez de movimento entre um exercício e outro.

A avaliação da amplitude de movimento da articulação da coluna cervical, tronco e quadril foi realizada segundo o protocolo sugerido pelo Instituto CODE de Pesquisa (ICP, 2010; KENDALL, 1995).

A flexibilidade articular é um termo usado para descrever a amplitude de movimento (ADM) permitida em cada um dos planos de movimento de uma articulação (HALL, 2000). A amplitude de movimento da coluna cervical pode ser visualizada através do plano coronal, frontal ou lateral, o qual divide o corpo em dois semi-planos, um anterior e outro, posterior (KENDALL, 1995).

A coluna cervical é composta por sete vértebras. A primeira e a segunda são consideradas atípicas e recebem os nomes respectivos de atlas e áxis. As quatro seguintes são consideradas típicas assim como a sétima, embora esta apresente alguma particularidade que será detalhada em seguida (DÂNGELO; FATTINI, 1998).

A primeira vértebra recebe esse nome por sustentar a cabeça, como a figura mitológica carregava o globo terrestre (Figura 27a,b). A segunda vértebra cervical (Figura 28a,b) tem este nome por servir de eixo para a rotação do atlas com o crânio que ele suporta. A superfície superior do corpo vertebral projetase no dente do axis (Figura 28a), com o qual se articula a face posterior do arco anterior do atlas (DÂNGELO; FATTINI, 1998). 


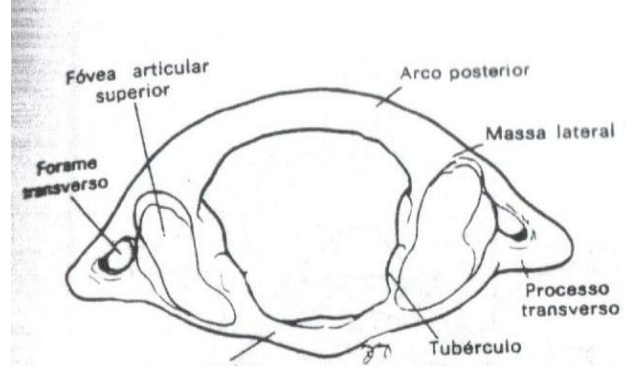

Fonte: DÂNGELO \& FATTINI (1998, p. 377) Figura 27a - Primeira vértebra cervical (Atlas) vista superior com processo transverso e forame transverso.

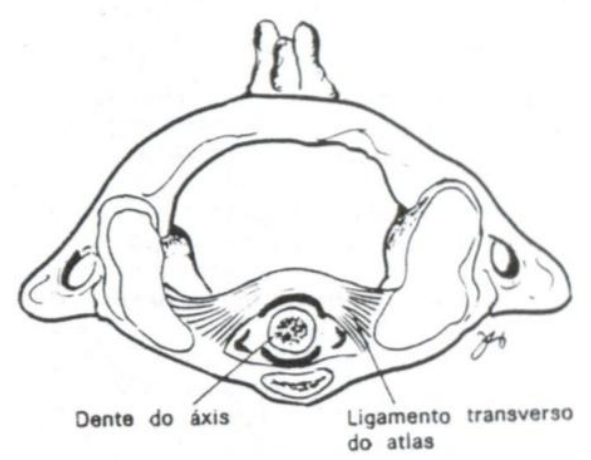

Fonte: DÂNGELO \& FATTINI (1998, p. 377) Figura 28a - Áxis com o dente do áxis.

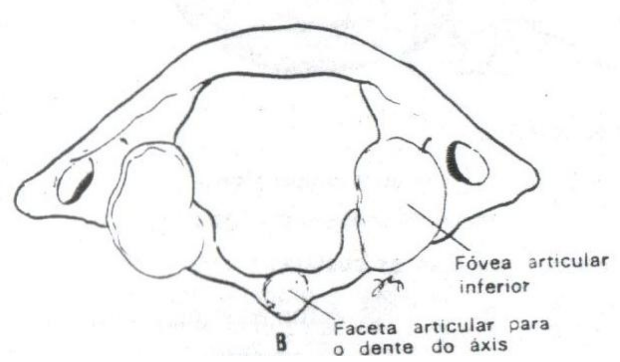

Fonte: DÂNGELO \& FATTINI (1998, p. 377) Figura 27b - Primeira vértebra cervical (Atlas) vista inferior com faceta articular para dente do atlas.

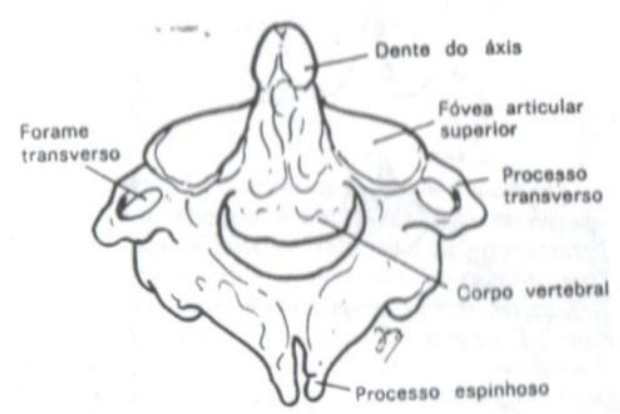

Fonte: DÂNGELO \& FATTINI (1998, p. 377) Figura 28b - Áxis.

Entre a terceira e a sexta vértebra, os processos transversos apresentam o forame transverso para a passagem da artéria vertebral; os processos espinhosos são curtos, bifurcados e pouco inclinados em relação ao plano dos corpos vertebrais; as facetas articulares dos processos articulares se situam mais horizontalmente do que verticalmente (Figura 29) (DÂNGELO; FATTINI, 1998).

Na sétima vértebra, o processo espinhoso é longo e não bifurcado; ela é facilmente palpável quando se flexiona a cabeça, esta é conhecida como vértebra proeminente (DÂNGELO; FATTINI, 1998). 


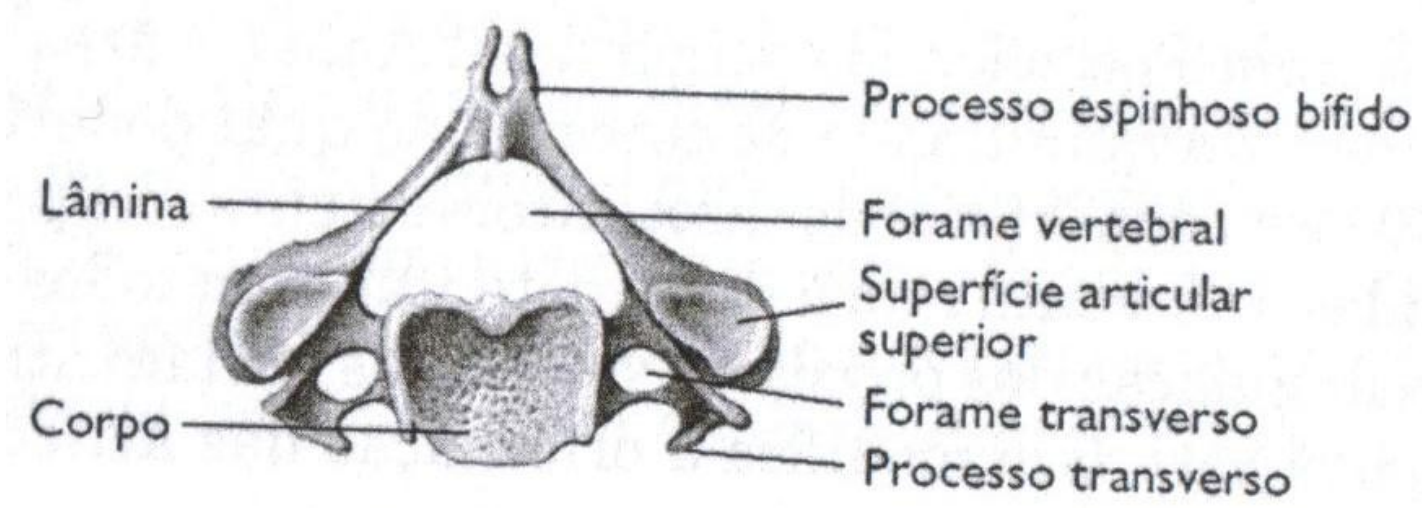

Fonte: DÂNGELO \& FATTINI (1998, p. 377)

Figura 29 - Vértebra cervical típica.

O teste de flexibilidade da coluna cervical (Figura 30a,b) foi realizado com o participante deitado em uma maca em decúbito dorsal, membros superiores estendidos e posicionados ao longo do tronco. Foi orientado ao voluntário que deixasse a cabeça e a nuca ultrapassar a extremidade superior da maca até que os ombros se posicionassem na borda superior da mesma. A fita do flexímetro foi passada ao redor da cabeça e o aparelho posicionado sobre a orelha direita do participante. Em seguida, executou-se a extensão máxima passivamente, zerou-se o flexímetro (Figura 30a) e foi pedido para o participante, ativamente, flexionar a cabeça o máximo que conseguisse, mas sem que fizesse insistências ao final do movimento para aumentar a ADM (Figura 30b). O avaliador manteve os ombros do participante fixados para que ele não os elevasse na fase ativa do teste (flexão). O movimento foi orientado ao participante anteriormente à realização do exame para que o mesmo fosse executado de forma tranqüila. 


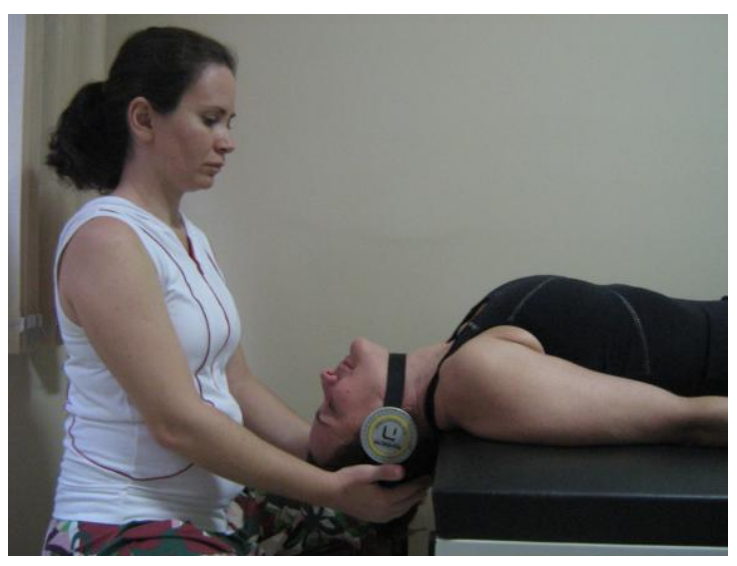

Figura 30a - Teste de flexibilidade da coluna cervical - posição inicial.

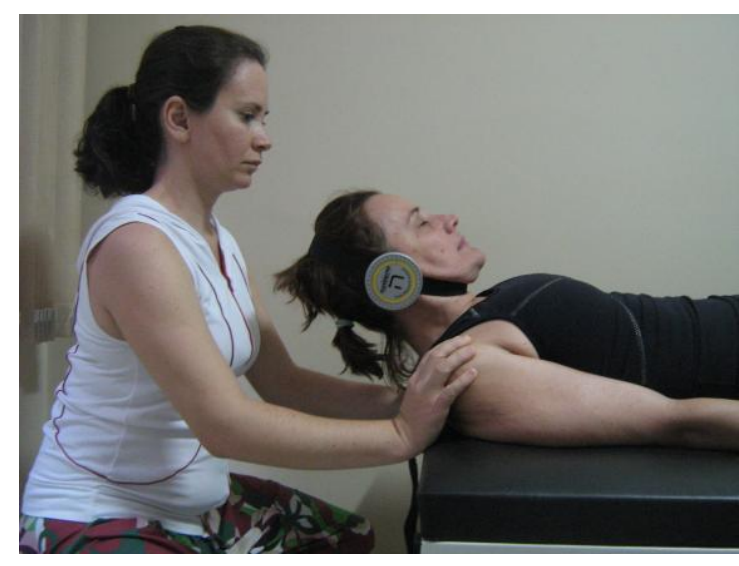

Figura 30b - Teste de flexibilidade da coluna cervical - posição final.

O tronco é formado pelas regiões do tórax, do abdômen e da pelve. O tórax constitui-se pelo osso esterno, pelas vértebras torácicas e pelas costelas e cartilagens costais (Figura 31a). $\mathrm{O}$ abdômen (Figura 31b) situa-se entre 0 tórax, superiormente e entre a pelve (Figura 31c), inferiormente. A cavidade abdominal está separada da torácica pelo músculo diafragma, mas interiormente ela tem continuidade com a cavidade pélvica (DÂNGELO; FATTINI, 1998).

A pelve consiste na junção do sacro, do cóccix e dos dois ossos inominados que são formados por uma fusão do íleo, do ísquio e do púbis. A pelve ou cintura pélvica, ou, mais popularmente conhecida como bacia, proporciona suporte e proteção aos órgãos abdominais e transmite força da cabeça, braços e tronco às extremidades inferiores (HALL, 2000). 


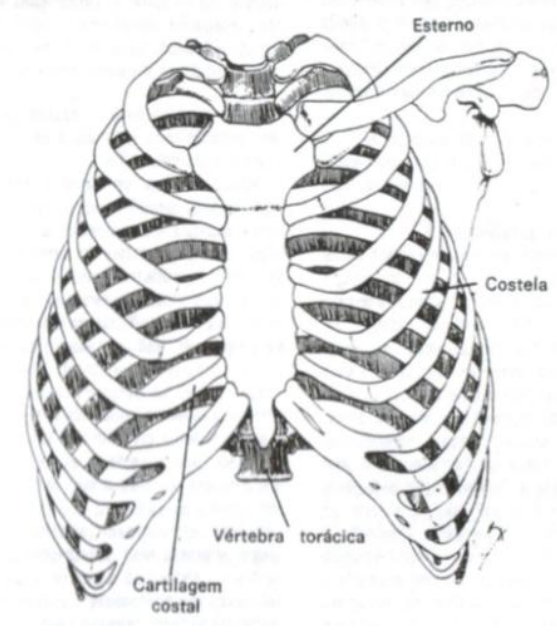

Fonte: DÂNGELO \& FATTINI (1998, p. 495). Figura 31a - Tórax.

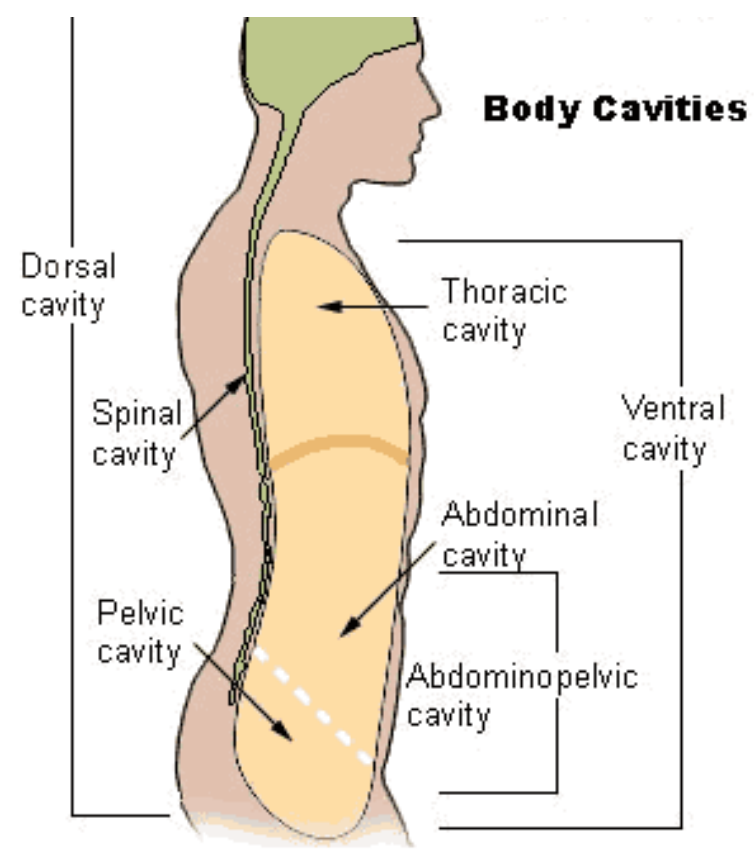

Fonte: New world encyclopedia (2008).

Figura 31b - Abdômen ou cavidade abdominal

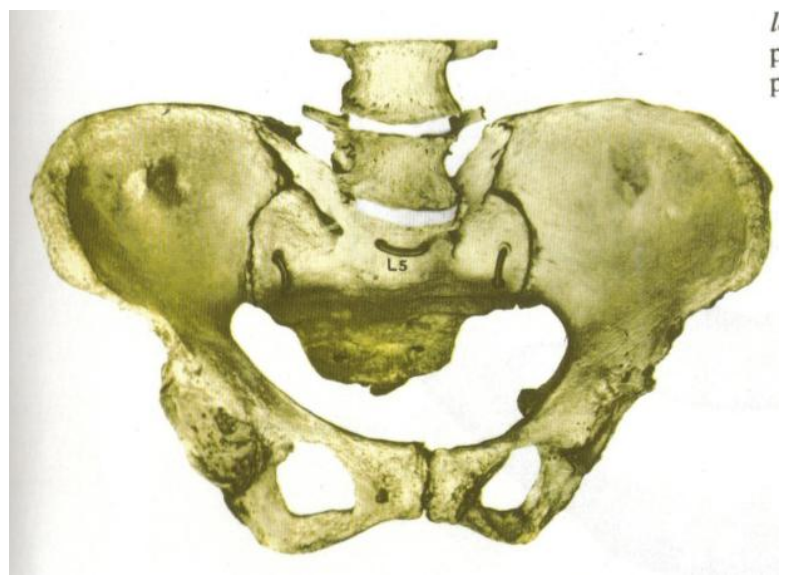

Fonte: Spaltehol \&-Spanner (1988, p.45)

Figura 31c - Pelve.

O movimento de flexo-extensão foi realizado no plano coronal e para o teste de flexibilidade do tronco, solicitou-se ao avaliado que ele ficasse em posição ortostática (em pé) e descalço com os pés levemente abduzidos com os calcanhares unidos. Orientou-se que se afastassem os dedos (abrindo os 
pés) até que o segundo artelho chegasse na direção da patela, ou seja, se fosse traçada uma linha vertical na direção desta até o chão, ela deveria cair na direção do segundo artelho; em seguida, com os braços elevados e os antebraços flexionados com as mãos sobrepostas e posicionados sobre o occiptal , a fita do flexímetro foi posicionada ao redor do tórax na altura da linha mamilar para o sexo masculino e supra mamilar para o feminino; posteriormente, solicitou-se ao avaliado que ele realizasse uma extensão de tronco máxima mantendo os joelhos unidos e extendidos (Figura 32a). Segundo Kendall, (1995), o movimento dessa região da coluna em extensão ocorre no sentido de diminuir a curva normal para trás. O movimento pode progredir até, porém normalmente, do ponto de retificação ou achatamento da coluna torácica.

Após realizar uma extensão máxima ativa, zerava-se o flexímetro e media-se a amplitude articular de todo o arco do movimento até o final da flexão de tronco (Figura 32b). O examinador deveria tomar todo o cuidado para que o avaliado não executasse uma flexão de quadril durante a flexão de tronco, caso isso ocorresse, o teste era interrompido. Para Kendall, (1995), na flexão normal de tronco, a coluna se curva com convexidade para trás, produzindo um contorno contínuo e delicadamente arredondado em toda a região torácica. A mesma orientação para que não insistissem ao final do movimento nem que executassem o teste com rapidez foram feitas e supervisionadas.

Todas as posturas do teste foram explicadas e demonstradas pelo avaliador anteriormente, além de quais e onde estavam as estruturas anatômicas de referência para o teste. 


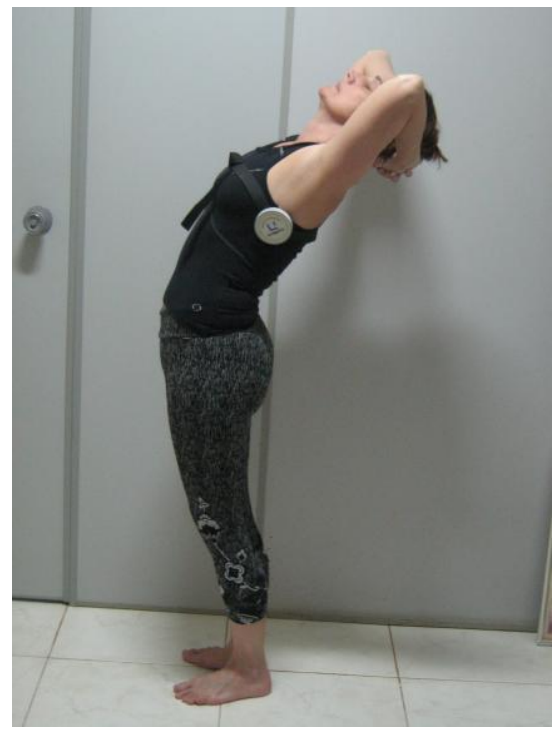

Figura 32a - Teste de flexibilidade de tronco - início

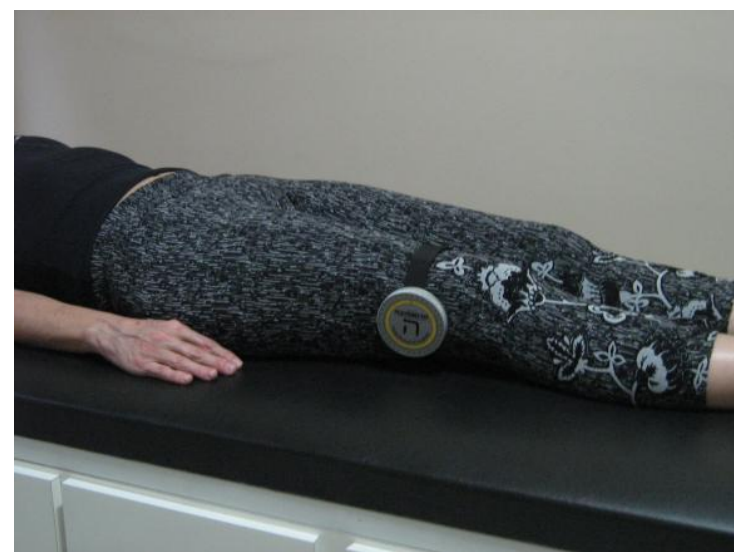

Figura 33a - Teste de flexibilidade de quadril realizado com membro inferior direito - início.

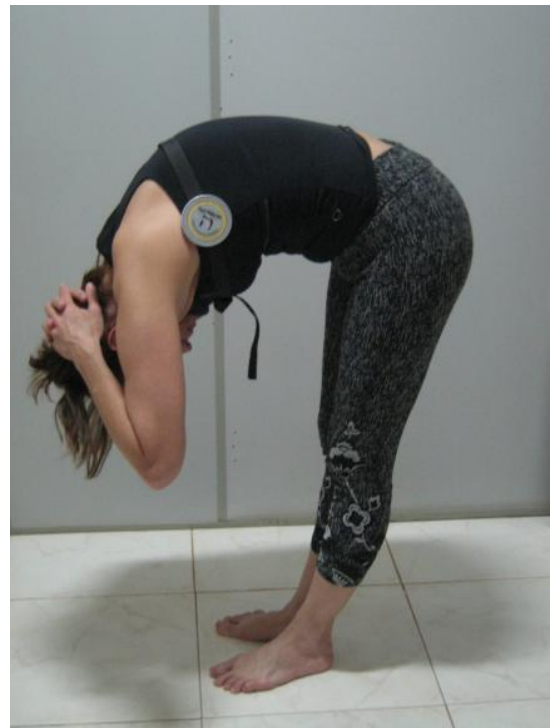

Figura 32b - Teste de

flexibilidade de tronco - fim

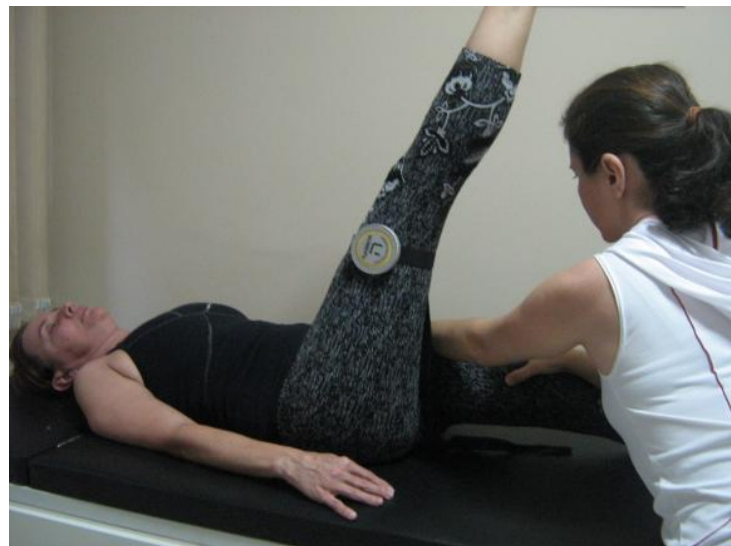

Figura 33b - Teste de flexibilidade de quadril realizada com membro inferior direito - fim.

O último teste de fleximetria foi o de flexão de quadril. Segundo Kendall (1995), a flexão e a extensão são movimentos em torno de um eixo coronal, a flexão é o movimento na direção anterior. Neste movimento pode se mover a coxa no sentido da pelve fixa, como na elevação alternada das pernas em decúbito dorsal ou o movimento pode ocorrer no sentido de trazer a pelve no sentido das coxas fixas. 
Os seis principais músculos responsáveis pela flexão do quadril são os que cruzam a articulação anteriormente: o ilíaco, o psoas maior (iliopsoas), o pectínio, o reto femoral, o sartório e o tensor da fascia lata, sendo que o principal nessa função é o iliopsoas (HALL, 2000).

Segundo protocolo do ICP, o teste de fleximetria na articulação do quadril deve ser realizado com o avaliado em decúbito dorsal em uma maca com o corpo estendido, os braços ao longo do corpo e os membros inferiores aduzidos e estendidos, os pés devem estar apoiados na maca em dorsiflexão (Figura 33a). O flexímetro deve estar com sua fita circundando a coxa no terço distal, acima do joelho, com a face voltada lateralmente. O movimento deve ser iniciado com uma elevação do membro inferior com a perna estendida e pés em dorsiflexão. $O$ avaliador deve fixar a pelve contralateral do voluntário fazendo uma pressão sobre a crista ilíaca em direção perpendicular à maca (Figura 33b). Deve-se pedir ao avaliado que ele mantenha a perna estendida e não exerça forças extremas ao final do movimento. Para (Kendall, 1995), esse mesmo teste é realizado com o membro contra-lateral flexionado e com o pé apoiado na maca.

Optou-se pela primeira variação do teste, pois nessa mesma posição é possível que se avalie também o encurtamento dos isquiotibiais, músculos importantes no movimento de anteriorização e retroversão da pelve.

O teste de dinamometria foi realizado no músculo glúteo máximo. Em se tratando do teste escolhido, Kendall (1995) relata que ao avaliar a força de glúteo máximo, pode-se ter uma noção da musculatura extensora de tronco, pois em uma situação na qual os músculos extensores do quadril são fracos, ao ser realizada uma extensão do tronco, os extensores do quadril (glúteo 
máximo) não conseguirão estabilizar a pelve em direção às coxas. Se os extensores do quadril não puderem proporcionar essa estabilização, a pelve será tracionada para cima pelos extensores da coluna em uma posição de extensão da coluna (KENDALL, 1995).

Daí então, a importância da avaliação da força e do fortalecimento desse músculo em função da estabilização pélvica e colaboração para a biomecânica adequada de outros grupos musculares dessa região.

Anatomicamente, o glúteo máximo (figura $34 a, b)$ possui sua origem na linha glútea posterior do ílio e porção do osso a ela superior e posterior, superfície posterior da parte inferior do sacro, lado do cóccix, aponeurose do eretor da espinha, ligamento sacrotuberoso e aponeurose glútea. Sua inserção ocorre na porção proximal maior e fibras superficiais da porção distal do músculo no trato iliotibial da fáscia lata. Fibras mais profundas da porção distal na tuberosidade glútea do fêmur (KENDAL, 1995).

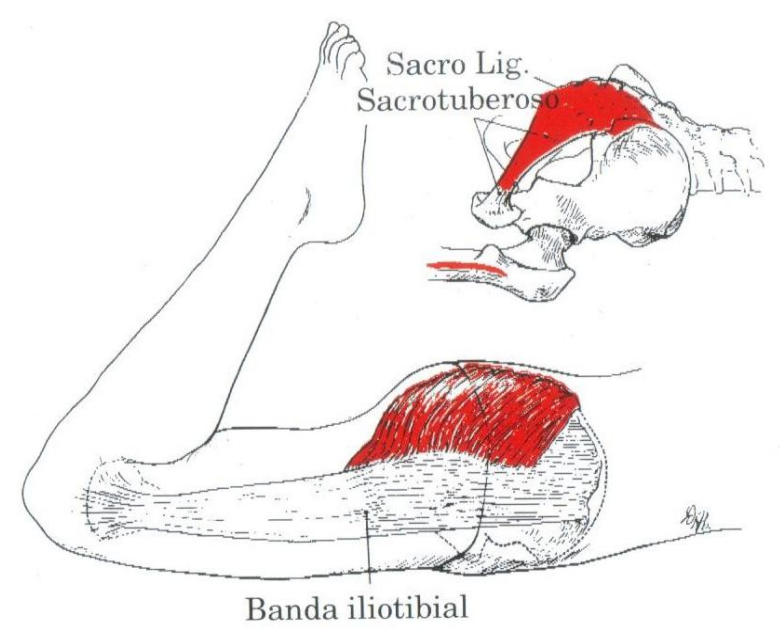

Fonte: KENDALL; MCCREARY; PROVANCE (1995, p. 226).

Figura 34a - Músculo glúteo máximo

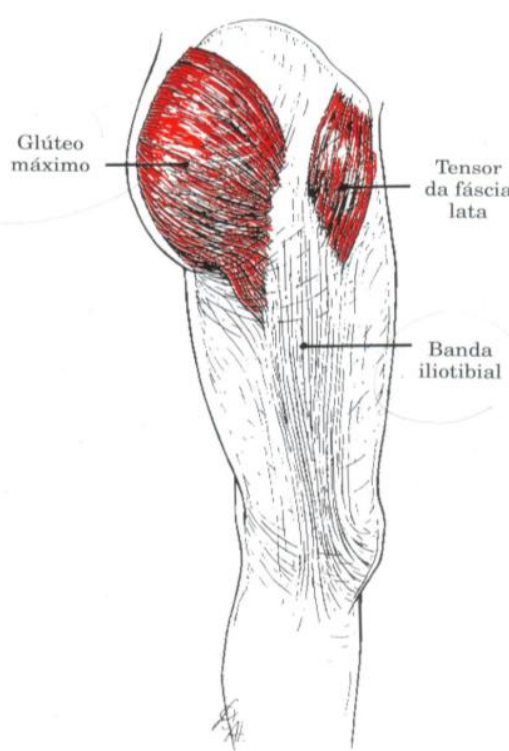

Fonte: KENDALL; MCCREARY; PROVANCE (1995, p. 226).

Figura 34b - Músculo glúteo máximo 
A ação muscular do glúteo máximo é realizar extensão, rotação lateral da articulação do quadril, sendo que as fibras inferiores auxiliam na adução e as superiores auxiliam na abdução da mesma articulação. Através de sua inserção no trato iliotibial, ajuda a estabilizar o joelho em extensão. Esse músculo recebe inervação do plexo lombo-sacro: $L_{5}, S_{1,2}$.

O teste é realizado com o avaliado em decúbito ventral, joelho flexionado a $90^{\circ}$ ou mais (Figura 35a). Nessa posição, posteriormente ficam fixadas a musculatura da coluna, lateralmente, os músculos abdominais laterais, e, anteriormente, os flexores do quadril oposto fixam a pelve ao tronco. A prova é realizada, solicitando ao avaliado uma extensão do quadril com joelho flexionado. Uma pressão contra a parte inferior da coxa posterior na direção da flexão do quadril é realizada com uma mão e com a outra, pressiona-se o quadril em direção à superfície de apoio para que o avaliado não realize uma flexão do quadril devido ao excesso de força em empurrar a coxa (do lado avaliado) no sentido da extensão.

$\mathrm{Na}$ dinamometria, a mão que realiza a pressão contra a parte inferior da coxa avaliada na direção da flexão do quadril tem acoplado o equipamento que medirá essa força (Figura 35b) e a outra mão, permanece assim como no teste descrito acima. 


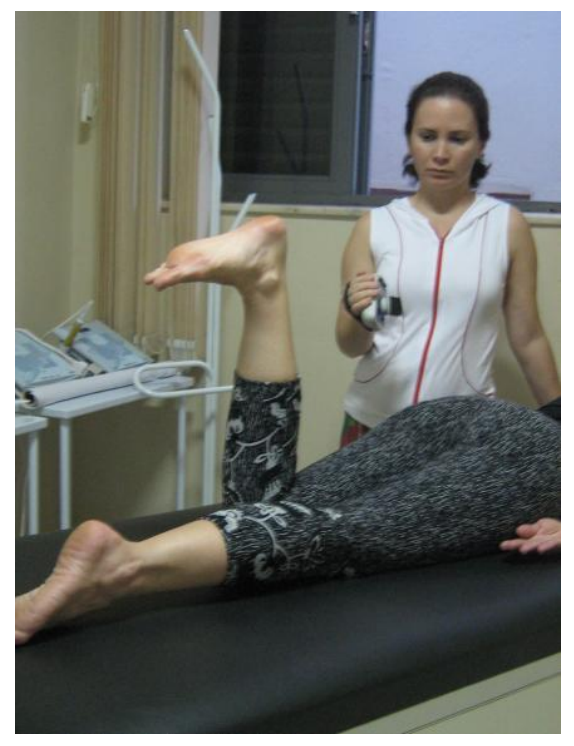

Figura 35a - Teste de força muscular de glúteo máximo esquerdo - posicionamento inicial.

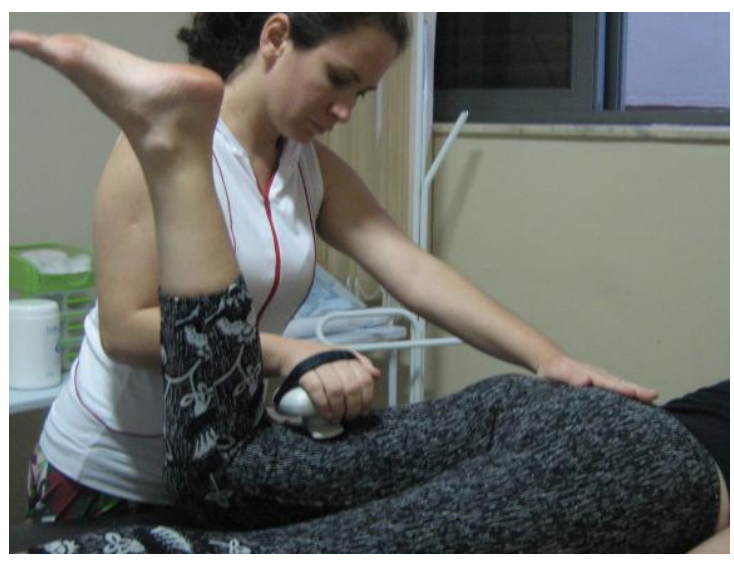

Figura 35b - Teste de força muscular de glúteo máximo esquerdo - execução.

Tanto na avaliação da flexibilidade articular como na da força de glúteo máximo, foram realizadas três medidas em cada teste com um intervalo de 30 segundos entre cada medida. Foi escolhido o maior valor medido para ser utilizado para a análise estatística dos dados.

\subsection{Processamento e análise dos dados}

Os dados foram organizados e inseridos em planilha eletrônica do programa Excel for Windows em forma de banco de dados eletrônico, seguido da digitação dos dados em duas planilhas independentes e a validação do banco. Atribuiu-se identificação única para cada resposta dos sujeitos e estas foram codificadas em categorias numéricas.

O banco de dados validado foi transferido para o "Statistical Package for the Social Science (SPSS) version 15.0 for Windows" e para o software 
statistical Analysis System (SAS), versão 9 para análise estatística. As variáveis analisadas no presente estudo foram categorizadas em quantitativas discreta (dor) e contínua (força e flexibilidade) (MARTINS, 2002).

Primeiramente, por meio do software SPSS, foram conduzidas as análises univariadas descritivas-exploratórias, sendo as variáveis categóricas submetidas à análise de distribuição de freqüência (absoluta e percentual) e as variáveis contínuas submetidas às análises de medidas de tendência central (média e mediana) e dispersão (desvio-padrão), visando descrever as variáveis e caracterizar os sujeitos da presente pesquisa.

Foram realizadas análises de associação bivariada com o objetivo de avaliar a associação entre as variáveis e obter uma compreensão inicial dos dados coletados. Em função do "n" reduzido, realizaram-se testes de normalidade de Shapiro-Wilk, antes da utilização do teste t na comparação dos grupos. O teste t foi utilizado para comparar a média da diferença dos escores quantitativos.

Testes não-paramétricos foram adequados e conclusivos para esse número de participantes $(n=19)$. Diferenças entre o $\mathrm{GC}$ e o $\mathrm{GP}$ foram analisadas utilizando-se o teste de Mann- Whitney quando o nível de mensuração do desfecho considerado era ordinal e o teste de Wilcoxon foi utilizado para identificar alguma mudança significativa que pode ter ocorrido depois da intervenção nos dois grupos. Fixou-se o nível de significância de a de 0,05 para todos os testes de hipótese.

Em seguida, por meio do software SAS foi realizada uma análise exploratória dos dados com objetivo de correlacionar as variáveis incapacidade funcional (dor), força e flexibilidade. O coeficiente de correlação de Spearman 
(Cs) foi utilizado variando de -1 a 1 sendo que valores próximos de 1 indicam alta correlação direta entre as variáveis e valores próximos de -1 indicam forte correlação inversa entre as variáveis. Os p-valores relacionados a eles são referentes ao teste de hipóteses, cuja hipótese nula é a de que o coeficiente é igual a zero.

Para se associar a incapacidade funcional (dor) com a postura, foi utilizado o teste exato de Fisher. Para se verificar se há diferença entre os grupos quanto à força glútea ao se verificar se ela decai no período pósintervenção quando comparado com o pré, foi utilizado um modelo de efeitos mistos por meio do procedimento PROC MIXED.

Os modelos lineares de efeitos mistos (efeitos aleatórios e fixos) são utilizados na análise de dados onde as respostas de um mesmo indivíduo ou corpo de prova estão agrupados e a suposição de independência entre observações num mesmo grupo não é adequada (SCHALL, 1991; LITTEL, 1996). Esses modelos têm como pressuposto que seus resíduos tenham distribuição normal com média 0 e variância $\sigma^{2}$. 


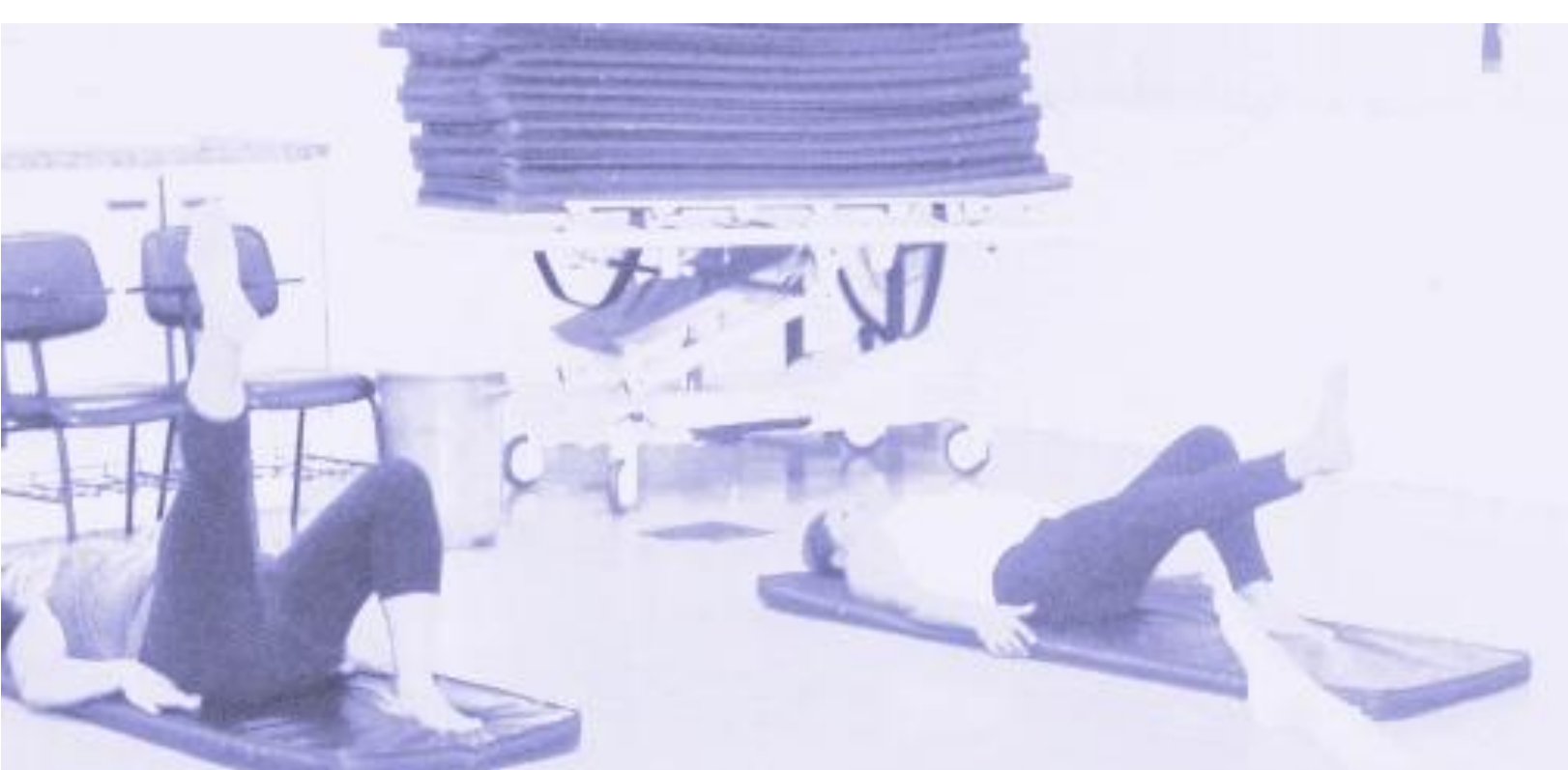

Resultados e Discussão 


\section{RESULTADOS E DISCUSSÃO}

\subsection{Caracterização da amostra}

A amostra estudada foi composta por 19 profissionais de enfermagem, sendo estes, três enfermeiros, um técnico e 15 auxiliares de enfermagem. Dois grupos foram formados, um grupo de intervenção com exercícios baseados no método Pilates (GP) e um grupo controle com intervenção de exercícios convencionais de alongamento e fortalecimento (GC). Cada um dos grupos foi composto por 14 indivíduos. O GP teve uma perda de seguimento de 21,43\%, constituindo uma amostra final de 11 participantes. O GC apresentou perda de $42,86 \%$, constituindo uma amostra final de oito participantes. Dois participantes foram excluídos por não se adequarem aos critérios de seleção do estudo.

\subsection{Caracterização dos sujeitos do estudo}

A Tabela 1 apresenta os aspectos individuais e sócio-demográficos dos participantes. 


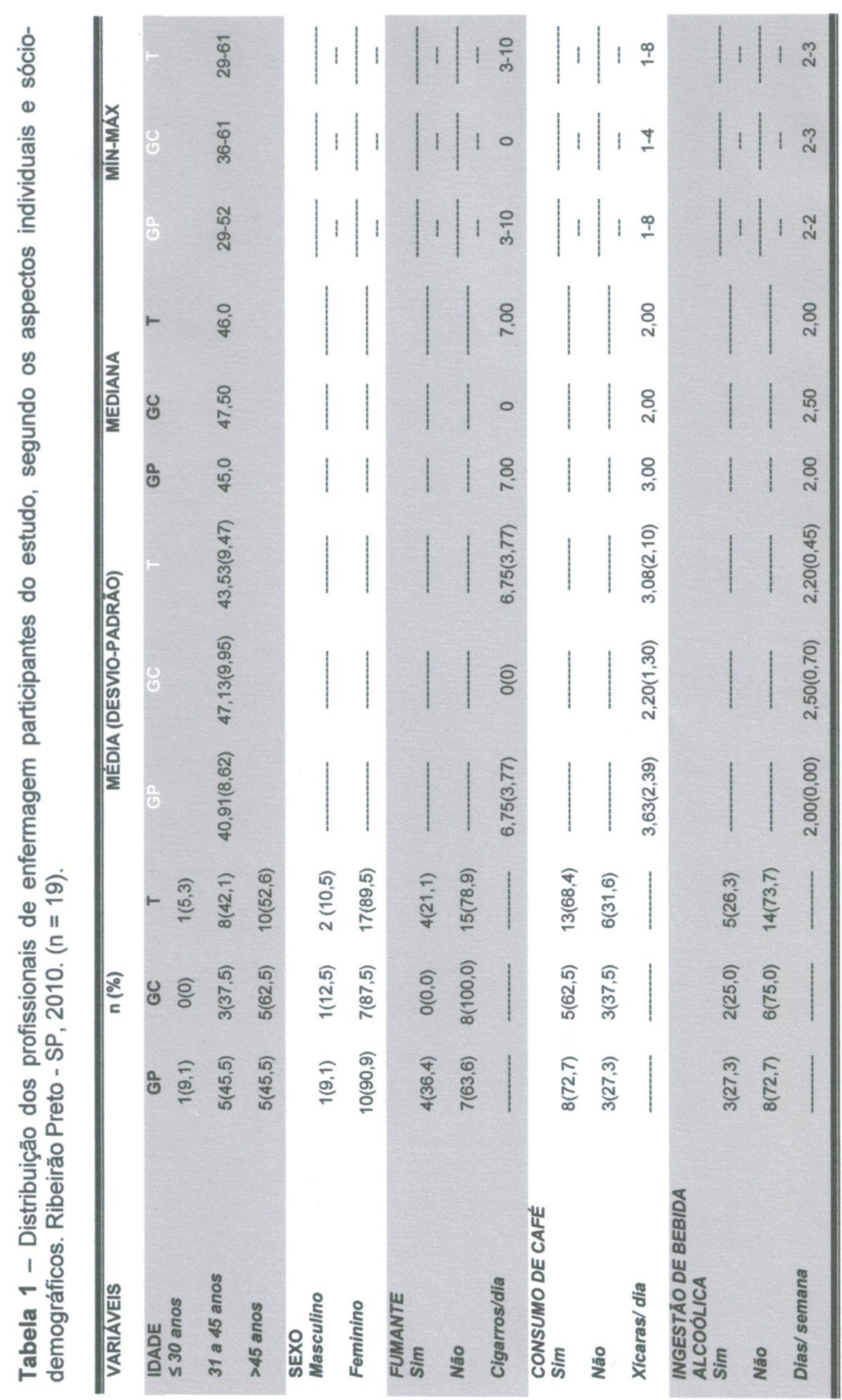


Observa-se na Tabela 1 que tanto no GP como no GC, a maioria dos voluntários tinha mais que 45 anos (52,6\% dos participantes do estudo). Tal resultado está de acordo com os estudos de Rosenthal, (1994) e Mendes (1999), os quais afirmam que esse tipo de lombalgia é mais comum em pacientes com idade entre 45 a 50 anos.

Em se tratando do gênero, em ambos os grupos houve a participação de apenas um voluntário do sexo masculino em cada grupo, o que configura a lombalgia uma moléstia que acomete predominantemente o sexo feminino. Segundo estudos realizados por Nieman, (1999) e Teixeira et al., (2002), é mais comum a dor lombar em mulheres que em homens.

Lopes e Leal (2005) constataram que o perfil da força de trabalho na enfermagem é eminentemente feminino. Somando-se os aspectos fisiológicos do gênero feminino às cargas físicas excessivas de trabalho, o sexo feminino fica muito mais susceptível para o desenvolvimento da dor lombar. A Organização Internacional do Trabalho (OIT) recomenda que deva se limitar o emprego de mulheres no transporte manual de cargas e que o peso máximo a ser transportado por trabalhadores do sexo feminino deve ser consideravelmente inferior à carga transportada pelos homens (ALEXANDRE et al., 1992).

Nesse sentido, as exigências da tarefa realizada pelas trabalhadoras de enfermagem são consideradas, por alguns autores, fatores de risco para o desenvolvimento de dores nas costas. A mulher tem menor número de fibras musculares e menor capacidade de converter glicogênio em energia, e, biomecanicamente, seus ossos tendem a ser mais curtos, o que implica em uma área de função mais reduzida. Além disso, soma-se a esses fatores a 
"dupla jornada de trabalho", o que resulta em maior desgaste físico para a mulher (ROCHA, 1997).

Em se tratando do hábito de fumar, quatro $(36,4 \%)$ participantes do GP relataram ter o hábito de fumar em média $6,75(3,77)$ cigarros por dia; nenhum participante do GC era fumante. Silva (2004); Almeida et al., (2008) constataram que o tabagismo apresentou forte associação com a dor lombar crônica, sendo que algumas teorias têm sido postuladas para explicar tal relação como a tosse crônica causada pelo hábito de fumar, tendo em vista que esta aumenta a pressão interna abdominal e dos discos vertebrais lombares; o efeito da nicotina que produz uma redução da circulação sanguínea e de algumas substâncias como o sulfato de oxigênio no corpo vertebral, o que provavelmente pode reduzir a nutrição dos discos vertebrais e por último, pode estar relacionado a fatores psicossociais de risco para 0 desfecho, como baixa condição sócio-econômica, o que implicaria em maior demanda física de trabalho e estresse.

A respeito do hábito de tomar café, oito $(72,7 \%)$ participantes do GP relataram tomar em média 3,63 $(2,39)$ xícaras de café por dia, enquanto no GC cinco $(62,5 \%)$ relataram tomar, em média, $2,20(1,30)$ xícaras por dia. Nenhuma relação foi encontrada na literatura entre àqueles que o fazem e 0 surgimento ou agravamento da dor lombar crônica. Já com relação ao consumo de álcool, 3 (27,3\%) participantes do GP relataram ingerir, em média, dois $(0,00)$ dias por semana enquanto no GC apenas dois $(25,0 \%)$ relataram ingerir bebida alcoólica numa freqüência de $2,5(0,70)$ dias por semana. A Sociedade Brasileira de Reumatologia (2007) considera o consumo de álcool como um fator psicossocial para o surgimento da dor lombar. 


\subsection{Aspectos profissionais dos sujeitos da amostra}

A Tabela 2 apresenta os aspectos profissionais dos voluntários participantes da pesquisa.

Tabela 2- Distribuição dos profissionais de enfermagem participantes do estudo, segundo os aspectos profissionais. Ribeirão Preto - SP, 2010. $(n=19)$

\begin{tabular}{|c|c|c|c|}
\hline VARIÁVEIS & & $n(\%)$ & \\
\hline PROFISSÃO & GP & GC & $T$ \\
\hline Enfermeiro & $3(27,3)$ & $0(0)$ & $3(15,8)$ \\
\hline Técnico de enfermagem & $1(9,1)$ & $0(0)$ & $1(5,3)$ \\
\hline Auxiliar de enfermagem & $7(63,6)$ & $8(100)$ & $15(78,9)$ \\
\hline $\begin{array}{l}\text { SETOR QUE TRABALHA } \\
\text { Centro cirúrgico }\end{array}$ & $1(9,1)$ & $0(0)$ & $1(5,3)$ \\
\hline CTI neo natal & $1(9,1)$ & $0(0)$ & $1(5,3)$ \\
\hline Clínica cirúrgica & $1(9,1)$ & $1(12,5)$ & $2(10,5)$ \\
\hline Clínica médica & $0(0)$ & $1(12,5)$ & $1(5,3)$ \\
\hline Controle pré-natal & $1(9,1)$ & $0(0)$ & $1(5,3)$ \\
\hline Central de materiais & $1(9,1)$ & $6(75)$ & $7(36,8)$ \\
\hline Neurocirurgia & $1(9,1)$ & $0(0)$ & $1(5,3)$ \\
\hline Pediatria & $2(18,2)$ & $0(0)$ & $2(10,5)$ \\
\hline Pronto atendimento & $3(27,3)$ & $0(0)$ & $3(15,8)$ \\
\hline $\begin{array}{l}\text { TURNO } \\
\text { Matutino }\end{array}$ & 327,3 & $5(62,5)$ & $8(42,1)$ \\
\hline Vespertino & 327,3 & $1(12,5)$ & $4(21,1)$ \\
\hline Noturno & 218,2 & $0(0)$ & $2(10,5)$ \\
\hline Mais de um turno & 327,3 & $2(25,0)$ & $5(26,3)$ \\
\hline
\end{tabular}


Os 19 participantes da pesquisa trabalhavam em média 8,37 ( $\pm 2,24)$ horas por dia e 5,53 $( \pm 0,90)$ dias por semana. Dentre os 11 participantes do GP, a média de horas trabalhadas por dia foi de $8,18( \pm 2,60)$ horas e 5,45 $( \pm 0,93)$ dias por semana. Em se tratando dos oito participantes do GC, esses valores foram respectivamente de $8,63( \pm 1,77)$ e $5,63( \pm 0,91)$.

O GP constituiu-se por três enfermeiros, um técnico e sete auxiliares de enfermagem, enquanto o GC era formado exclusivamente por auxiliares de enfermagem. Em se tratando dos setores dos quais mais se originaram participantes na presente pesquisa, teve-se que o setor de Central de materiais, Pronto atendimento, Clínica cirúrgica e Pediatria foram os setores que apresentaram mais que um funcionário participante, sendo 7, 3, 2 e 2, respectivamente.

Um dos objetivos da Central de Materiais e Esterilização (CME) é cuidar da saúde das pessoas, e mesmo que todo o trabalho envolvido não receba o nome de assistencial, o sucesso do atendimento depende desse cuidar indireto. Dentre as atribuições da CME, destacamos a esterilização (ALEXANDRE et al, 1992), embora este setor do hospital seja responsável também pela limpeza e desinfecção de materiais e instrumentos.

As posturas físicas mais adotadas na rotina dos trabalhadores de enfermagem desse setor, segundo relato dos participantes desse estudo, foram quatro posturas estáticas (inclinado em pé parado, inclinado agachado, inclinado sentado e ereto sentado) e duas posturas dinâmicas (inclinado em pé andando e ereto em pé andando).

A demanda de esforço físico nessa unidade é excessiva e inclui o preparo das caixas de instrumentais e o seu transporte, entre outros. Além 
disso, o dispêndio elevado de força muscular e gasto excessivo de energia física têm ocasionado problemas de postura e fadiga geral nesses trabalhadores, tornando-se mais grave na medida em que se constata 0 predomínio de mulheres na força de trabalho empregada no hospital (SCHMIDT e DANTAS, 2006).

A Unidade de Pronto Atendimento (UPA) é responsável pelo atendimento médico a urgências e emergências médicas e odontológicas, com demanda espontânea de pacientes ou referenciamentos a partir das Unidades Básicas de Saúde (UBS) (DORNAS JÚNIOR e FERREIRA, 2003).

Os profissionais provenientes desse setor elegeram nove posturas utilizadas em suas rotinas de trabalho, sendo essas, sete estáticas e duas dinâmicas. As posturas inclinado, sentado (estática) e em pé andando (dinâmica) foram as citadas mais de uma vez, com três e duas repetições, respectivamente.

Em estudo realizado por Dalri (2007), os trabalhadores de enfermagem que atuam em setores de Pronto atendimento queixam-se de algumas situações antiergonômicos como a altura fixa das macas e dos leitos, postura inadequada durante o transporte de pacientes no interior da ambulância, ambientes pequenos para a realização dos procedimentos e situações inadequadas para o descanso.

O terceiro setor com maior representação de voluntários na presente pesquisa, juntamente com a clínica cirúrgica, foi a Pediatria. Segundo Campestrini, (1991), a Unidade de Internação de Pediatria é um setor que vem desenvolvendo uma nova concepção de assistência integral ao indivíduo onde novas responsabilidades passaram a ser assumidas pela equipe de 
enfermagem, principalmente em relação à criança em algumas áreas especializadas, dando ênfase ao aperfeiçoamento de métodos, técnicas, normas e rotinas com a finalidade de atingir o seu objetivo primordial: o bem estar e sua reabilitação num menor tempo possível.

Para Collet; Rocha (1996), o trabalho nos setores de Pediatria deve estar balizado pela integridade que está relacionada a não fragmentação do cuidado em tarefas, à participação da mãe neste cuidado, à interação com a mãe e a criança e também pelo trabalho multidisciplinar. Em se tratando da atuação do enfermeiro nesse setor, tem-se que a maioria de suas ações são planejadas e realizadas em função do diagnóstico e da terapêutica médica (OLIVEIRA, COLLET, 1999; VERNIER, 2004). Sobre a atuação da equipe de enfermagem, é ela quem administra a Unidade e permanece 24 horas por dia no cuidado da criança e de seu familiar (CORREA, 2005).

Os profissionais deste setor que participaram do estudo elegeram sete posturas adotadas no dia-dia durante o expediente de trabalho sendo elas quatro posturas estáticas e três dinâmicas, sendo uma delas, inclinado em pé parado (postura estática) relatada duas vezes. Marziale e Silva (2000) constataram em estudo realizado que a pediatria foi o setor onde se constatou - menor índice de afastamento por doenças entre os auxiliares de enfermagem.

Outro setor representado por dois voluntários foi a Clínica Cirúrgica. Um estudo realizado por Luvisotto et. al, (2010) com o intuito de identificar as atividades administrativas e assistenciais realizadas pelos enfermeiros destas unidades e conhecer quais das atividades realizadas eram mais ou menos prazerosas para esses profissionais, teve-se que as atividades assistenciais 
ocorreram com maior freqüência quando comparadas às administrativas por enfermeiros desse setor. Dentre as atividades assistenciais consideradas mais prazerosas pelos trabalhadores, destacava-se a assistência direta ao paciente, avaliação do paciente e implementação da Sistematização da Assistência de Enfermagem (SAE).

Com relação às posturas físicas adotadas por esses profissionais durante suas rotinas de trabalho, percebeu-se que as posturas inadequadas adotadas pelos trabalhadores de enfermagem que atuam no setor de Clínica Cirúrgica ocorrem em função do mobiliário inadequado, do esforço físico realizado para auxiliar os pacientes em suas mobilizações, do local onde são guardados os materiais e da desorganização ao realizar as tarefas (RIBEIRO; DINIZ, 2006).

Para os profissionais atuantes nesse setor que participaram deste estudo, três posturas foram escolhidas como as adotadas na rotina de trabalho, sendo dessas uma estática e duas dinâmicas, e sendo uma destas últimas citadas duas vezes (ereto em pé andando).

\subsection{Aspectos relacionados ao trabalho}

A Tabela 3 apresenta a distribuição dos profissionais de enfermagem participantes do estudo, segundo aspectos relacionados ao trabalho. 
Tabela 3- Distribuição dos profissionais de enfermagem participantes do estudo, segundo aspectos relacionados ao trabalho. Ribeirão Preto - SP, 2010.

\section{VARIÁVEIS}

LOCOMOÇÃO CASA-TRABALHO

À pé

Ônibus

Carro

Moto

DURAÇÃO DO TRAJETO (MIN)

$10<$ tempo $\leq 30$

$30<$ tempo $\leq 60$

$60<$ tempo $\leq 90$

POSTURA FÍSICA MAIS ADOTADA NO

TRABALHO

Dorso inclinado em pé parado

Dorso inclinado em pé andando

Dorso inclinado sentado

Dorso torcido em pé parado

Mais de uma postura

\begin{tabular}{|c|c|c|}
\hline \multicolumn{3}{|c|}{$n(\%)$} \\
\hline GP & GC & TOTAL \\
\hline $1(9,1)$ & $0(0)$ & $1(5,3)$ \\
\hline $4(36,4)$ & $4(50,0)$ & $8(42,1)$ \\
\hline $5(45,5)$ & $3(37,5)$ & $8(42,1)$ \\
\hline $1(9,1)$ & $1(12,5)$ & $2(10,5)$ \\
\hline $10(52,63)$ & $631,58)$ & $16(84,21)$ \\
\hline $0(0)$ & $2(10,53)$ & $2(10,53)$ \\
\hline $1(5,26)$ & $0(0)$ & $1(5,26)$ \\
\hline $2(18,2)$ & $0(0)$ & $2(10,5)$ \\
\hline $0(0)$ & $1(12,5)$ & $1(5,3)$ \\
\hline $1(9,1)$ & $0(0)$ & $1(5,3)$ \\
\hline $0(0)$ & $1(12,5)$ & $1(5,3)$ \\
\hline $8(72,7)$ & $6(75,0)$ & $14(73,7)$ \\
\hline
\end{tabular}

Carro e ônibus foram os meios de locomoção mais utilizados entre os trabalhadores de enfermagem. Cinco participantes (45,5\%) do GP e três $(37,5 \%)$ do GC utilizavam carro como meio de locomoção para trabalhar e 4(36,4\%) do GP e $4(50,0 \%)$ do GC utilizavam ônibus. Nenhuma correlação foi encontrada entre o meio de locomoção utilizado na rotina de trabalho dos 
profissionais de enfermagem e o desenvolvimento e/ou agravamento da lombalgia.

O tempo médio de duração do trajeto casa-trabalho entre os funcionários do GP foi de 23,18 $( \pm 23,05)$ minutos com valores variando entre 10 e 90 minutos. Entre os participantes do GC, esse valor foi de $25,63( \pm 14,74)$ com valores variando entre 10 e 50 minutos. O tempo médio dos grupos foi de $24,21( \pm 19,53)$ minutos, tendo sua variação num intervalo entre 10 e 90 minutos.

Em se tratando das posturas físicas mais adotadas na rotina de trabalho dos profissionais de enfermagem avaliados, teve-se como base um protocolo para registro de posturas corporais assumidas pelos trabalhadores de enfermagem durante as atividades laborais, segundo a posição do dorso e das pernas proposto e utilizado por Marziale (1995), o qual consta no formulário de dados pessoais (APÊNDICE C). Esse protocolo foi visualizado pelos participantes durante a pré avaliação no formulário de dados pessoais e foi solicitado que estes escolhessem e sinalizassem àquela ou àquelas posturas as quais assumiam com maior freqüência em suas rotinas diárias de trabalho.

Quanto às posturas adotadas pelos trabalhadores, observa-se na Tabela 3 que a maioria dos sujeitos oito (72,7\%) do GP e seis $(75,0 \%)$ do GC assumia mais de uma postura na realização de suas atividades laborais. Dentre as posturas adotadas pelos participantes, quatro foram mais citadas: inclinado em pé parado (estática), inclinado em pé andando (dinâmica), inclinado sentado e torcido (estática) e em pé parado (estática). Têm-se, desta forma, que a 
maioria das posturas adotadas nas rotinas de trabalho por esses trabalhadores são estáticas.

Andrusaitis et al., (2006) relataram que a manutenção de posturas estáticas por longos períodos, a elevação de objetos pesados, as inclinações e as torções do tronco podem causar lombalgia. Esta queixa, assim como outros desconfortos causados na coluna vertebral também podem ser desencadeados por prolongada flexão da coluna vertebral, forçando o núcleo pulposo posteriormente, comprimindo o ligamento longitudinal e algumas raízes nervosas (PONTE, 2005).

Smith; Weiss; Lehmkuhl, (1997) definem postura como sendo uma posição ou atitude do corpo ao submeter algumas partes do mesmo à determinada atividade específica, ou uma maneira característica de sustentar o próprio corpo. O corpo pode assumir muitas posturas buscando melhor conforto quando ocorre um desconforto postural por contração muscular contínua, tensão, compressão ligamentar ou oclusão circulatória, normalmente procura-se uma nova atitude postural. Quando não se alteram tais posições podem ocorrer lesões teciduais, limitação de movimentos, deformidades ou encurtamentos musculares restringindo as atividades de vida diária.

Segundo Anjos (2008), o comportamento postural adotado pelos trabalhadores é motivado pela fuga do desconforto, contudo esta atitude tende a aumentar a solicitação e o gasto energético de grupos musculares desnecessários causando o desenvolvimento de sintomas como dor, formigamento, câimbras, entre outros. A adaptação muscular no padrão postural refere-se à capacidade dos músculos de se adaptarem às funções que vivenciam. 
Lima (2005) constata que nenhuma postura de trabalho é neutra. Nenhuma "má postura" é adotada "livremente" pelo sujeito, mas é resultado de um conjunto de fatores que se combinam para que o indivíduo adote posturas inadequadas, tais como mobiliário inadequado, descondicionamento físico do indivíduo, condições ergonômicas do ambiente inadequadas, dentre outras.

Uma postura inadequada causa tensões mecânicas nos músculos, ligamentos e articulações, resultando em dores no pescoço, costas, ombros, punhos e outras partes do sistema musculoesquelético (DUL; WEERDMEESTER, 1995).

Constata-se na Tabela 3 que apenas uma postura adotada na rotina de trabalho era sentada, sendo esta, inclinado sentado. A respeito da postura sentada, Rio (1999) comenta que, mesmo seguindo todas as orientações para posicionamento dos seguimentos corporais de forma adequada, como apoiar antebraços, posicionar costas e membros inferiores, essa postura acarreta uma carga biomecânica significativa sobre os discos intervertebrais, principalmente na região lombar, e quando o trabalho possibilita pouca margem para a movimentação, estabelece-se, como conseqüência, uma carga estática sobre certos segmentos corporais que, embora não intensa, mas contínua e associada à inércia musculoligamentar pode provocar fadiga. Reis; Moro; Contijo, (2003) afirmam que esta postura tem o agravante do mobiliário inadequado, principalmente quando este não apresenta as condições antropométricas ideais para o usuário.

Observa-se que três posturas em pé são adotadas, sendo elas: inclinado em pé parado (estática), inclinado em pé andando (dinâmica) e torcido em pé parado (estática). Nascimento e Ennes (2009) relataram que estudos 
realizados a respeito das posturas laborais adotadas demonstraram que inclinações anteriores de tronco ou torções do mesmo devido às exigências de tarefas laborais acarretam um aumento de mais de $30 \%$ de carga sobre os discos intervertebrais.

Nas posturas inclinado em pé parado e torcido em pé parado, ambas estáticas, existem desvantagens com relação às posturas dinâmicas adotadas. Segundo Orofino (2004), a postura estática exige o trabalho da musculatura envolvida para a manutenção da postura referida provocando facilmente a fadiga muscular. Além disso, ocorre um aumento importante da pressão hidrostática sanguínea e dos líquidos tissulares nas veias dos membros inferiores favorecendo a formação de varizes e edemas em tornozelos.

\subsection{Incapacidade funcional devido à dor lombar}

O questionário Osweatry foi aplicado com a finalidade de identificar a incapacidade funcional para a dor lombar. A Tabela 4 apresenta as médias dos valores obtidos na aplicação do questionário Oswestry antes e após a intervenção nos dois grupos a partir dos escores brutos do instrumento. 
Tabela 4. Médias dos valores obtidos do Questionário Oswestry - incapacidade para a dor lombar - antes e após a intervenção a partir dos escores brutos do Instrumento. Ribeirão Preto - SP, 2010. $(n=19)$

\begin{tabular}{|c|c|c|c|c|c|}
\hline VARIÁVEIS & GRUPOS & $\begin{array}{l}\text { MÉDIA (DESVIO- } \\
\text { PADRÃO) }\end{array}$ & MEDIANA & MÍN-MÁX & $\mathbf{p}^{*}$ \\
\hline \multirow{2}{*}{$\begin{array}{l}\text { INCAPACIDADE } \\
\text { ANTES }\end{array}$} & GP & $25,45(11,97)$ & 26,00 & $2,00-46,00$ & \\
\hline & GC & $27,50(6,93)$ & 29,44 & $12,00-34,00$ & \\
\hline \multirow{2}{*}{$\begin{array}{l}\text { INCAPACIDADE } \\
\text { DEPOIS }\end{array}$} & GP & $6,54(5,14)$ & 6,00 & $2,00-20,00$ & \\
\hline & GC & $6,14(6,95)$ & 4,00 & $0,00-16,00$ & \\
\hline \multirow{2}{*}{$\begin{array}{l}\text { DIMINUIÇÃO DA } \\
\text { INCAPACIDADE } \\
\text { TOTAL (ESCORE } \\
\text { TOTAL) }\end{array}$} & GP & $18,91(10,17)$ & 18,00 & $-4,00-38,00$ & \multirow{2}{*}{0,56} \\
\hline & GC & $21,36(6,90)$ & 21,00 & $12,00-31,11$ & \\
\hline
\end{tabular}

${ }^{*}$ Teste $t$ de studant

Conforme a Tabela 4, pode-se visualizar que tanto no grupo controle (GC) como no grupo de intervenção com exercícios de Pilates (GP) houve um decréscimo da dor lombar de acordo com os escores brutos do questionário Oswestry, porém, a melhora da dor no o GC foi discretamente maior, o que fica demonstrado por meio da diferença entre as médias dos valores de dor antes e depois no GP $(25,45$ e 6,54$)$ e do GC $(27,50$ e 6,14$)$, traduzindo uma diferença menor (18.91) quando comparada à diferença do GC com $(21,36)$.

Gladwell et al., (2006) ao realizarem um estudo clínico randomizado controlado com 34 sujeitos, sendo 14 pertencentes ao grupo controle o qual foi acompanhado com uso de analgésicos e orientados a manter vida normal em suas atividades físicas regulares e 20 do grupo de intervenção com exercícios de Pilates tiveram como resultado que o Programa com exercícios de Pilates proporcionou aos seus participantes uma melhora significativa da dor lombar 
quando comparados ao GC. Todos os outros parâmetros comparados obtiveram melhora significativa quando comparados ao GC como propriocepção e flexibilidade.

Outro estudo realizado com o objetivo de avaliar a influência da dor durante uma caminhada através da reação de força em uma plataforma vertical (VGRF) em pacientes com lombalgia e o efeito do método Pilates na maneira de caminhar desses pacientes, Pilates mostrou-se satisfatório ao reeducar a marcha através da estabilização lombar e reduzir significativamente a dor quando comparado ao grupo controle, pois pacientes com lombalgia podem adotar formas de caminhar inadequadas devido a dor (FONSECA; MAGNI; FREITAS, 2009).

Em se tratando da presente pesquisa, o grupo controle também foi submetido a um protocolo de exercícios físicos, sendo este de exercícios de alongamento e fortalecimento gerais. Houve melhora da dor em ambos os grupos, não evidenciando a melhora significativa dos exercícios baseados no método Pilates. Este resultado pode estar relacionado ao fato de ter ocorrido duas intervenções com atividades físicas direcionadas ao fortalecimento de extensores e estabilizadores de tronco, o que evidentemente, embora tecnicamente diferentes, as intervenções mostraram-se efetivas para a dor lombar.

Segundo Kolyniak, (2004), o desequilíbrio entre a função dos músculos extensores e flexores do tronco é um forte indício para o desenvolvimento de distúrbios da coluna lombar. Atualmente, evidências sugerem que é imprescindível a inclusão de exercícios voltados para o fortalecimento dos músculos envolvidos na flexão e extensão do tronco nos programas de 
prevenção e reabilitação da lombalgia (FLORY et al., 1993 e RISSANEN et al., 1995).

A Tabela 5 apresenta a distribuição dos profissionais de enfermagem participantes do estudo segundo os escores do questionário Oswestry incapacidade para a dor lombar antes e após a intervenção.

Tabela 5. Distribuição dos profissionais de enfermagem participantes do estudo segundo os escores do questionário Oswestry - incapacidade para a dor lombar antes e após a intervenção nos dois grupos. Ribeirão Preto - SP, 2010. $(\mathrm{n}=19)$

\begin{tabular}{lcc}
\hline \hline CATEGORIAS & \multicolumn{2}{c}{ GRUPOS DE INTERVENÇÃO } \\
Pilates $(\boldsymbol{n}=\mathbf{1 1})$ & $\begin{array}{c}\text { Controle }(\boldsymbol{n}=\mathbf{8}) \\
\text { DOR LOMBAR TOTAL ANTES }\end{array}$ & $\mathbf{n}(\%)$ \\
Incapacidade mínima (0 a 20) & $4(36,4)$ & $1(12,5)$ \\
Incapacidade moderada (21 a 40) & $6(54,50)$ & $7(87,5)$ \\
Incapacidade severa (41 a 60) & $1(9,10)$ & $\mathbf{n}(\%)$ \\
DoR LOMBAR TOTAL DEPOIS & $\mathbf{n}(\%)$ & $8(100)$ \\
Incapacidade mínima (0 a 20) & $11(100)$ & \\
\hline \hline
\end{tabular}

O questionário Oswestry para avaliação da incapacidade funcional em indivíduos com lombalgia é um instrumento dividido em dez escalas (ANEXO B) designadas a avaliar limitações em diversas atividades de vida diária como cuidados pessoais, levantar, andar, sentar e viajar. Cada item contido em cada 
escala (cada escala contém seis itens) pode ser pontuado de 0 (zero) a 5 (cinco) pontos com valores mais altos representando as maiores deficiências (WALSH et al., 2008).

Segundo Nordin; Alexandre; Campello, (2003), o valor total (a soma de todas as escalas) é exprimido em percentual o que permite classificar a condição do indivíduo em quatro categorias, sendo três delas representadas na tabela 5: deficiência mínima (de 0 a 20\%), deficiência moderada (de 21 a 40\%), deficiência severa (de 41 a $60 \%$ ) e deficiência total (61 a 100\%), pacientes que são severamente limitados pela dor em diversas atividades de vida diária, situação essa não representada por nenhum voluntário na presente pesquisa.

Neste estudo, a maioria dos participantes, de ambos os grupos, foram categorizados dentro da incapacidade moderada antes da intervenção, sendo $54,50 \%$ dos participantes do GP e $87,50 \%$ do GC. Após a intervenção, todos os participantes migraram para a categoria de menor deficiência (deficiência mínima), o que ratifica a melhora da dor lombar em ambos os grupos.

As Tabelas 6 e 7 apresentam a distribuição dos profissionais de enfermagem participantes do estudo segundo os itens das 10 escalas que contem o questionário Oswestry antes e após a intervenção. Ribeirão Preto SP, 2010. $(n=19)$ 
Tabela 6- Distribuição dos profissionais de enfermagem participantes do estudo segundo os itens das 5 primeiras escalas contidas no questionário Oswestry (dor, cuidados pessoais, levantar objetos, caminhar e sentar) antes e após a intervenção nos dois grupos. Ribeirão Preto - SP, 2010. $(n=19)$

\begin{tabular}{|c|c|c|c|}
\hline $\begin{array}{l}\text { ESCALAS DO } \\
\text { OSWESTRY }\end{array}$ & $\begin{array}{l}\text { ITENS } \\
n=19\end{array}$ & $\begin{array}{l}\text { ANTES } \\
\text { n (\%) }\end{array}$ & $\begin{array}{l}\text { DEPOIS } \\
\text { n (\%) }\end{array}$ \\
\hline \multirow{6}{*}{ DOR } & Não sinto dor no momento & $2(10,5)$ & $11(57,9)$ \\
\hline & A dor é muito leve no momento. & $4(21,1)$ & $7(36,8)$ \\
\hline & A dor é moderada no momento. & $8(42,1)$ & $1(5,3)$ \\
\hline & A dor é razoavelmente intensa no momento & $4(21,1)$ & 0 \\
\hline & A dor é muito intensa no momento & $1(5,3)$ & 0 \\
\hline & A dor é a pior que se pode imaginar no momento & 0 & 0 \\
\hline \multirow{6}{*}{$\begin{array}{l}\text { CUIDADOS } \\
\text { PESSOAIS }\end{array}$} & $\begin{array}{l}\text { Posso cuidar de mim mesmo normalmente sem que isso aumente } \\
\text { a dor }\end{array}$ & $7(36,8)$ & $18(94,7)$ \\
\hline & Posso cuidar de mim mesmo normalmente, mas sinto muita dor & $9(47,4)$ & $1(5,3)$ \\
\hline & $\begin{array}{l}\text { Sinto dor ao cuidar de mim mesmo e faço isso lentamente e com } \\
\text { cuidado }\end{array}$ & $3(15,8)$ & 0 \\
\hline & $\begin{array}{l}\text { Necessito de alguma ajuda, porém consigo fazer a maior parte dos } \\
\text { meus cuidados pessoais }\end{array}$ & 0 & 0 \\
\hline & $\begin{array}{l}\text { Necessito de ajuda diária na maioria dos aspectos de meus } \\
\text { cuidados pessoais }\end{array}$ & 0 & 0 \\
\hline & Não consigo me vestir, lavo-me com dificuldade e permaneço na cama & 0 & 0 \\
\hline \multirow{6}{*}{$\begin{array}{l}\text { LEVANTAR } \\
\text { OBJETOS }\end{array}$} & Consigo levantar objetos pesados sem aumentar a dor & $1(5,3)$ & $11(57,9)$ \\
\hline & Consigo levantar objetos pesados, mas isso aumenta a dor & $6(31,6)$ & $4(21,1)$ \\
\hline & $\begin{array}{l}\text { A dor me impede de levantar objetos pesados do chão, mas } \\
\text { consigo levantá-los se estiverem convenientemente } \\
\text { posicionados, por exemplo, sobre uma mesa }\end{array}$ & $8(42,1)$ & $2(10,5)$ \\
\hline & $\begin{array}{l}\text { A dor me impede de levantar objetos pesados, mas consigo levantar } \\
\text { objetos leves a moderados, se estiverem convenientemente } \\
\text { posicionados }\end{array}$ & $3(15,8)$ & $2(10,5)$ \\
\hline & Consigo levantar apenas objetos muito leves & $1(5,3)$ & 0 \\
\hline & Não consigo levantar ou carregar absolutamente nada & 0 & 0 \\
\hline \multirow{6}{*}{ CAMINHAR } & A dor não me impede de caminhar qualquer distância & $9(47,4)$ & $18(94,7)$ \\
\hline & $\begin{array}{l}\text { A dor me impede de caminhar mais de } 1.600 \text { metros } \\
\text { (aproximadamente } 16 \text { quarteirões de } 100 \text { metros). }\end{array}$ & $4(21,1)$ & $1(5,3)$ \\
\hline & $\begin{array}{l}\text { A dor me impede de caminhar mais de } 800 \text { metros } \\
\text { (aproximadamente } 8 \text { quarteirões de } 100 \text { metros). }\end{array}$ & $5(26,3)$ & 0 \\
\hline & $\begin{array}{l}\text { A dor me impede de caminhar mais de } 400 \text { metros (aproximadamente } \\
4 \text { quarteirões de } 100 \text { metros). }\end{array}$ & $1(5,3)$ & 0 \\
\hline & Só consigo andar usando uma bengala ou muletas. & 0 & 0 \\
\hline & $\begin{array}{l}\text { Fico na cama a maior parte do tempo e preciso me arrastar para ir ao } \\
\text { banheiro. }\end{array}$ & 0 & 0 \\
\hline \multirow{6}{*}{ SENTAR } & $\begin{array}{l}\text { Consigo sentar em qualquer tipo de cadeira durante o tempo que } \\
\text { quiser. }\end{array}$ & $1(5,3)$ & $7(36,8)$ \\
\hline & $\begin{array}{l}\text { Consigo sentar em uma cadeira confortável durante o tempo que } \\
\text { quiser }\end{array}$ & $5(26,3)$ & $9(47,4)$ \\
\hline & A dor me impede de ficar sentado por mais de 1 hora & $10(52,6)$ & $3(15,8)$ \\
\hline & A dor me impede de ficar sentado por mais de meia hora. & $2(10,5)$ & 0 \\
\hline & A dor me impede de ficar sentado por mais de 10 minutos. & $1(5,3)$ & 0 \\
\hline & A dor me impede de sentar. & 0 & 0 \\
\hline
\end{tabular}


Tabela 7- Distribuição dos profissionais de enfermagem participantes do estudo segundo os itens das 5 últimas escalas contidas no Questionário Oswestry (ficar em pé, dormir, vida sexual, vida social e locomoção) antes e após a intervenção nos dois grupos. Ribeirão Preto - SP, 2010. $(n=19)$

\begin{tabular}{|c|c|c|c|}
\hline $\begin{array}{l}\text { ESCALAS DO } \\
\text { OSWESTRY }\end{array}$ & $\begin{array}{l}\text { ITENS } \\
\mathrm{n}=19\end{array}$ & $\begin{array}{l}\text { ANTES } \\
\text { n (\%) }\end{array}$ & $\begin{array}{l}\text { DEPOIS } \\
\text { n (\%) }\end{array}$ \\
\hline \multirow{6}{*}{$\begin{array}{l}\text { FICAR } \\
\text { EM PÉ }\end{array}$} & Consigo ficar em pé o tempo que quiser sem aumentar a dor. & $1(5,3)$ & $10(52,6)$ \\
\hline & $\begin{array}{l}\text { Consigo ficar em pé durante o tempo que quiser, mas isso aumenta a } \\
\text { dor. }\end{array}$ & $13(68,4)$ & $9(47,4)$ \\
\hline & A dor me impede de ficar em pé por mais de 1 hora. & $2(10,5)$ & 0 \\
\hline & A dor me impede de ficar em pé por mais de meia hora. & $3(15,8)$ & 0 \\
\hline & A dor me impede de ficar em pé por mais de 10 minutos. & 0 & 0 \\
\hline & A dor me impede de ficar em pé. & 0 & 0 \\
\hline \multirow{6}{*}{ DORMIR } & Meu sono nunca é perturbado pela dor. & $1(5,3)$ & $13(68,4)$ \\
\hline & Meu sono é ocasionalmente perturbado pela dor. & $14(73,7)$ & $6(31,6)$ \\
\hline & Durmo menos de 6 horas por causa da dor. & $3(15,8)$ & 0 \\
\hline & Durmo menos de 4 horas por causa da dor. & $1(5,3)$ & 0 \\
\hline & Durmo menos de 2 horas por causa da dor. & 0 & 0 \\
\hline & A dor me impede totalmente de dormir. & 0 & 0 \\
\hline \multirow{6}{*}{$\begin{array}{l}\text { *VIDA } \\
\text { SEXUAL }\end{array}$} & Minha vida sexual é normal e não aumenta minha dor. & $6(31,6)$ & $16(84,2)$ \\
\hline & Minha vida sexual é normal, mas causa um pouco mais de dor. & $10(52,6)$ & $1(5,3)$ \\
\hline & Minha vida sexual é quase normal, mas causa muita dor. & $1(5,3)$ & 0 \\
\hline & Minha vida sexual é severamente limitada pela dor. & 0 & 0 \\
\hline & Minha vida sexual é quase ausente por causa da dor. & 0 & 0 \\
\hline & A dor me impede de ter uma vida sexual. & 0 & 0 \\
\hline \multirow{6}{*}{ VIDA SOCIAL } & Minha vida social é normal e não aumenta a dor. & $5(26,3)$ & $18(94,7)$ \\
\hline & Minha vida social é normal, mas aumenta a dor. & $4(21,1)$ & $1(5,3)$ \\
\hline & $\begin{array}{l}\text { A dor não tem nenhum efeito significativo na minha vida social, } \\
\text { porém limita alguns interesses que demandam mais energia, } \\
\text { como por exemplo, esporte, etc. }\end{array}$ & $8(42,1)$ & 0 \\
\hline & $\begin{array}{l}\text { A dor tem restringido minha vida social e não saio de casa com tanta } \\
\text { freqüência. }\end{array}$ & $2(10,5)$ & 0 \\
\hline & A dor tem restringido minha vida social ao meu lar. & 0 & 0 \\
\hline & Não tenho vida social por causa da dor. & 0 & 0 \\
\hline \multirow{6}{*}{ LOCOMOÇÃO } & Posso ir a qualquer lugar sem sentir dor. & $2(10,5)$ & $18(94,7)$ \\
\hline & Posso ir a qualquer lugar, mas isso aumenta a dor. & $13(68,4)$ & $1(5,3)$ \\
\hline & A dor é intensa, mas consigo me locomover durante 2 horas. & $3(15,8)$ & 0 \\
\hline & A dor restringe-me a locomoções de menos de 1 hora. & $1(5,3)$ & 0 \\
\hline & $\begin{array}{l}\text { A dor restringe-me a pequenas locomoções necessárias de } \\
\text { menos de } 30 \text { minutos. }\end{array}$ & 0 & 0 \\
\hline & A dor impede de locomover-me, exceto para receber tratamento. & 0 & 0 \\
\hline
\end{tabular}


Como foi observado melhora da dor lombar tanto no GP como no GC, os resultados apresentados foram da amostra inteira $(n=19)$. Observa-se nas Tabelas 6 e 7 que em todas as classes avaliadas pelo instrumento Oswestry (dor, cuidados pessoais, levantar objetos, caminhar, sentar, ficar em pé, dormir, vida sexual, vida social e locomoção) houve melhora em todos os itens avaliados; os sujeitos mostraram-se mais hábeis ou menos incapacitados para a realização dessas atividades após as intervenções.

Segundo Salvetti, (2010), incapacidade quando relacionada à dor crônica pode ser definida pela dificuldade ou impossibilidade de realização de tarefas e atividades em função da dor. Essas tarefas, as quais foram citadas anteriormente, podem estar prejudicadas ou mesmo inviabilizadas em função da dor. Wittink (2005) afirma que incapacidade é um termo "guarda-chuva" para prejuízos, limitações de atividades e restrições na participação. Para Leeuw et al., (2007), a incapacidade relacionada à dor refere-se aos problemas em executar tarefas da vida diária e atividades nas situações de casa e do trabalho.

Atualmente, a Classificação Internacional de Funcionalidade (CIF), Incapacidade e Saúde da Organização Mundial da Saúde (OMS) é utilizada para padronizar os termos na área da saúde e a incapacidade é compreendida como uma resultante da interação entre a disfunção apresentada pelo indivíduo (seja orgânica e/ou da estrutura do corpo), a limitação de suas atividades e a restrição na participação social, envolvendo os fatores ambientais que podem atuar como facilitadores ou barreiras para o desempenho e participação nessas atividades (WHO, 2002; FARIAS, BUCHALLA, 2009). 
Constatou-se, de acordo com o Oswestry, a melhora da incapacidade em $100 \%$ dos avaliados quando comparados aos escores antes e após as intervenções. Acredita-se que a atividade física orientada, supervisionada e direcionada para a dor lombar, conforme realizado nesse estudo e aplicada nos dois grupos por meio dos dois protocolos, pôde trazer benefícios analgésicos para os portadores dessa moléstia osteomuscular.

\subsubsection{Relação da incapacidade funcional devido à dor lombar com as posturas adotadas nas rotinas de trabalho.}

As Tabela 8 e 9 apresentam uma descrição intra e inter grupos das variáveis incapacidade funcional e o tipo de postura predominante adotado na rotina de trabalho diário antes e após a intervenção.

Tabela 8 - Associação intra grupos das variáveis incapacidade funcional e o tipo de postura predominante adotado na rotina de trabalho diário antes e após a intervenção. Ribeirão Preto - SP, 2010. $(n=19)$

\begin{tabular}{|c|c|c|c|c|c|c|c|c|c|c|}
\hline GRUPO & POSTURA & $\mathbf{N}$ & OSWESTRY & MÉDIA & DP & MINIMO & $\begin{array}{c}1^{\circ} \\
\text { QUARTIL }\end{array}$ & MEDIANA & $\begin{array}{c}3^{\circ} \\
\text { QUARTIL }\end{array}$ & MÁXIMO \\
\hline \multirow{4}{*}{ GP } & \multirow{2}{*}{ ESTÁTICA } & \multirow{2}{*}{9} & antes & 24,00 & 10,44 & 2,00 & 18,00 & 26,00 & 32,00 & 36,00 \\
\hline & & & depois & 6,89 & 5,49 & 2,00 & 4,00 & 6,00 & 8,00 & 20,00 \\
\hline & \multirow{2}{*}{ DINÂMICA } & \multirow{2}{*}{2} & antes & 31,00 & 21,21 & 16,00 & 16,00 & 31,00 & 46,00 & 46,00 \\
\hline & & & depois & 5,00 & 4,24 & 2,00 & 2,00 & 5,00 & 8,00 & 8,00 \\
\hline \multirow{4}{*}{ GC } & \multirow{2}{*}{ ESTÁTICA } & \multirow{2}{*}{2} & antes & 30,44 & 2,21 & 28,88 & 28,88 & 30,44 & 32,00 & 32,00 \\
\hline & & & depois & 12,56 & 2,04 & 11,11 & 11,11 & 12,56 & 14,00 & 14,00 \\
\hline & \multirow{2}{*}{ DINÂMICA } & \multirow{2}{*}{6} & antes & 26,52 & 7,85 & 12,00 & 24,00 & 29,00 & 31,10 & 34,00 \\
\hline & & & depois & 4,00 & 6,69 & 0,00 & 0,00 & 0,00 & 8,00 & 16,00 \\
\hline
\end{tabular}


Constata-se que, em ambos os grupos (GP e GC), todos os trabalhadores que adotavam posturas dinâmicas em suas rotinas de trabalho tiveram melhora mais acentuada da incapacidade funcional quando comparados àqueles que permanecem em posturas estáticas, sendo assim, constata-se que as posturas de trabalho adotadas no dia-dia puderam colaborar com a melhora da dor após a intervenção.

Tabela 9- Correlação entre as variáveis incapacidade funcional e o tipo de postura predominante adotado na rotina de trabalho diário antes e após a intervenção. Ribeirão Preto - SP, 2010. $(n=19)$

\begin{tabular}{|c|c|c|c|c|c|c|c|c|}
\hline Postura & Variável & Média & DP & Mediana & Mínimo & Máximo & $\begin{array}{l}\text { Diferença } \\
\text { entre } \\
\text { médias }\end{array}$ & $\begin{array}{l}{ }^{*} p- \\
\text { valor }\end{array}$ \\
\hline Estática & $\begin{array}{l}\text { Incapacidade } \\
\text { antes }\end{array}$ & 25,17 & 9,72 & 28,88 & 2,00 & 36,00 & \multirow[b]{2}{*}{$-2,47$} & \multirow[b]{2}{*}{0,61} \\
\hline Dinâmica & $\begin{array}{l}\text { Incapacidade } \\
\text { antes }\end{array}$ & 27,64 & 10,61 & 29,00 & 12,00 & 46,00 & & \\
\hline Estática & $\begin{array}{c}\text { Incapacidade } \\
\text { depois }\end{array}$ & 7,92 & 5,46 & 8,00 & 2,00 & 20,00 & \multirow[b]{2}{*}{3,67} & \multirow[b]{2}{*}{0,18} \\
\hline Dinâmica & $\begin{array}{l}\text { Incapacidade } \\
\text { depois }\end{array}$ & 4,25 & 5,90 & 1,00 & 0,00 & 16,00 & & \\
\hline
\end{tabular}

${ }^{*}$ Teste $t$ de studant

Como mostra a Tabela 9, em se tratando dos voluntários que adotavam posturas estáticas e dinâmicas em suas rotinas de trabalho, embora tenham apresentado melhora clínica geral após a intervenção, àqueles que adotavam posturas dinâmicas em suas funções diárias de trabalho, apresentaram menor incapacidade após a reavaliação, mas essa melhora não mostrou-se significativa. Embora tenha ocorrido uma melhora clínica, o valor de "p" após a intervenção era de 0,18 ( $p>0,05)$, considerado não significativo estatisticamente. 
O gráfico 1- correlaciona as variáveis incapacidade funcional para a dor lombar com as posturas predominantemente adotadas nas rotinas de trabalho dos profissionais de enfermagem.

Gráfico 1- Correlação entre as variáveis incapacidade funcional e postura predominante na rotina de trabalho diário. Ribeirão Preto - SP, 2010. $(n=19)$
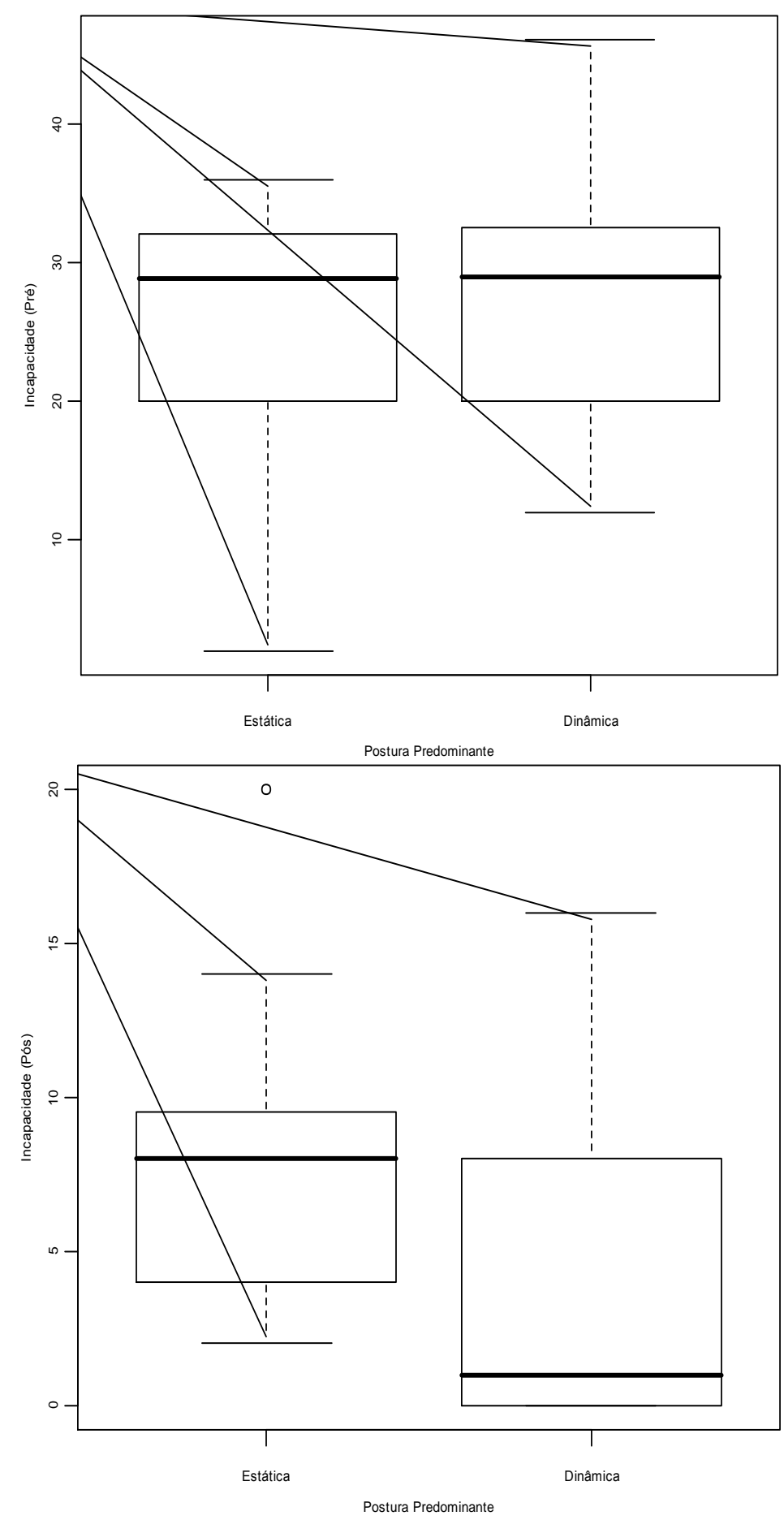
Para qualquer postura assumida, há pressão interna sobre os discos intervertebrais da coluna vertebral e de acordo com o pesquisador sueco Nachemson (1999), essa pressão se modifica em diferentes posições do corpo. O referido autor relata que quando o indivíduo está sentado, a pressão nos discos intervertebrais é maior que na postura em pé, explicado pela rotação posterior da bacia, provocando uma alteração na biomecânica da coluna vertebral, produzindo uma cifose da região lombar, conduzindo a um aumento da pressão nos discos intervertebrais da coluna lombar. Kendall (1995) afirma que os padrões culturais e o estilo de vida da população moderna propiciam sobrecargas estruturais no corpo humano, impondo cada vez mais atividades especializadas e limitadas. Em se tratando das posturas estáticas, estas devem ser evitadas segundo Alencar (2001), pois exigem contrações contínuas de alguns grupos musculares para a manutenção de uma determinada postura.

Quando o trabalho em uma postura estática não tem como ser evitado, as estruturas musculotendíneas e ligamentares podem ser aliviadas por meio de mudanças das posturas, melhora do posicionamento do mobiliário e das ferramentas ou providenciando apoios para as partes do corpo com o objetivo de reduzir as contrações estáticas dos músculos. Pausas de curta duração também devem ser concedidas com maior freqüência para permitir o relaxamento muscular e alívio da fadiga (LIDA, 1995).

Em se tratando das posturas dinâmicas, estudos epidemiológicos e biomecânicos sugerem que atividades dinâmicas também estão relacionadas com o risco de lombalgias, especialmente quando associadas com tarefas que exigem velocidades nos movimentos de inclinação lateral e rotações do tronco 
(GRANATA; MARRAS, 1993, 1995). Em um estudo epidemiológico realizado por Kumar e Narayan, (1998) com um grupo de trabalhadores, as posturas em rotação de tronco constituíram o terceiro movimento mais comum do corpo em indivíduos que apresentam lombalgia.

Ao se analisar os movimentos dinâmicos e a força muscular, é necessário se levar em consideração a utilização dos membros superiores, visto que a mobilização dos mesmos conforme o ângulo utilizado pode promover interferência das articulações escápulo-torácica, acrômio-clavicular e esterno-costo-clavicular, o que pode favorecer ou dificultar o movimento pelo fato de interferir no sistema de alavancas (KAPANDJI, 1990).

Looze; Zinzen; Caboor, (1998) comentam que ter pouca força muscular é fator de risco para a lombalgia por apresentar redução da capacidade de resistir às cargas mecânicas. Sendo assim, Garg; Owen (1994) verificaram em seu estudo que programas de treinamento muscular têm evidenciado diminuição nas incidências de lombalgias em enfermeiras.

Em relação às posturas ostostáticas, onde observamos inclinação do tronco anteriormente, a coluna lombar tem pouca contribuição até $30^{\circ}$ de flexão, fato este de haver maior participação da coluna torácica nesse movimento. Quando o tronco é flexionado de 30 a $60^{\circ}$, a coluna lombar atua ativamente nessa angulação de movimento, principalmente de L1 a L3. Flexões de tronco com amplitudes maiores que $60^{\circ}$ exigem participação, predominantemente do quadril, tendo sua contribuição nos últimos $30^{\circ}$ de flexão (CHENG, 2000). 


\subsection{Amplitude de movimento articular}

A Tabela 10 apresenta as médias das amplitudes de movimentos articulares mensuradas nos profissionais de enfermagem participantes do estudo antes e após as intervenções. Ribeirão Preto - SP, 2010. ( $n=19)$

Tabela 10 - Médias das amplitudes de movimentos articulares mensuradas nos profissionais de enfermagem participantes do estudo antes e após as intervenções. Ribeirão Preto - SP, 2010. $(n=19)$

\begin{tabular}{|c|c|c|c|c|c|c|}
\hline \multirow[t]{2}{*}{ VARIÁVEL } & \multicolumn{3}{|c|}{ GRUPO PILATES $(n=11)$} & \multicolumn{3}{|c|}{ GRUPO CONTROLE $(\mathrm{n}=8)$} \\
\hline & $\begin{array}{c}\text { MEDIA } \\
\text { (DESVIO } \\
\text { PADRÃO) }\end{array}$ & MEDIANA & $\begin{array}{l}\text { MíNIMO- } \\
\text { MÁXIMO }\end{array}$ & $\begin{array}{c}\text { MEDIA } \\
\text { (DESVIO } \\
\text { PADRÃO) }\end{array}$ & MEDIANA & $\begin{array}{l}\text { MíNIMO- } \\
\text { MÁXIMO }\end{array}$ \\
\hline $\begin{array}{l}\text { Flexo-extensão } \\
\text { da CC antes }\end{array}$ & $\begin{array}{c}87,55 \\
(31,41)\end{array}$ & 103,00 & $34-125$ & $\begin{array}{c}99,88 \\
(18,88)\end{array}$ & 108,00 & $60-115$ \\
\hline $\begin{array}{l}\text { Flexo-extensão } \\
\text { da CC depois }\end{array}$ & $\begin{array}{l}110,45 \\
(9,92)\end{array}$ & 108,00 & $96-130$ & $\begin{array}{l}114,25 \\
(14,94)\end{array}$ & 116,00 & $85-132$ \\
\hline $\begin{array}{l}\text { Flexo-extensão } \\
\text { do quadril } D \\
\text { antes }\end{array}$ & $\begin{array}{c}64,18 \\
(15,84)\end{array}$ & 66,00 & $35-90$ & $\begin{array}{c}66,00 \\
(10,41)\end{array}$ & 68,00 & $51-85$ \\
\hline $\begin{array}{l}\text { Flexo-extensão } \\
\text { do quadril } D \\
\text { depois }\end{array}$ & $\begin{array}{c}83,82 \\
(12,65)\end{array}$ & 82,00 & $65-110$ & $\begin{array}{c}79,38 \\
(12,97)\end{array}$ & 75,50 & $61-99$ \\
\hline $\begin{array}{l}\text { Flexo-extensão } \\
\text { do quadril E } \\
\text { antes }\end{array}$ & $\begin{array}{c}69,18 \\
(16,85)\end{array}$ & 70,00 & $46-100$ & $\begin{array}{c}72,63 \\
(10,45)\end{array}$ & 72,50 & $53-86$ \\
\hline $\begin{array}{l}\text { Flexo-extensão } \\
\text { do quadril E } \\
\text { depois }\end{array}$ & $\begin{array}{c}83,45 \\
(13,99)\end{array}$ & 80,00 & $62-111$ & $\begin{array}{c}78,00 \\
(14,97)\end{array}$ & 77,50 & $55-96$ \\
\hline $\begin{array}{l}\text { Flexo-extensão } \\
\text { de tronco } \\
\text { antes }\end{array}$ & $\begin{array}{l}113,73 \\
(31,38)\end{array}$ & 120,00 & $63-150$ & $\begin{array}{l}{ }^{*} 135,75 \\
(19,59)\end{array}$ & 137,00 & $103-158$ \\
\hline $\begin{array}{l}\text { Flexo-extensão } \\
\text { de tronco depois }\end{array}$ & $\begin{array}{l}163,27 \\
(23,85)\end{array}$ & 156,00 & $126-213$ & $\begin{array}{l}{ }^{*} 166,25 \\
(27,12)\end{array}$ & 168,50 & $121-205$ \\
\hline
\end{tabular}


De acordo com os dados da Tabela 10, verifica-se que todos os indivíduos participantes da pesquisa, os quais foram submetidos a um tipo de atividade física (convencional ou Pilates), obtiveram melhora nas variáveis mensuradas (flexibilidade de coluna cervical, flexão de quadril e flexo-extensão de tronco).

A manutenção dos níveis de flexibilidade é importante para a realização das tarefas do dia a dia, como calçar sapatos, subir escadas ou colocar e retirar objetos de prateleiras. Há evidências de que níveis elevados de flexibilidade associam-se significativamente com a diminuição dos episódios de lombalgia (UENO et al., 2000).

A flexibilidade, uma das principais variáveis da aptidão física relacionada à saúde e ao desempenho, é definida como sendo a amplitude máxima passiva fisiológica de um dado movimento articular (ARAÚJJ, 2004). Na presente pesquisa, optou-se em realizar todos os testes de flexibilidade articular ativamente, de forma que o avaliador não ultrapassasse a amplitude de movimento do avaliado e não houvesse interferência da força do avaliador sobre o avaliado; apenas o comando verbal era o incentivo para que o avaliado atingisse níveis máximos de amplitude articular.

A flexibilidade corporal varia em função da idade, do gênero e da prática de exercício físico regular (RUBINI; COSTA; GOMES, 2007). Segundo Dickinson (1968), a flexibilidade não se apresenta de modo uniforme nas diversas articulações e nos movimentos corporais, sendo comum, em um dado indivíduo que sua amplitude máxima seja boa para determinados movimentos e limitada para outros, representando o que se convencionou denominar especificidade da flexibilidade. 
Em ambos os grupos (GC e GP) havia indivíduos de sexos diferentes, faixas etárias diferentes e com flexibilidades diferentes. Tais aspectos, como gênero, idade e mobilidade articular individual, são características que também exercem influência na melhora ou aumento da flexibilidade individual e, não somente os aspectos laborais e álgicos analisados (GRAHAME, 2000; ARAÚJO; CHAVES, 2005; ABREU et al., 2007).

Embora o teste de flexibilidade seja, geralmente, utilizado como um exame semiológico com o intuito de determinar se o grau de movimento articular, permitido pelo comprimento do músculo esteja normal ou limitado (ALEXANDRE E MORAES, 2001), na presente pesquisa o teste foi utilizado como um parâmetro para avaliar a melhora da flexibilidade diante de um programa de exercícios físicos para a melhora da dor lombar.

Acredita-se que a melhora da flexibilidade de coluna cervical, quadril e tronco possam influenciar na melhora da dor lombar por realinhar as estruturas músculo-tendíneas e articulares e restabelecer a mobilidade de flexores e extensores de tronco (KENDALL, 1995).

O gráfico 2 correlaciona as variáveis incapacidade funciona devido a dor lombar e a flexibilidade de coluna cervical antes e após a intervenção. 
Gráfico 2- Dispersão e Correlação entre as variáveis incapacidade funcional e amplitude de flexo- extensão da coluna cervical antes e após a intervenção. Ribeirão Preto - SP, 2010. ( $n=19)$

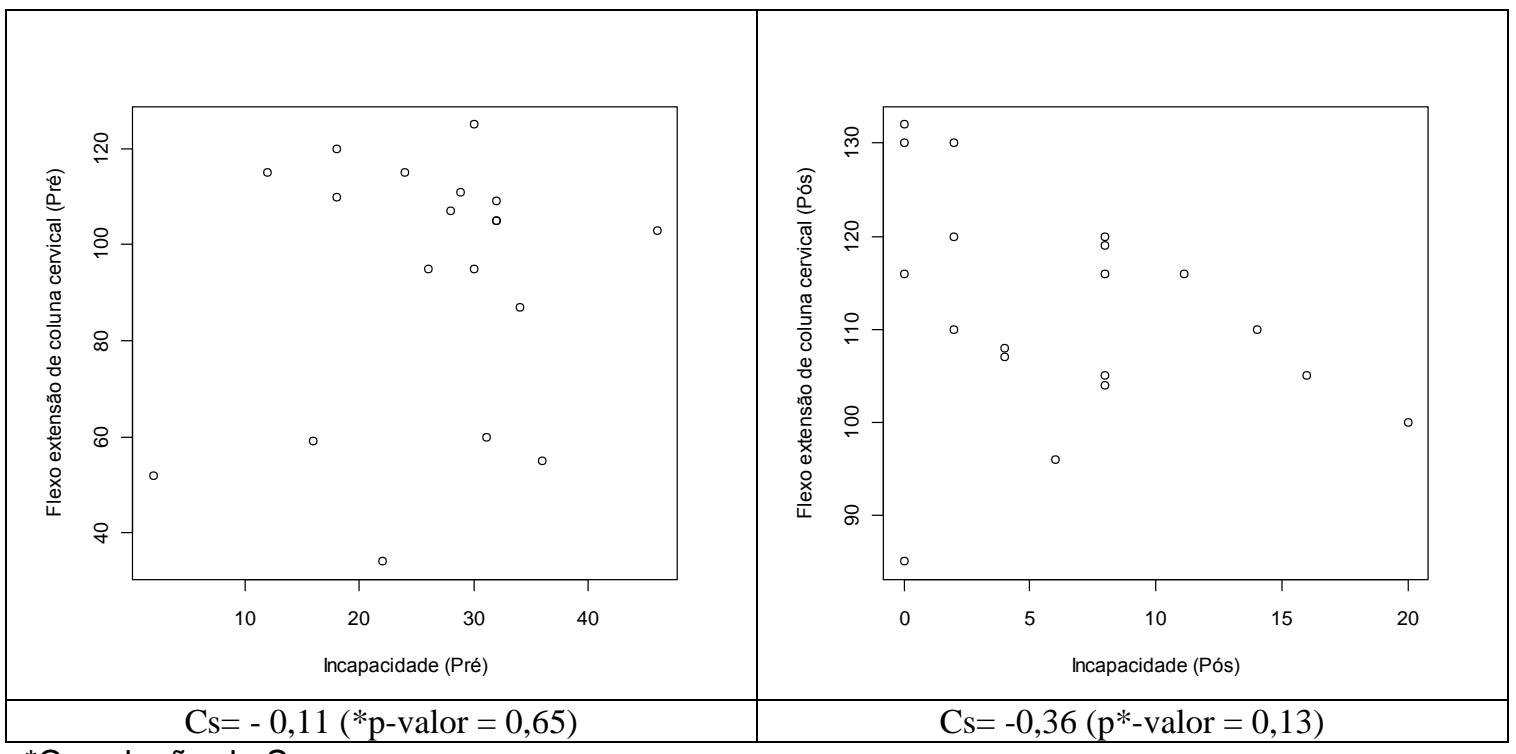

${ }^{*}$ Correlação de Spearman

O Gráfico 2 mostra que, embora tenha havido melhora clínica de amplitude de flexo-extensão da coluna cervical conforme foi mostrado na Tabela 10, não houve correlação significativa entre os valores de flexibilidade dessa região e da incapacidade antes e após a intervenção. Essa correlação pode ter sido fraca em função da amostra pequena.

O gráfico 3 correlaciona as variáveis incapacidade funcional devido a dor lombar e a flexibilidade do tronco antes e após a intervenção. 
Gráfico 3- Dispersão e correlação entre as variáveis incapacidade funcional e amplitude de flexo-extensão do tronco antes e após a intervenção. Ribeirão Preto - SP, 2010. $(n=19)$

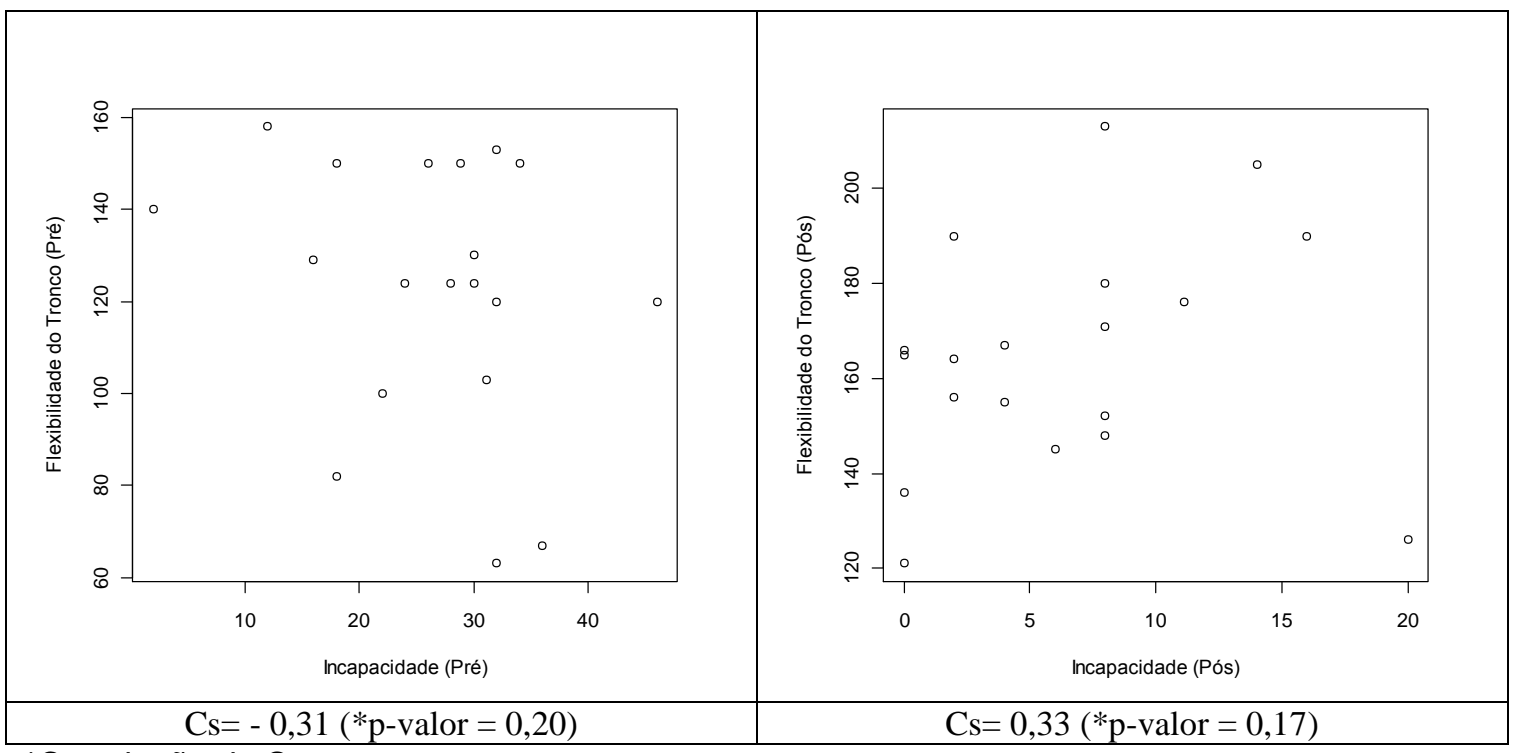

${ }^{*}$ Correlação de Spearman

O gráfico 3 mostra que assim como a correlação da incapacidade com a mobilidade de flexo-extensão de coluna cervical, a correlação realizada com a flexo-extensão de tronco não se mostrou significativa $(C s=0,33 ; p=0,17)$, embora tenha apresentado uma melhora clínica conforme mostra a tabela 10.

Numa análise realizada intra grupo, o GC apresentou uma melhora significativa da amplitude de tronco $(C s=0,91-p$-valor $<0,01)$ quando comparado aos valores anteriores à intervenção.

A Figura 36 apresenta os participantes do estudo e seus respectivos tempos de cumprimento do protocolo de exercícios. 
Figura 36- Participantes do estudo e seus respectivos tempos de cumprimento dos protocolos de exercícios. Ribeirão Preto - SP, 2010. $(n=19)$

\begin{tabular}{ccc}
\hline GRUPOS & VOLUNTÁRIO & $\begin{array}{c}\text { DURAÇÃO DO CUMPRIMENTO DAS } \\
\text { SESSÕES PROPOSTAS (DIAS) }\end{array}$ \\
& 1 & 131 \\
2 & 76 \\
3 & 160 \\
4 & 126 \\
5 & 87 \\
& 6 & 124 \\
GP & 7 & 96 \\
& 8 & 91 \\
9 & 158 \\
& 10 & 75 \\
11 & 105 \\
& 12 & 158 \\
& 13 & 75 \\
14 & 64 \\
15 & 62 \\
16 & 66 \\
& 17 & 66 \\
GC & 18 & 64 \\
& 19 & 66 \\
& & \\
& &
\end{tabular}

A Figura 36 mostra os voluntários participantes da pesquisa e seus respectivos tempos de cumprimento dos protocolos de exercícios propostos. Os indivíduos de 1 a 11 compõem o grupo pilates (GP) e do $12^{\circ}$ ao $19^{\circ}$ correspondem ao grupo controle (GC).

Segundo os critérios estabelecidos nesse estudo, os sujeitos da pesquisa não podiam apresentar três faltas consecutivas sob pena de serem retirados do estudo, sendo assim, por motivos não questionados alguns dos participantes faltavam duas sessões consecutivas e compareciam na próxima e faltavam mais duas, e, dessa forma, houve participantes que cumpriram suas 20 sessões em períodos mais longos quando comparados àqueles que eram assíduos. 
Em detrimento dessa variação considerável do tempo de cumprimento dos protocolos, a Figura 36 aponta àquele que levou mais tempo $\left(3^{\circ}\right.$ indivíduo do GP) e o que levou menos tempo ( $4^{\circ}$ indivíduo do GC) para o cumprimento das 20 sessões.

O gráfico 4 apresenta a correlação entre as variáveis incapacidade funcional e tempo de tratamento.

Gráfico 4- Correlação entre as variáveis incapacidade funcional e tempo de tratamento. Ribeirão Preto - SP, 2010. $(n=19)$

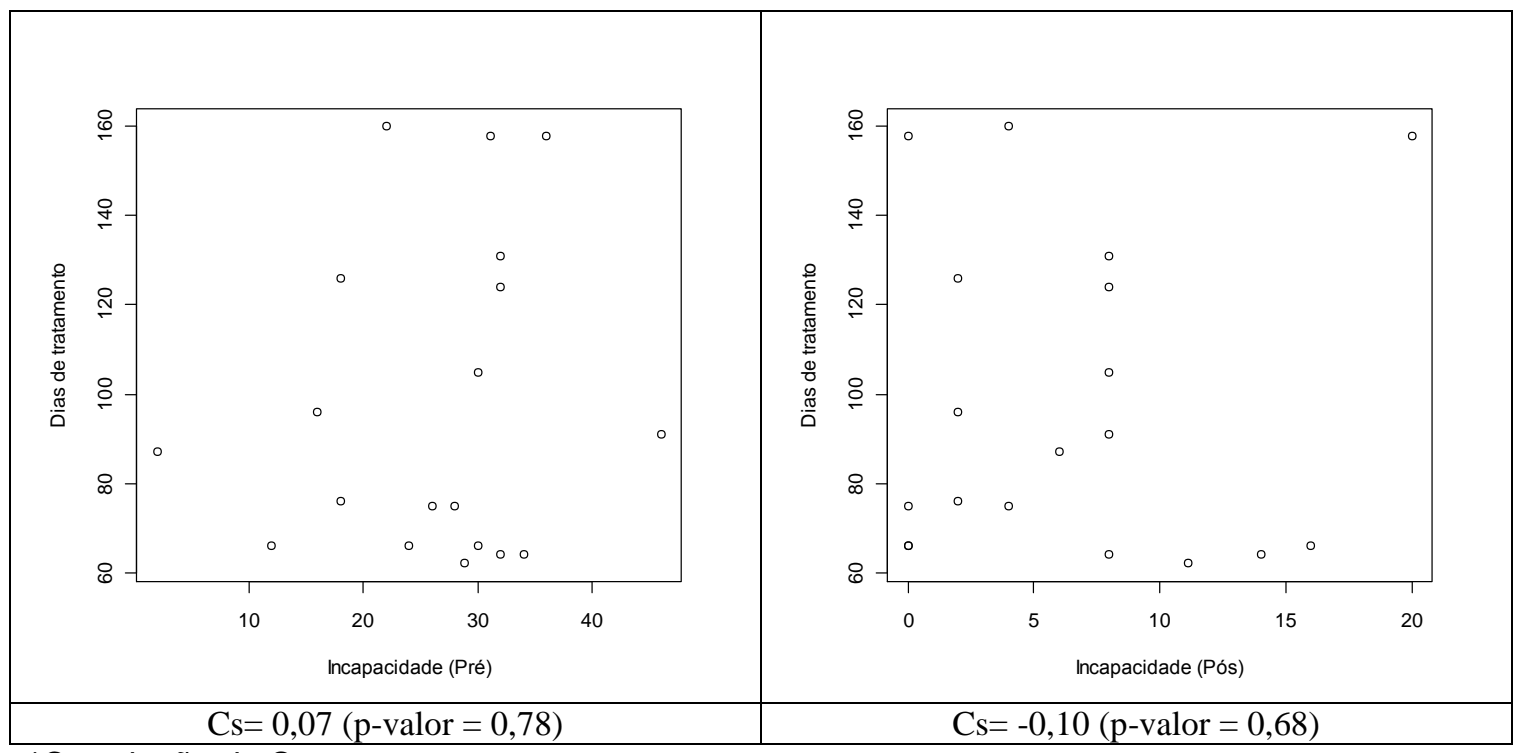

${ }^{\star}$ Correlação de Spearman

Numa análise realizada para averiguar se essa variação de tempo poderia estar interferindo na melhora da incapacidade devido a dor lombar nos participantes, o Gráfico 4 mostra a correlação entre a assiduidade dos trabalhadores e a melhora da incapacidade em função da dor lombar. O tempo levado por cada voluntário para a realização das 20 sessões, tanto no GP 
como no GC correlacionado com a melhora da incapacidade não apresentou uma significância estatística após o término do tratamento $(p=0,68)$, o que nos leva a inferir que, embora alguns indivíduos não tenham se mostrado assíduos durante a participação no estudo, essa irregularidade durante as sessões não comprometeu os resultados no que tange os aspectos apresentados pelo questionário Oswestry com relação à dor lombar.

A literatura é escassa com relação aos estudos sobre assiduidade em programas de exercícios. Os poucos estudos existentes são referentes a programas de exercícios para reabilitação cardiovascular. A maioria dos estudos faz comparações entre sujeitos ativos e sedentários, onde àqueles que praticam atividades físicas regulares apresentam melhor cognição e melhor resposta cardiovascular quando submetidos ao estresse (KREMER, 2002).

A participação em programas de exercício físico constitui um fenômeno complexo no qual intervêm diversos fatores tanto psicológicos como psicossociológicos. Assim, quando se discute os fatores que determinam a realização do exercício físico é necessário conhecer o tipo de população, o tipo de exercício e ainda, o momento em que se pratica (BLASCO, 1994).

Segundo o referido autor, alguns fatores, os quais considera, independente do tipo de exercício e população, são motivadores para a melhora da forma física, da manutenção da vida saudável, da melhora do aspecto físico, dentre outros. Para esse mesmo autor, se é possível identificar os fatores que induzem à inicialização e/ou à manutenção da prática do exercício físico, também se pode distinguir àqueles que conduzem ao abandono. Esses fatores podem ser naturais (disponibilidade de tempo, 
instalações, percepção de bem ou mal estar) ou artificiais (estratégias criadas propositadamente para a iniciação ou manutenção da prática).

Percebeu-se que, neste estudo, o local da prática não se mostrou um fator indutor de motivação e que, embora a intervenção tenha sido realizada dentro do horário de trabalho, para que não houvesse desistências, alguns funcionários aproveitavam esse período para realizar outras atividades, como ir ao banco e resolver problemas pessoais.

Um dos aspectos observados neste estudo é que alguns indivíduos sedentários que iniciaram a atividade, tanto do GC quanto do GP para melhorar sua condição física (dor lombar), abandonam-na quando começaram a não sentir mais o incômodo da dor.

\subsection{Força Muscular de glúteo máximo}

A tabela 11 indica as médias das forças musculares mensuradas nos profissionais de enfermagem participantes do estudo antes e após as intervenções .

Tabela 11 - Médias das forças musculares mensuradas nos profissionais de enfermagem participantes do estudo antes e após as intervenções. Ribeirão Preto - SP, 2010. $(n=19)$

\begin{tabular}{|c|c|c|c|c|c|c|c|c|}
\hline \multirow[b]{2}{*}{ VARIÁVEL } & \multicolumn{4}{|c|}{ GRUPO PILATES $(n=11)$} & \multicolumn{4}{|c|}{ GRUPO CONTROLE $(n=8)$} \\
\hline & MÉDIA & $\begin{array}{c}\text { DESVIO } \\
\text { PADRÃOO }\end{array}$ & MEDIANA & $\begin{array}{l}\text { MINIMO- } \\
\text { MÁXIMO }\end{array}$ & MÉDIA & $\begin{array}{l}\text { DESVIO } \\
\text { PADRÃO }\end{array}$ & MEDIANA & $\begin{array}{l}\text { MININIMO- } \\
\text { MÁXIMO }\end{array}$ \\
\hline $\begin{array}{l}\text { GLÚTEO D } \\
\text { ANTES }\end{array}$ & 23,56 & 4,25 & 23,80 & $15,9-28,7$ & 26,47 & 3,47 & 28,70 & $19,6-29,0$ \\
\hline $\begin{array}{l}\text { GLÚTEO D } \\
\text { DEPOIS }\end{array}$ & 28,14 & 1,38 & 28,60 & $24,1-28,7$ & 26,81 & 5,62 & 28,70 & $12,9-29,1$ \\
\hline $\begin{array}{l}\text { GLÚTEO E } \\
\text { ANTES }\end{array}$ & 14,42 & 4,70 & 13,80 & $7,8-23,5$ & 15,81 & 5,30 & 16,90 & $8,2-24,3$ \\
\hline $\begin{array}{l}\text { GLÚTEO E } \\
\text { DEPOIS }\end{array}$ & 17,21 & 3,57 & 17,90 & $13,0-21,9$ & 18,06 & 3,97 & 17,80 & $11,9-25,4$ \\
\hline
\end{tabular}


Conforme mostra a tabela 11, tanto no GC como no GP a média das forças medidas antes e após as intervenções apresentaram-se aumentadas tanto em glúteo direito como em esquerdo.

A tabela 12 apresenta um detalhamento dos dados que se constitui numa peculiaridade com relação às forças medidas em glúteo direito e em esquerdo, pois todos os indivíduos avaliados, tanto no GP como no GC, apresentaram maior força muscular em glúteo direito que em esquerdo.

Tabela 12 - Medidas das forças musculares de glúteo máximo direito e esquerdo $(\mathrm{Kg})$ antes e após a intervenção e a diferença dos valores dessas medidas antes e após a intervenção. Ribeirão Preto - SP, 2010. $(n=19)$

\begin{tabular}{|c|c|c|c|c|c|c|}
\hline \multirow[b]{2}{*}{$\begin{array}{c}\text { GRUPO } \\
\text { PILATES } \\
(n=11)\end{array}$} & \multicolumn{2}{|c|}{$\begin{array}{c}\text { Glúteo máximo direito } \\
(\mathbf{k g})\end{array}$} & \multicolumn{2}{|c|}{$\begin{array}{c}\text { Glúteo máximo esquerdo } \\
(\mathbf{k g})\end{array}$} & \multicolumn{2}{|c|}{$\begin{array}{l}\text { Diferença das medidas } \\
\text { direito e esquerdo }\end{array}$} \\
\hline & ANTES & DEPOIS & ANTES & DEPOIS & ANTES & DEPOIS \\
\hline 1 & 21,2 & 28,7 & 12,7 & 18,2 & 8,5 & $10,5^{*}$ \\
\hline 2 & 23,8 & 28,6 & 22 & 21,9 & 1,8 & $6,7^{*}$ \\
\hline 3 & 26,6 & 28,7 & 13,8 & 17,9 & 12,8 & 10,8 \\
\hline 4 & 28 & 28,7 & 15,8 & 21,4 & 12,2 & 7,3 \\
\hline 5 & 19,4 & 28,6 & 11,4 & 13,3 & 8 & $15,3^{*}$ \\
\hline 6 & 23 & 28,6 & 10,7 & 16,5 & 12,3 & 12,1 \\
\hline 7 & 24,6 & 27,6 & 13,8 & 21,7 & 10,8 & 5,9 \\
\hline 8 & 19,4 & 24,1 & 11,6 & 13 & 7,8 & $11,1^{*}$ \\
\hline 9 & 28,7 & 28,6 & 23,5 & 18,8 & 5,2 & $9,8^{*}$ \\
\hline 10 & 15,9 & 28,7 & 7,8 & 13,2 & 8,1 & $15,5^{*}$ \\
\hline 11 & 28,6 & 28,7 & 15,5 & 13,4 & 13,1 & $15,3^{*}$ \\
\hline \multicolumn{7}{|l|}{$\begin{array}{c}\text { GRUPO } \\
\text { CONTROLE } \\
(n=8)\end{array}$} \\
\hline 1 & 19,6 & 12,9 & 8,2 & 11,9 & 11,4 & 1 \\
\hline 2 & 28,7 & 28,7 & 17,3 & 18,4 & 11,4 & 10,3 \\
\hline 3 & 28,7 & 28,8 & 17 & 25,4 & 11,7 & 3,4 \\
\hline 4 & 23,6 & 28,6 & 16,8 & 17,6 & 6,8 & $11^{*}$ \\
\hline 5 & 28,7 & 28,7 & 19,9 & 17,8 & 8,8 & $10,9^{*}$ \\
\hline 6 & 29 & 28,7 & 9,4 & 17,8 & 19,6 & 10,9 \\
\hline 7 & 28,7 & 29 & 13,6 & 14,8 & 15,1 & 14,2 \\
\hline 8 & 24,8 & 29,1 & 24,3 & 20,8 & 0,5 & $8,3^{*}$ \\
\hline
\end{tabular}

*Obtiveram aumento da assimetria de forças entre glúteo máximo direito e esquerdo. 
As disfunções do movimento humano originam-se como resultados de processos patológicos. Entretanto, movimentos realizados nas atividades de vida diária (AVD) também são possíveis causadores destas patologias (SAHRMANN, 2002). Por meio dos efeitos cumulativos de movimentos repetitivos e posturas sustentadas adotadas nas AVDs, os tecidos muscular e neural podem ser lesionados, implicando em modificações na performance muscular (SOLOMONOW et al., 2003). Estas modificações podem ocorrer devido a uma fraqueza ou alterações no padrão de recrutamento muscular, o que repercutiria sobre os movimentos articulares (SAHRMANN 2002).

A alteração na atividade muscular afeta a estabilidade articular por meio da diminuição do contato entre as superfícies articulares que estes músculos atravessam, permitindo movimentos translatórios excessivos (COMEFORD e MOTTRAM). Esta redução da estabilidade articular poderia levar ao início insidioso de dor e patologias musculoesqueléticas (COMEFORD; MOTTRAM, 2001).

Conforme mostra a tabela 12, de acordo com as medidas obtidas das forças de glúteo máximo direito e esquerdo, houve uma assimetria dessas forças nos voluntários avaliados em ambos os grupos em 100\% dos participantes. Estas disfunções podem iniciar um ciclo de eventos que induzem a lesões teciduais, podendo progredir de micro para macrotraumas (COMEFORD; MOTTRAM, 2001).

Também pode ser observada na Tabela 12, a ocorrência de diminuição da assimetria das forças glúteas entre glúteo máximo direito e esquerdo em nove participantes $(47,37 \%)$, sendo quatro $(36,36 \%)$ do GP e cinco $(62,5 \%)$ do GC após a intervenção. 
Estudos realizados concordam que o conceito de que a restauração e a manutenção do movimento coordenado de um segmento é fundamental para o tratamento e prevenção das lesões musculoesqueléticas (LEE, 2000; SAHRMANN, 2002) . Percebe-se que a assimetria de glúteos aparece em $100 \%$ dos participantes da pesquisa e ela diminui ao final da intervenção em 9 indivíduos sem que os valores se igualassem, sendo assim, talvez exista a necessidade de se observar e de se investigar se essa assimetria de força possa ser umas das causas desencadeantes ou agravantes para as algias na região lombar, ou seja, quanto maior essa assimetria de forças, maior a disfunção e conseqüentemente, a dor lombar.

\subsubsection{Comparação da força do glúteo máximo direito e esquerdo por grupo, antes e após a intervenção}

Os Gráfco 5 e 6 fazem uma comparação da força do glúteo máximo direito e esquerdo, por grupo, antes e após a intervenção. 
Gráfco 5 e 6 - Comparação da força do glúteo máximo direito e esquerdo, por grupo, antes e após a intervenção. Ribeirão Preto - SP, 2010. $(n=19)$

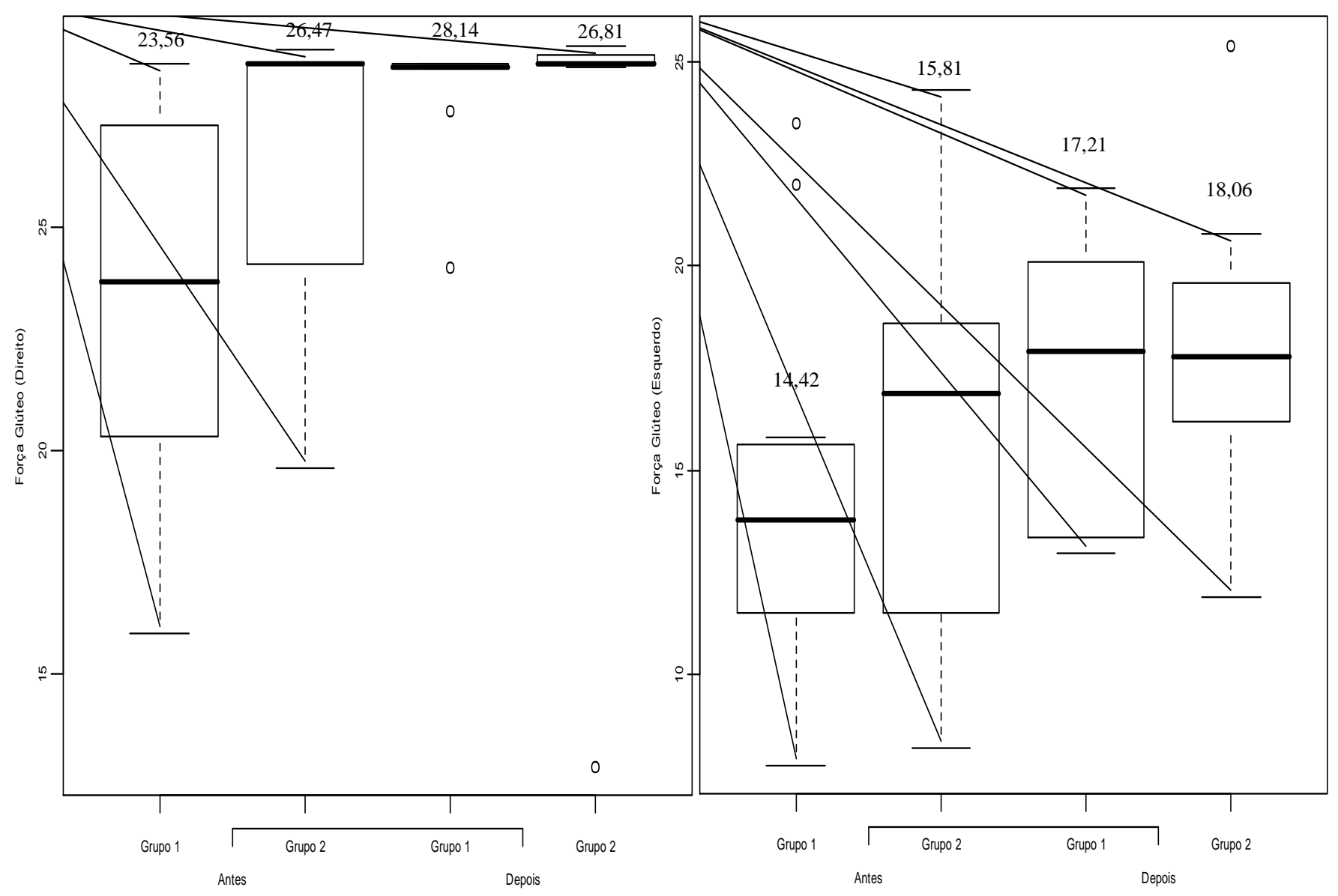

Observa-se nos gráfico 5 e 6 que a média das forças de glúteo direito antes e após a intervenção eram de, respectivamente, 23,56 Kg e 28,14 Kg para o GP e de 26,47 Kg e 26,81Kg para o GC. Para o glúteo esquerdo, esses valores foram de $14,42 \mathrm{Kg}$ e 17,21 Kg para o GP e 15,81 Kg e 18,06 Kg para o GC. 
A Tabela 13 apresenta os resultados de acordo com o modelo de efeitos mistos para a variável Força de glúteo máximo direito.

Tabela 13 - Resultados do modelo de efeitos mistos para a variável Força de Glúteo máximo Direito. Ribeirão Preto - SP, 2010. $(n=19)$

\begin{tabular}{cccccccc}
\hline Grupos & Tempo & Grupo & Tempo & $\begin{array}{c}\text { Diferença estimada } \\
\text { entre as médias }\end{array}$ & Erro padrão & ${ }^{*}$ p-valor \\
\hline Pilates & Antes & Controle & Antes & $-2,91$ & 1,79 & 0,12 \\
Pilates & Depois & Controle & Depois & 1,33 & 1,79 & 0,47 \\
\hline Controle & Antes & Controle & Depois & $-0,34$ & 1,36 & 0,81 \\
Pilates & Antes & Pilates & Depois & $-4,58$ & 1,16 & $<\mathbf{0 , 0 1}$ \\
\hline
\end{tabular}

*Mann- Whitney

A Tabela 14 apresenta os resultados de acordo com o modelo de efeitos mistos para a variável força de glúteo máximo esquerdo.

Tabela 14 - Resultados do modelo de efeitos mistos para a variável força de glúteo máximo esquerdo. Ribeirão Preto - SP, 2010. $(n=19)$

\begin{tabular}{ccccccc} 
Grupo & Tempo & Grupo & Tempo & $\begin{array}{c}\text { Diferença estimada } \\
\text { entre as médias }\end{array}$ & Erro padrão & ${ }^{*}$ p-valor \\
\hline Pilates & Antes & Controle & Antes & $-1,39$ & 2,04 & 0,50 \\
Pilates & Depois & Controle & Depois & $-0,85$ & 2,04 & 0,68 \\
\hline Controle & Antes & Controle & Depois & $-2,25$ & 1,45 & 0,14 \\
Pilates & Antes & Pilates & Depois & $-2,79$ & 1,23 & $\mathbf{0 , 0 4}$ \\
\hline
\end{tabular}

*Mann- Whitney

As Tabelas 13 e 14 mostram, segundo o modelo dos efeitos mistos, que quando foi realizada uma comparação entre os grupos antes e após a intervenção, não houve melhora significativa das forças de glúteo direito e 
esquerdo, mas quando se realizou uma comparação dentro de cada grupo, a melhora de força em glúteo direito e esquerdo foi significativa para o GP, apresentando $p<0,01$ para glúteo direito e $p<0,04$ para o glúteo esquerdo. Sendo assim, os exercícios baseados no método Pilates mostraram-se superiormente eficazes para o fortalecimento do glúteo máximo quando comparados aos exercícios convencionais de alongamentos e fortalecimentos.

Em estudo recente realizado com indivíduos sadios e com indivíduos com lombalgia crônica idiopática, constataram-se, por meio de exames eletromiográficos, que o comprometimento do músculo glúteo máximo, assim como de outros quatro extensores, estava presente nos indivíduos com lombalgia crônica (LARIVIÈRE, 2010). Nesse mesmo estudo, quando os indivíduos foram submetidos a movimentos de flexão e extensão de tronco, o glúteo máximo apresentou fadiga anteriormente aos outros extensores nos indivíduos acometidos pela lombalgia. 


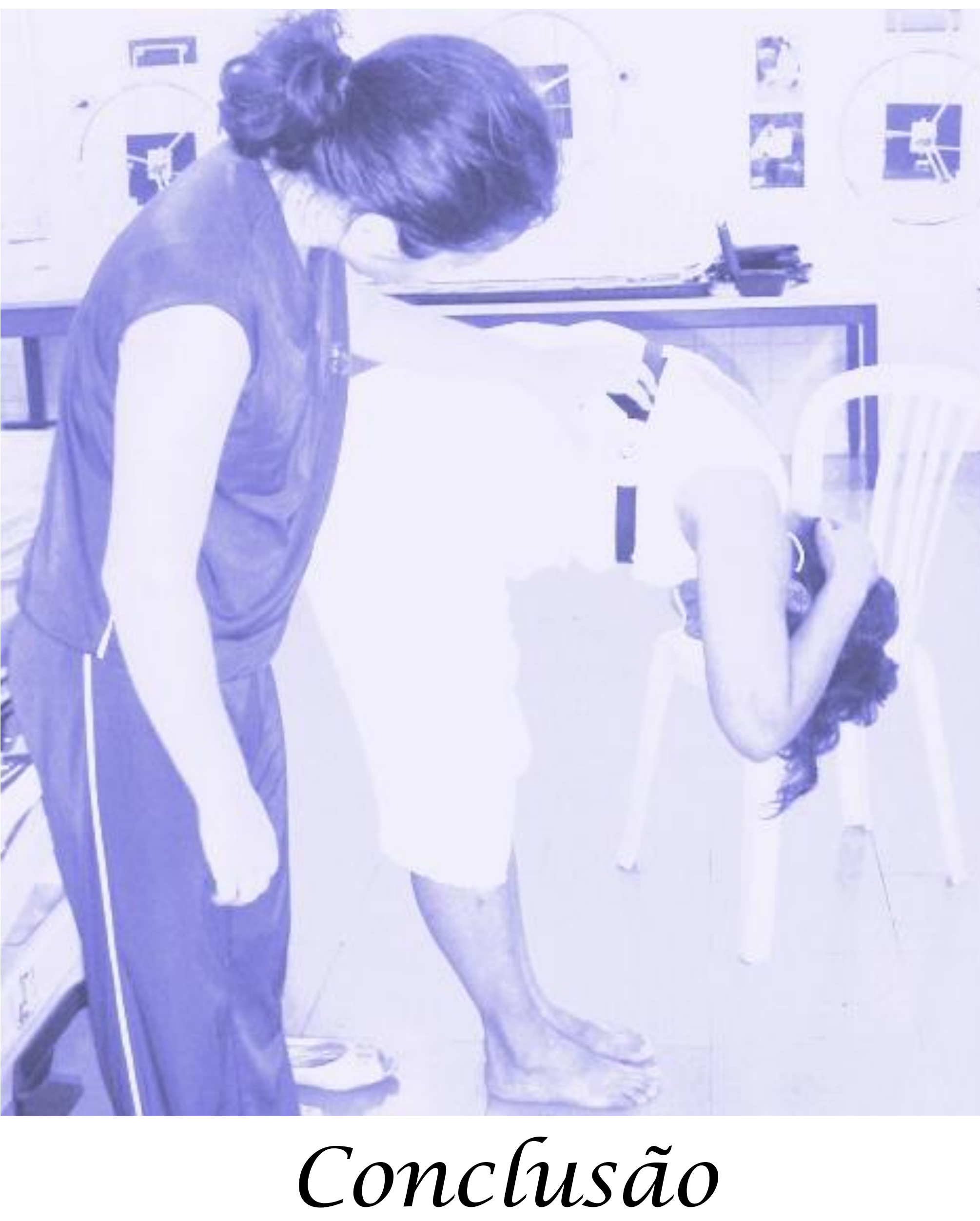




\section{CONCLUSÃO}

A amostra caracterizou-se apresentando a maioria dos participantes com mais de 45 anos de idade (52,6\%), do sexo feminino (89,5\%), não-fumantes (78,9\%), com hábito diário de ingestão de café $(68,4 \%)$, sem hábito de consumir bebida alcoólica $(73,7 \%)$, sendo $(78,9 \%)$, auxiliares de enfermagem .

Com relação aos aspectos profissionais, a maioria dos participantes era proveniente do setor de Central de materiais $(36,8 \%)$ e trabalhavam no turno matutino $(42,1 \%)$. Em se tratando do meio de locomoção para o trabalho, a maioria também relatou ir de carro $(42,1 \%)$ ou ônibus $(42,1 \%)$ e levar de 10 a 30 minutos para chegarem ao destino (84,21\%).

Em se tratando do comportamento postural adotado na rotina de trabalho desses profissionais, a maioria $(73,7 \%)$ relatou utilizar mais de uma postura em suas rotinas de trabalho, sendo essas, convenientemente categorizadas em estáticas e dinâmicas para fins de discussão.

Com relação à dor lombar, avaliada indiretamente por meio do questionário Oswestry através da incapacidade para a realização de algumas atividades funcionais, teve-se que, dentre todos os participantes que apresentaram incapacidade mínima, moderada ou severa, 100\% desses migraram para a categoria de incapacidade mínima, sendo que àqueles que participaram do GC apresentaram uma melhora discreta superior ao GP, embora não significativa.

Com relação aos programas de exercícios aplicados, ambos os protocolos de exercícios físicos mostraram-se eficazes, apresentando melhora 
clínica no tratamento da dor lombar em trabalhadores de enfermagem (auxiliares, técnicos e enfermeiros).

Ao se correlacionar as posturas estáticas e dinâmicas com a melhora da incapacidade funcional após a intervenção, teve-se que àqueles que assumiam, predominantemente, posturas dinâmicas em suas rotinas de trabalho, tiveram uma melhora mais acentuada da incapacidade funcional quando comparados àqueles que assumiam posturas estáticas.

A respeito da melhora da flexibilidade, todos os participantes, de ambos os grupos, apresentaram melhora das ampliturdes de movimento. Numa análise realizada intra grupo, o GC apresentou uma melhora significativa da amplitude de tronco $(\mathrm{Cs}=0,91-\mathrm{p}<0,01)$ quando comparado aos valores anteriores à intervenção.

Para se verificar se houve diferença entre os grupos, quanto à força glútea, comparando-se o período pré com o pós intervenção, foi utilizado um modelo de efeitos mistos o qual evidenciou que não houve melhora significativa das forças de glúteo direito e esquerdo entre os grupos, mas quando se realizou uma comparação dentro de cada grupo, a melhora de força em glúteo direito e esquerdo foi significativa para o GP, apresentando $p<0,01$ para glúteo direito e $\mathrm{p}=0,04$ para glúteo esquerdo.

Nenhuma associação foi encontrada com a melhora da incapacidade funcional em função da dor lombar e o tempo de participação no estudo. 


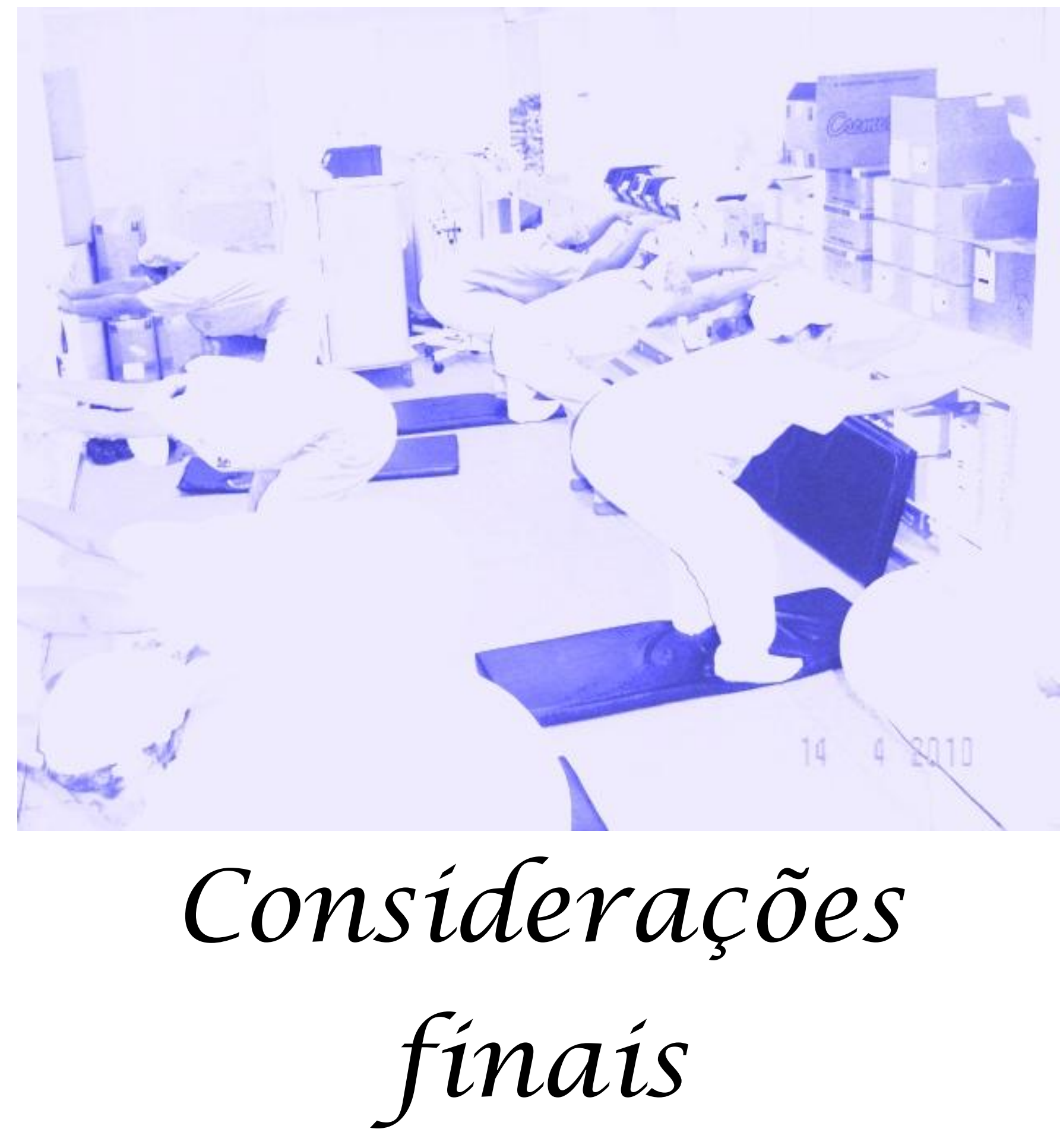




\section{Considerações finais}

No início da pesquisa, no período de seleção dos participantes, houve uma dificuldade para que os trabalhadores de enfermagem que procuravam atendimento médico no SAMSP com queixa de dor lombar ou que já tinham sido indicados para a fisioterapia (Centro de Reabilitação Lucí Montouro) soubessem da realização desse estudo e quando o faziam, requisitavam intervenção imediata. Por esse motivo, cada voluntário que ia aparecendo, era indicado para o grupo que estava em formação, sendo este, ou GP ou o GC. Dessa forma, o voluntário não ficava aguardando tempo de início da intervenção e a pesquisadora responsável não "perdia" o participante.

Outro aspecto também relevante foi com relação à falta de adesão ao estudo. Acredita-se que em função da considerável perda de follow up em ambos os grupos, uma análise prévia a respeito da população - alvo poderia ter sido realizada, ou seja, encontrar quais os fatores que teriam sido motivadores e desmotivadores para a realização dessa intervenção, como local, período de intervenção, dentre outros fatores. Dentre os vinte e oito participantes que deram início a participação no estudo, apenas dezenove $(67,86 \%)$ deram seguimento, e $32,14 \%$ abandonaram antes da $5^{\text {a }}$ sessão.

Em se tratando dos dois tipos de intervenção realizadas, acredita-se que, embora os dois métodos tenham se mostrado eficazes para o tratamento da dor lombar, o método Pilates foi superior em função de suas peculiaridades, de seus aspectos desafiadores, por trabalhar o corpo como um todo e, principalmente, por mostrar-se mais efetivo na melhora da força de glúteo 
máximo, músculo este importante na biomecânica da estabilização pélvica e lombar.

Espera-se, a partir deste estudo, que a atividade física ministrada para os trabalhadores de enfermagem seja feita de forma criteriosa, por meio de grupos reduzidos, em ambientes físicos adequados. Espera-se que a prática de atividade física realizada como atividade física laboral, seja algo benéfico e prazeroso para o trabalhador de enfermagem, que ele possa obter êxito não apenas com relação à lombalgia, mas com relação ao corpo como um todo.

Outro aspecto muito relevante é com relação a intervenções que poderiam ser realizadas futuramente em trabalhadores que apresentassem problemas semelhantes, pois assim se poderia elaborar protocolos de avaliação e de tratamento que também pudessem ser replicados e aplicados periodicamente para avaliar o estado físico (muscular e articular) daquele trabalhador e de outros atuantes em outros setores e outras instituições.

Outra preocupação nesse estudo foi a de que não se fosse utilizado instrumentos caros, de difícil manuseio e uma intervenção que necessitasse de equipamentos ou aparelhos para a prática dos exercícios. Os instrumentos utilizados na avaliação foram de baixo custo e de fácil manuseio e forneciam dados numéricos e fidedignos. Os exercícios propostos eram realizados com a própria resistência física e não careciam de nenhum acessório, tanto o protocolo para o GC como o protocolo do GP.

Sendo assim, espera-se que os trabalhadores sejam vistos com maior critério nos programas de ginástica laboral, que as atividades físicas propostas tenham objetivos para com os seus alvos e sejam ministradas por profissionais 
qualificados e aptos à ministração de práticas em grupo, pois se percebeu nesse estudo que a presença constante e freqüente durante toda a sessão do profissional fisioterapeuta junto aos trabalhadores tornou-se um fator motivador para o trabalhador que saía de seus setores, às vezes, nervosos, chateados, tristes, cansados, dentre outros sentimentos expressos, mas que, naquele momento, encontravam um profissional qualificado para assisti-lo naquela atividade. 
REFERÊNCIAS BIBLIOGRÁFICAS ${ }^{1}$

ABDESSEMED. D.; DUCHÉ, P.; HAUTIER, C.; POUMARAT, G.; BEDU, M. Effect of recovery duration on muscular power and blood lactate during the bench press exercise. International Journal Sports Medicine. New York. v.20, n.6, p.368-373,1999.

ABREU, A.V.; MELLO, A.P.; TROVÃO, G.S.; FONTENELLE, C.R.C. Avaliação clínico-radiográfica da mobilidade da lordose lombar. Revista Brasileira de Ortopedia. São Paulo. v. 42, n. 10, p. 313-323, 2007.

ACHOUR JR, A. Bases para exercícios de alongamento: Relacionado com a saúde e no desempenho atlético. 2 ed. Londrina: Ed. Phorte, 1999. p. 5-23.

ALARANTA, H.; TALLROTH, K.; SOUKKA, A.; HELIOVAARA, M. Fat content in lumbar extensor muscles and low back disability: a radiographic and clinical comparison. Journal of Spinal Disorders. v. 6, n 2, p. 137-140, 1993.

ALENCAR, M.C.B. Fatores de risco das lombalgias ocupacionais: O caso de mecânicos de manutenção e produção. 2001. 114f. Dissertação (Mestrado em Ergonomia) - Programa de Pós-Graduação em Engenharia de Produção, Universidade de Santa Catarina, Florianópolis, 2001.

ALEXANDRE, N.M.C.; MORAES, M.A.A. Modelo de avaliação físico-funcional da coluna vertebral. Revista Latino-Americana de Enfermagem. Ribeirão Preto. v.9, n.2, p.67-75, 2001.

ALEXANDRE, N.M.C.; MORAES, M.A.A.; MAHAYRI, N.; CUNHA, S.H.F. Aspectos ergonômicos e posturais em centro de material. Revista da Escola de Enfermagem da USP. São Paulo. v. 26, n. 1, p. 87-94, 1992.

ALEXANDRE, N.M.C.; ANGERAMI, E.L.S.; MOREIRA, D.C. Filho. Dores nas costas e enfermagem. Revista da Escola de Enfermagem da USP. São Paulo. v. 30, n. 2, p. 267-84, 1996.

ALEXANDRE, N.M.C.; BENATTI, M.C.C. Acidentes de trabalho afetando a coluna vertebral: um estudo realizado com trabalhadores de enfermagem de um hospital universitário. Revista Latino-Americana de Enfermagem. Ribeirão Preto. v. 6, n. 2, p. 65-72, 1998.

ALMEIDA, I.C.G.B.; SÁ, K.N.; SILVA,M.; BAPTISTA, A.; MATOS, M.A.; LESSA, I. Prevalência de dor lombar crônica na população da cidade de Salvador. Revista Brasileira de Ortopedia. Salvador. v.43, n. 3, p.96-102, 2008.

ANDRADE, S.C.; ARAÚJO, A.G.R.; VILAR, M.J.P. Escola de Coluna: Revisão Histórica e sua Aplicação na Lombalgia Crônica. Revista Brasileira de Reumatologia. São Paulo. v. 45, n. 4, p. 224-8, 2005.

ANDRUSAITIS, S.F.; OLIVEIRA, R.P.; BARROS FILHO, T.E.P. Estudo da prevalência e os fatores de risco da lombalgia em caminhoneiros do estado de São Paulo. Brasil. Clinics. São Paulo. v.61, n.6, p.503-510, 2006. 
ANJOS, D.C.S. Aspectos da biomecânica ocupacional na abordagem fisioterapêutica preventiva. 2008. Disponível em: http://www.preventivafisioterapia.com.br/admprev/public/up_artigo/arq_21.pdf. Acesso em: 22 nov. 2010.

ARAÚJO, C.G.S. Flexitest: An innovative flexibility assessment method. Champaign: Human Kinetics. 2004. 216p.

ARAÚJO, C.G.S.; CHAVES, C.P.G. Adult women with mitral valve prolapsed are more flexible. British Journal Sports Medicine. Rio de janeiro. v.39, n. 10, p. 720-724, 2007.

BANDY, W.D.; IRON, J.M.; BRIGGLER, M. The effect of time and frequency of static stretching on flexibility of the hamstring muscles. Physical Therapy. v.77, n.10, p.1090-1096,1997.

BARBANTI, V.J.; UGRINOWITSCH, C. O ciclo de alongamento e encurtamento e a "performance" no salto vertical. Revista Paulista de Educação Física. São Paulo. v.12, n.1, p.85-94,1998.

BARBANTI, V.J. Teoria e Prática do treinamento esportivo. São Paulo: Ed. Edgard Blucher, 1997.

BARROS FILHO, T.E.P.; BASILE JR, R. Coluna Vertebral: diagnóstico e tratamento das principais patologias. São Paulo (SP): Ed. Sarvier, 1995.

BARROS FILHO, T.E.P.; LECH, O. Exame Físico em Ortopedia. 2 ed. São Paulo: Ed. Sarvier, 2001.

BATTAGLINI, C.L.; BOTTARO, M; CAMPBELL, J.S; NOVAES, J; SIMÃO, R. Atividade física e níveis de fadiga em pacientes portadores de câncer. Revista Brasileira de Medicina do Esporte. Niterói. v.10, n.2, p.98-104, 2004.

BEHM, D.G.; BAMBUERY, A; CAHIL, F; POWER, K. Effect of acute static stretching on force, balance, reaction time and movement time. Medicine \& Science in Sports \& Exercices. Quebec. v. 36, n. 3, p.1397-1402, 2004.

BERGMARK, A. Stability of the lumbar spine. A study in mechanical engineering. Acta Orthopedica Scandinava. v. 230, s.1p. 1-54, 1989.

BERNARD, C. Lombalgia e lombociatalgias em medicina ocupacional. Revista Brasileira de Medicina. v. 50, n. 1, p. 3-9, 1993.

BLASCO, T. Actidad física y Salud: Uma perspectiva psicológica. In: ACPE (ed.), X Jornada de L'a Associación Catalana de Psicologia de I Esport (ACPEE). 1 ed, novembro, 1994. Arts Estudis Gràfics, S.L., p. $12-31$.

BLUM, C.L. Chiropractic and Pilates Therapy for the Treatment of Adult Scoliosis. Journal of Manipulative and Physiological Therapeutics. V.25, n.4, 2002.

BRASIL. Ministério da Saúde. Conselho Nacional de Saúde. Resolução n. 196 de 10 de outubro de 1996: diretrizes e normas regulamentadoras de pesquisa 
envolvendo

seres

humanos. www.conselho.saude.gov.br/docs/Resolucoes/Reso 196.doc. Acesso em 20 de setembro de 2009.

BRAZIL, A.V., et al. Diagnóstico e tratamento das lombalgias e lombociatalgias. Revista Brasileira de Reumatologia. São Paulo. v.44, n. 6, p. 419-425, 2004.

BUCKLE, P. Epidemiological aspects of back pain within the nursing profession. Internacional Journal of Nursing Studies. v.24, p. 319-324, 1987.

CAILLIET, R. Síndrome da dor Lombar. 5 ed. Porto Alegre. Ed. Artmed, 2001.

CAMPESTRINI, S. Súmula Pediátrica. Curitiba, EDUCA, 1991.

CARVALHO, C. Treino da força em crianças e jovens: Questões, controvérsias e orientações metodológicas. In: Gaya, A.; Marques, A.; Tani, G. (Ed). Desporto para crianças e jovens: Razões e finalidades. UFRGS. p. 353412, 2004.

CECIN, H., A., et al. (Ed). Dor lombar e trabalho: um estudo sobre a prevalência de lombalgia e lombociatalgia em diferentes grupos ocupacionais. Revista Brasileira Reumatologia. São Paulo. v.32, p.50-56,1991.

CHENG, Y.L. Predicting the vertebral inclination of the lumbar spine. Ergonomics. v. 43, n.6, p.744-751, 2000.

CHENG, J.; ISACOWITZ; R. Pilates: The pelvic Curl. Couples Company. Com. p. 1-3, 2003. Disponível em: http://www.couplescompany.com/Advice/Health/PelvicCurl.htm. Acesso em: set. 2010.

CHIESA, L.C. Força e Hipertrofia muscular. Revista Virtual Efartigos. Natal. v.1, n.14, 2003. Disponível em: < http://efartigos.atspace.org/fitness/artigo14.html>. Acesso em: jul de 2010.

COLLET, N.; ROCHA S.M.M. Transformações no ensino das técnicas em enfermagem pediátrica. Goiânia: Ed. AB, 1996, 176p.

COMERFORD, M.,J.; Mottram, S.,L. Movement and stability dysfunctioncontemporary developments. Man Ther journal articles, v.6, v.1,p. 15-26, 2001.

CONGRESSO BRASILEIRO DE ERGONOMIA; 14., 2006, Curitiba. Avaliação postural nas enfermarias da clínica cirúrgica de um hospital em São Luís, MA. Curitiba: UFMA, 2006. Disponível em: http://www.nepp.ufma.br/documentos/avaliacaoposturalnasenfermariasdaclinica cirurgica.pdf>. Acesso em set. 2010. 
COORDENAÇÃO DE URGÊNCIA E EMERGÊNCIA SMSA. Unidade de Pronto atendimento 24 horas: estrutura organizacional. Belo Horizonte, 1997. 20p. Mimeografado.

CORONA, G.; AMEDEI, F.; MISELLI, F.; PADALINO, M.P.; TIBALDI, S.; FRANCO, G. Association between relational and organization factors and occurrence of musculoskeletal disease in health personnel. Giornale Italiano di Medicina del Lavoro ed Ergonomia. v. 27, n. 2, p. 208-212, 2005.

CORRÊA I. Vivências do profissional de saúde diante do familiar da criança internada na unidade pediátrica. Revista Mineira de Enfermagem, da Escola de Enfermagem da Universidade Federal de Minas Gerais. v.9, n.3, p.237241, 2005.

COSTA, F.M.; VIEIRA, M.A.; SENA, R.R. Absenteísmo relacionado a doenças entre membros da equipe de enfermagem de um hospital escola. Revista Brasileira de Enfermagem. Brasília. v.62, n.1, p.38-44, 2009.

COUTINHO, E.L; GOMES, A.R.S; FRANÇA, C.N; OISHI, J; SALVINI, TF. Effect of passive stretching on the immobilized soleus muscle fiber morphology. Brazilian Journal of Medical and Biological Reserch. Ribeirão Preto. v.37, n.12, p.1853-1861, 2004.

CRAIG, C. Pilates com a bola. São Paulo. 2 ed. 2004. Ed. Phorte. 171p.

CUNNINGHAN, L.S.; KELSEY, J.L. Epidemiology of musculoskeletal impairments and associated disability. American Journal of Public Health. V.74, n. 6, p. 574-579, 1984.

DAHER, D.J.; GUISELINI, M.; GHORAYEB, N.; DIOGUARDI, G. Avaliação cardiovascular pré-participação na academia: aspectos médicos e fisiológicos. Revista Sociedade Cardiologia do Estado de São Paulo. São Paulo. v.15, n.2, p.105-113, 2005.

DALRI, R.C.M.B. Riscos ocupacionais entre trabalhadores de enfermagem de unidades de pronto atendimento em Uberaba - MG. 2007. $146 f$. Dissertação (Mestrado) - Programa de Pós-Graduação em Enfermagem Fundamental da Escola de Enfermagem de Ribeirão Preto, Universidade de São Paulo (USP), Ribeirão Preto, 2007.

DALTRO, F.; FERNANDES, F. Curso de Sistema de Abordagem Corporal: Fundamentado na Técnica de Pilates. Curso de Capacitação Profissional. Corpore - Centro de Desenvolvimento Físico. Salvador. n. 4, 2004.

DAL PAI, D; SCHRANK, G; PEDRO, E.N.R. O enfermeiro como ser sóciopolítico: refletindo a visibilidade da profissão do cuidado. Acta Paulista Enfermagem. São Paulo. v.19, n.1, p.82-87, 2006. 
DÂNGELO, J.G; FATTINI, C.A. Crânio, coluna vertebral e partes moles do dorso. In: Anatomia Humana Sistêmica e Segmentar - para o estudante de medicina. Cap. 19. pp. 376-378, 2 ed. Ed. Atheneu. São Paulo, Rio de Janeiro, Belo Horizonte, 1998.

DAVIS, D.S; ASHBY, P.E; MAcCALE, K.L; McQUAIN, J.A; VINHO, J.M. The Effectiveness of three Stretching Techniques on Hamstring Flexibility Using Consistent Stretching Parameters. Journal of Strength and Conditioning Research. v.19, n.1, p.27-32, 2005.

DE VITTA, A. A lombalgia e suas relações com o tipo de ocupação com a idade e o sexo. Revista Brasileira de Fisioterapia. v.1, p.67-72, 1996.

DEYO, R.A. Measuring the Functional Status of Patients with Low-Back Pain. Archives of Physical Medicine and Rehabilitation. v.69, p.11, p.1044-1053, 1988.

DEYO, R.A., et al. Outcome measures for studying patients with low back pain. Spine. v.19, s.1, p.2032-2036,1994.

DICKINSON, R.V. The specificity of flexibility. Conflict Resolution Quarterly. v.39, p.792-794,1968.

DONZELLI, S; DI DOMENICA, E; COVA, A.M; GALLETTI, R; GIUNTA, N. Two differents techniques in the rehabilitation treatment of low back pain: a randomized control trial. Europa medicophysica. Milão. v.42, n.3, p.205-210, 2006.

DORNAS JR, G.; FERREIRA, J.M. Informações de unidades de pronto atendimento - Possibilidades de uso como sentinelas da atenção básica à saúde. Informática Pública. Belo Horizonte. v.5, n.1, p.27-48,2003.

DOWSHEN, S. Strength training your children. Kidshealth, 2001 january. Disponível em: $<$ http://www.kidshealth.org/parent/nutrition_fit/fitness/strength_training_p4.html> . Acesso em março de 2008.

DUL, J.; WEERDMEESTER, B. Ergonomia prática. São Paulo: Ed. Edgard Blücher, 1995. $147 \mathrm{p}$.

EDLICH, R.,F. et al. (Ed). Prevention of disabling back injuries in nurses by the use of mechanical patient lift systems. Journal of Long-Term Effects of Medical Implants. v.14, n.6, p521-533, 2004.

ESCOSTEGUY, C.C. Metodologia de ensaios clínicos randomizados. Arquivos Brasileiros de Cardiologia. Rio de Janeiro. V. 72, n. 2, p. 139-143, 1999. 
EVANS, W.J. Exercise training guidelines for the elderly. Medicine and science in sports and exercise. v. 31, n. 1, p. 12-17, 1999.

\section{EVIDENCE BASED MANAGEMENT OF ACUTE MUSCULOSKELETAL PAIN GUIDELINES. Disponível em: $<h t t p: / / w w w . n h m r c . g o v . a u / p u b l i c a t i o n s / s y n o p s e s / c p 94 s y n . h t m>$. Acesso em: jun., 2003.}

FAIGENBAUM, A. Youth resistance training. President's Council on physical fitness and sports. Boston. v.4, n.3, p.1-8, 2003.

FAIRBANK, J.C.T., PYNSENT, P.B. The Oswestry Disability Index. Spine. New Hampshirev, 25, n.15, p.2940-2953, 2000.

FARIAS, N; BUCHALLA, C.M. A Classificação Internacional de Funcionalidade, Incapacidade e Saúde da Organização Mundial da Saúde: Conceitos, Usos e Perspectivas. Revista Brasileira de Epidemiologia. São Paulo. v.8, n.2, p.187-193, 2009.

FLECK, S.J. Cardiovascular adaptations to resistance training. Medicine \& Science Sports \& Exercise. v.20, n.5, p.146-151,1988.

FLECK, S.J.; KRAEMER, W.J. Fundamentos do treinamento de força muscular. 3 ed. São Paulo: Ed. Artmed Bookman, 2006, 373 p.

FLICKER, P.L; FLECKENSTEIN, J.L; FERRY, K; PAYNE, J; WARD, C; MAYER, T, et al. Lumbar muscle usage in chronic low back pain: magnetic resonance image evaluation. Spine. New Hampshire. v.18, n.5, p.582-586, 1993.

FLORÊNCIO, L.L; PEREIRA, P.A; SILVA, E.R.T; PEGORETTI, K.S, et al. Concordância e confiabilidade de dois métodos não-invasivos para a avaliação da amplitude de movimento cervical em adultos jovens. Revista Brasileira de Fisioterapia. São Carlos. v.14, n.2, p.175-181, 2010.

FLORY, P.D.; RIVENBURGH, D.W.; STINSON, J.T. Isokinetic back testing in the athletic. Clinical Journal of Sport Medicine. v. 12, n. 3, p. 529-546.

FOLLETI, I. et al. (Ed). Prevalence and determinants of low back pain in hospital workers. Giornale Italiano di Medicina del Lavoro ed Ergonomia. v.27, n.3, p359-361, 2004.

FONSECA, J.L.; MAGNI, M.; FREITAS, T.H. Laboratory Gait Analysis in patients with low back pain before and after a Pilates intervention. Journal of Sport Rehabilitation. Kentucky. v.18, n.2, p.269-282, 2009. 
FRONTERA W.R.; DAWSON, D.M.; SLOVIK, D.M. Exercise in rehabilitation medicine. USA. Human Kinetics, 2006, 464p.

FRYMOYER, J.W; CATS-BARIL, W.L. Na overview of the incidences and costs of low back pain. Orthopedic Clinics North America. Burlington. v.22, n.2, p.263-271, 1991.

GALLAGHER, S.P.; KRYZANOWSKA, R. 0 método de Pilates de Condicionamento Físico. São Paulo: The Pilates Studio® do Brasil, 2000.

GARG, A.; OWEN, B. Prevention of back injuries in healthcare workers. International Journal of Industrial Ergonomics. v.14, p.315-331, 1994.

GLADWELL, V., et al. Does a program of Pilates improve chronic non-specific low back pain?. Journal Sport of Rehabilitation. Champaign. v.15, n.4, p.338-350, 2006.

GOLDSPINK, G.; SCUTT, P.; LOUGHNA, P.T.; WELLS, D.J., et al. Gene expression in skeletal muscle in response to stretch and force generation. American Journal Physiology. United kingdom. v. 262, n.3(pt. 2), p.356- 363, 1992.

GONÇALVES, M; BARBOSA, F.S.S. Análises de parâmetros de forças e resistência dos músculos eretores da espinha lombar durante a realização de exercício isométrico em diferentes níveis de esforço. Revista Brasileira de Medicina do Esporte. Niterói. v.11, n.2, p.109-114, 2005.

GOSSMANN, M.R; SAHRMANN, S.A; ROSE, SJ. Review of length-associated changes in muscle: experimental evidence and clinical implications. Physical Therapy. v 62, n.12, p.1799-1808, 1982.

GRAHAME, R. Pain, distress and joint hyperlaxity. Joint Bone Spine. London. v.67, n.3, p.157-163, 2000.

GRANATA, K; MARRAS, W. EMG assisted model of loads of lumbar spine during asymmetric trunk extensions. Journal Biomechanics. Lowa. v. 26, n.12, p.1429-1438, 1993.

EMG assisted model of biomechanical trunk loading during freedynamic liftingasymmetric trunk extensions. Journal Biomechanics. Lowa. v.28, n.11, p.1309-1317, 1995.

GRIEVE. G. P. Moderna terapia manual da coluna vertebral. São Paulo: Ed. Panamericana, 1994.

GUEDES, D.P.Jr. Personal training na musculação. 2 ed. Rio de Janeiro. NP, 1997. 
GUO, H.R., et al. (Ed). Prevalence of musculoskeletal disorder among workers in Taiwan: a nationwide study. Journal of Occupational Health. v. 46, n.1, p. 26-36, 2004.

GURGUEIRA, G.P.; ALEXANDRE, N.M.; CORRÊA FILHO, H.R. Prevalência de sintomas musculoesqueléticos em trabalhadoras de enfermagem. Revista Latino- Americana de Enfermagem. Ribeirão Preto. v.11, n.5, p.608-613, 2003.

HÄKKINEN, K.; PAKARINEN, A. Acute hormonal responses to two different fatiguing heavy-resistance protocols in male athletes. Journal of Applied Physiology. Finlândia. v.74, n.2, p.882-887, 1993.

HALL, S.J. Biomecânica da Coluna Vertebral. In: Biomecânica Básica. 3 ed. Rio de Janeiro: Ed. Guanabara Koogan, 2000. cap. 8, p. 263-291.

HENNEKENS, C.H; BURING, J.E. Epidemiology in Medicine. Philadelphia: Lippincott Williams \& Wilkins, 1987. p.178-204. Edited by Sherry L. Mayrent.

HILYER, J.C; BROWN, K.C; SIRLES, A.T; PEOPLES, L. A flexibility intervention to reduce the incidence and severity of joint injures among municipal firefighters. Journal of Occupational Medicine. Birmingham, v.32, n.7, p. 631-637, 1990.

HODGES, P.W. Is there a role for transversus abdominis in lumbopelvic stability? Manual Therapy journal articles. v.4, v.2, p. 74-86, 1999.

. Lumbopelvic stability: a functional model of the biomechanics and motor control. In: Richardson, C.; Hodges, P.; Hides, J. Therapeutic exercise for lumbopelvic stabilization: A motor control approach for the treatment and prevention of low back pain. 2 ed. Edinburgh: Churchill Livingstone, 2004. p. 13-28.

HODGES, P.W.; MOSELEY, G.,L. Pain and motor control of the lumbopelvic region: effect and possible mechanisms. Journal of Electromyography Kinesiology. New York. v.13, v.4, p. 361-370, 2003.

HORTOBÁGYI, T.J.; FALUDI, J.; TIHANYI, J.; MERKELY, B. Effects of intense "stretching"- flexibility training on the mechanical profile of the knee extensors and on the range of motion of the hip joint. Internacional Journal Sports Medicine. New York. v.6, n.6, p.317-321,1985.

IMAMURA, S.T.; KAZIYAMA, H.H.S.; IMAMURA, M. Lombalgia. Revista Medicina. São Paulo. v.80, s.2, p. 375-390, 2001.

ICP - INSTITUTO CODE DE PESQUISA. Guarulhos, 2008. Disponível em: <http: //www.institutocode.com>. Acesso em agosto. 2009. 
JOSEPHSON, M; LAGRSTROM, M; HAGBERG, M; HJELM, EW. Musculoskeletal symptoms and job strain among nursing personnel: a study over a three year period. Occupational Environmental Medicine. Solna. v.54, n.9, p. 681-685, 1997.

KAPANDJI, I.A. Fisiologia Articular. 4 ed. São Paulo: Ed. Manole, 1990. p.979.

KAWANO, M.M.; SOUZA, R.G.; OLIVEIRA, B.R.; MENACHO, M.O., et al. Comparação da fadiga eletromiográfica dos músculos paraespinhais e da cinemática angular da coluna entre indivíduos com e sem dor lombar. Revista Brasileira de Medicina do Esporte. Niterói. v.14, n.3, p. 209-214, 2008.

KELSEY, J.L; GITHENS, P.B; O'CONNER, T; WERL, et al. Acute prolapsed lumbar intervertebral disc: An epidemiologic study with special reference to driving automobiles and cigarette smoking. Spine. New Hampshire. v.9, n.3, p. 608-613, 1984.

KENDALL, F.P.; McCREARY, E.K.; PROVANCE, P.G. Provas de comprimento muscular e exercícios de alongamento. In: Músculos - Provas e funções. 4 ed. São Paulo: Ed. Manole, 1995, cap.3, p. 39-45.

KERBER, A. Ergonomia: indicação de postura a ser adotada na concepção de [Ministério do trabalho e emprego secretaria de inspeção do trabalho departamento de saúde e segurança no trabalho coordenação de normalização]. [citado 2009 out 28]. Disponível em http://www.alexkerber.eng.br/arquivos/ergonomia/notatecnica602001.doc

KISNER, C; COLBY, L.A. A coluna: postura. In: Exercícios terapêuticos Fundamentos e técnicas. 2 ed. São Paulo: Ed. Manole, 1992. cap.14, p. 459460.

KLIGYTE, I.; LUNDY-EKMAN, L.; MEDEIROS, J.M. Relationship between lower extremity muscle strength and dynamic balance in people post-stroke. Medicina (Kaunas). Lituania. v.39, n.2, p.122-128, 2003.

KOLYNIAK, I.E.G.; CAVALCANTI, S.M.B.; AOKI, M.S. Avaliação isocinética da musculatura envolvida na flexão e extensão do tronco: Efeito do método Pilates. Revista Brasileira de Medicina do Esporte. v. 10, n. 6, p. 487-490, 2004.

KRAEMER, W.J., et al. Hormonal and growth factor responses to heavy resistance exercise protocols. Journal of Applied Physiology. Massachusetts. v. 69 , n. 4 , p.1442-1450, 1990. 
KRAEMER, W.J., et al. Changes in hormonal concentrations after different heavy-resistance exercise protocols in woman. Journal of Applied Physiology. Massachusetts. v.75, n.2, p.594-604, 1993.

KRAEMER, W.J., et al. Progression models in resistance training for healthy adults. Medicina \& Science in Sports \& Exercise. 34, p.364-380, 2002.

KRAEMER, W.J.; RATAMESS, N.A. Fundamentals of resistance training: progression and exercise prescription. Medicine \& Science Sports \& Exercise. Connecticut. v.36, n.4, p.674-678, 2004.

KUMAR, S; NARAYAN, Y. Trunk strength in combined motions of rotation and flexion/ extension in young adults. Ergonomics. v.41, n. 6, p. 835-852, 1998.

LANGE, C; UNNITHAN, U; LARKAM, E; LATTA, M. Maximizing the beneficits of Pilates - inspired exercise for learning functional motor skills. Journal of Bodywork and Movement Therapies. v.4,n.2, p.99-107.2000.

The Lafayette Manual Muscle test system: LAFAYETTE INSTRUMENT COMPANY. Loughborough, 2003. Manual.

LARIVIÈRE, C.; SILVA, R.A.; ARSENAULT, A.B.; NADEAU, S., et al. Specificity of a back muscle exercise machine in healthy and low back pain subjects. Medicine \& Science in Sports \& Exercices. Quebec. v. 42, n. 3, p.592-599, 2010.

LATEY, P. The Pilates method: history and philosophy. Journal of Bodywork and movement therapies. Austrália. v.5, n.4, p.275-282, 2001.

LEE, D. The pelvic girdle; an approach to the examination and treatement of the lumbo-pelvic-hip region. London: Churchill Livingstone, 2000.

LIDA, I. Ergonomia: Projeto e Produção. 3 ed. São Paulo: Ed. Edgard Bluscher Ltda, 1995.

LEEUW, M.; GOOSSENS, M.E.J.B.; Linton, S.J.; Crombez, G.; Boersma, K.; Vlaeyen, J.W.S. The fear-avoidance model of musculoskeletal pain: current state of scientific evidence. Journal of Behavioral Medicine. v.30,n.1,p.77-94, 2007.

LIEBLER, E.J., et al. The effect of thoracic spine mobilization on lower trapezius strength testing. The Journal of Manual \& Manipulative Therapy. v.9, n.4, p.207-212, 2001.

LIMA-COSTA, M.F; BARRETO, S.M.; GIATTI, L. Condições de saúde e gastos com medicamentos da população idosa brasileira: um estudo descritivo baseado na Pesquisa Nacional por Amostra de Domicílios. Cadernos de Saúde Pública, Rio de Janeiro. v.19, n.3, p.735-743, 2003. 
LIMA, R.C.M; PESSOA, L.B.F; MARTINS, B.L.T; FREITAS, D.B.N., et al. Análise da durabilidade do efeito do alongamento muscular dos isquiotibiais em duas formas de intervenção. Acta Fisiátrica. Belo Horizonte. v.13, n.1,p. 3238, 2006.

LIMA, V. Ginástica laboral: atividade física no ambiente de trabalho. $2^{\mathrm{a}}$ ed. São Paulo - SP: Ed. Phorte, 2005.

LITTELL, R.C.; MILLIKEN, G.A.; SROUP, W.W.; WOLFINGER, R.D. SAS System for Mixed Models. Cary. NC: SAS Institute Inc., 1996.

LONG, D.M. Chronic back pain. In: Wall PD, Melzack R. Textbook of pain. Churchill Livingstone. 1999. Forth edition. United Kingdom. p. 539-558.

LOOZE, M; ZINZEN, E; CABOOR, D. Muscle strenght, task performance and low back load in nurses. Ergonomics. v.41,n.8, p.1095-1104, 1998.

LOPES, M.J.M.; LEAL, S.M.C. A feminilização persistente na qualificação profissional da enfermagem brasileira. Cadernos pagu, (24), janeiro-junho de 2005, p. 105-125.

LUVISOTTO, M.M.; VASCONCELOS, A.C.; SCIARPA, L.C.; CARVALHO, R. Atividades assistenciais e administrativas do enfermeiro na clínica médicocirúrgica. Einstein. São Paulo. v. 8, n. 2, p. 209-214, 2010.

MARTINS, G.A. Distribuições de Probabilidades de variáveis aleatórias discretas. In: Estatística Geral e Aplicada. 2 ed. São Paulo: Ed. Atlas, 2002. p. 95 a 97.

MARZIALE, M.H.P. Condições ergonômicas da situação de trabalho, do pessoal de enfermagem, em uma unidade de internação hospitalar. 1995. 163p. Tese (Doutorado em Enfermagem) - Programa de Pós-Graduação em Enfermagem Fundamental do Departamento de Enfermagem Geral e Especializada da Escola de Enfermagem de Ribeirão Preto, Universidade de São Paulo, Ribeirão Preto, 1995.

MARZIALE, M.H.P. Enfermeiros apontam as inadequadas condições de trabalho como responsáveis pela deteriorização da qualidade da assistência de enfermagem. Revista Latino-Americana de Enfermagem. Ribeirão Preto. v.9, n.3, p.1-5, 2001.

McARDLE, W.D.; KATCH, F.I.; KATCH V.L. Fisiologia do exercício: energia e nutrição e desempenho humano. Rio de Janeiro: Ed. Guanabara, 1998.

MENDES, R. Patologia do Trabalho. Rio de Janeiro. Atheneu. 1999.

MERSKEY. H.; BOGDUK. N. Classification of Chronic Pain. Descriptions of Chronic Pain Syndromes and Definitions of Pain Terms. (2nd Edition). IASP Press: Seattle. 1994.

MONTEIRO, W.; SIMÃO, R.; FARINATTI, P. Manipulação na ordem dos exercícios e sua influência sobre número de repetições e percepção subjetiva 
de esforço em mulheres treinadas. Revista Brasileira de Medicina do Esporte. Niterói. v.11, n.2, p. 146-150, 2005.

MORENO, M.,A. et al. (Ed). Efeito de um programa de alongamento muscular pelo método de Reeducação Postural Global sobre a força muscular respiratória e a mobilidade toracoabdominal de homens jovens sedentários. Jornal Brasileiro de Pneumologia. São Paulo. v.33,n.6, p.679-686, 2007.

MOSS, C.L.; WRIGHT, P.T. Comparison of three methods of assessing muscle strength and imbalance ratios of the knee. Journal of Athletic Train. Bowling Green. v.28, n.1, p.55-58,1993.

MUROFUSE, N.T; MARZIALE, M.H.P. Enfermedades del sistema osteomuscular em trabajadores de enfermería. Revista Latino-Americana de Enfermagem. Ribeirão Preto. v.13, n.3, p.364-373, 2005.

MUSCOLINO, JE; CIPRIANI, S. Pilates and the "powerhouse"- I. Journal of Bodywork and Movement Therapies. v.8, n.1, p. 15-24, 2004.

NACHEMSON, A. Back pain: delimiting the problem in the next millennium. International Journal of Law and Psychiatry. Sweden, v.22, p.473-490,1999.

NASCIMENTO, G.M. Estudo do absenteísmo dos trabalhadores de enfermagem em uma Unidade Básica e Distrital de Saúde do município de Ribeirão Preto. 2003. 118p. Dissertação (Mestrado em Enfermagem) - Escola de Enfermagem de Ribeirão Preto, Universidade de São Paulo, Ribeirão Preto, 2003.

NASCIMENTO, F.N.; ENNES, K.S.N. Qualidade de vida, postura e dor em funcionários administrativos da empresa tecmesul em Tubarão/SC. 2009. 58p. Trabalho de conclusão de curso apresentado ao curso de fisioterapia da Universidade di Sul de Santa Catarina, como requisito parcial à obtenção de grau de Bacharel em Fisioterapia, Universidade do Sul de Santa Catarina, Tubarão, 2009.

NELSON, A.G; KOOKKONEN, J; ARNALL, D.A. Acute Muscle Stretching Inhibits Muscle Strength Endurance Performance. Journal of Strength and Conditioning Research. Lousiana. v.19, n.2, p.338-343, 2005.

NEW WORLD ENCYCLOPEDIA, 2008. Disponível em: <http://www. Newworldencyclopedia.org/entry/ Body_cavity>. Acesso em set. 2010.

NIEMAN, C.,D. Exercício e Saúde como se prevenir as doenças usando o exercício com seu medicamento. São Paulo. Manole, 1999.

NORDIN, M.; ALEXANDRE; N.M.C.; CAMPELLO, M. Measures for low back pain: A proposal for clinical use. Revista Latino-americana de Enfermagem. Ribeirão Preto. v.11, n.2, p.152-159, 2003.

OLIVEIRA, B.R.G.; COLLET, N. Criança hospitalizada: percepção das mães sobre o vínculo afetivo criança-família. Revista Latino-Americana de Enfermagem. Ribeirão Preto. v.7, n.5, p.95-102,1999. 
OROFINO, C.I. Proposta de educação profissional com base em uma análise ergonômica do trabalho: Estudo de caso para as copeiras do Hospital Universitário da Universidade Federal de Santa Catarina. Dissertação (Mestrado em Engenharia) - Programa de Pós-Graduação em Engenharia de Produção, Universidade Federal de Santa Catarina (UFSC), Florianópolis, 2004.

Ossos da coluna vertebral. Disponível em: <http://emfermagemfaal2010.blogspot.com/2010/09/ossos-da-colunavertebral.html>. Acesso em: out. 2010.

OSTELO, R.W.J.G.; DE VET, H.C.W. Clinically important outcomes in low back pain. Best Practice Research Clinical Rheumatology. Amsterdam. v.19, n.4, p.593-607, 2005.

PANJABI, M.M. The stabilizing system of the spine. Part I. Function, dysfunction, adaptation and enhancement. Journal of Spinal Disorders \& Techniques. Florida. v. 5, n. 4, p. 383-389, 1992a.

The stabilizing system of the spine. Part II. Neutral zone and instability hypotesis. Journal of Spinal Disorders \& Techniques. Florida. v.5, n. 4, p. 390-396, 1992.

Clinical spinal instability and low back pain. Journal of Electromyography Kinesiology. New York. v.13, n. 4, p. 371-379, 2003.

PARKKOLA, R; RYTOTOSKI, U; KORMANO, M. Magnetic resonance imaging of the discs and trunk muscles in patients with chronic low back pain and healthy control subjects. Spine. v. 18, n. 7 p.830-836,1993.

PENTEADO, O. Braço de ferro. Boa Forma, São Paulo, 10 nov. 2010 Disponível em: <http://boaforma.abril.com.br/fitness/local-musculacao/bracoferro-528080.shtml?pagina=1a>. Acesso em set. 2010.

PHEASANT, S., STUBBS, D. Back pain in Nurses: epydemiology and risk assesment. Applied Ergonomics. Guildford. v.23, n.4, p. 226-231,1992.

PILATES, J. A. obra completa de Joseph Pilates - Sua saúde: 0 retorno à vida pela Contrologia. São Paulo: Ed. Phorte, 2010.

PINHO, L.; ARAÚJO, M.G.F.; GOES, S.R.; SAMPAIO, R.F. Dores na coluna em profissionais de enfermagem. Acta Fisiátrica. São Paulo. v.8, n.2 p.75-81, 2001.

POLLOCK, M.L.; GAESSER, G.A.; BUTCHER, J.D; DESPRÉS, J.P, et al. The recommended quantity and quality of exercise for developing and maintaining 
cardiorespiratory and muscular fitness, and flexibility in healthy adults. Medicine \& Science Sports \& Exercise. v.30, p.975-991,1998.

PONTE, C. Lombalgia em cuidados de saúde primários: sua relação com características sociodemográficas. Revista Portuguesa de Clínica Geral. v.21, n.3 p.259-267, 2005.

PONTES, H. A incidência da lombalgia em indústria de fundição: Um estudo de caso sob a ótica da ergonomia. 2005. Ponta Grossa. 137p. Dissertação (Mestrado em Engenharia de Produção) - Programa de Pós-Graduação em Engenharia de Produção do Departamento de Pesquisa e Pós-Graduação da Universidade Tecnológica Federal do Paraná, Ponta Grossa, 2005.

PORTO, C.C. Exame Clínico - bases para a prática médica. Goiânia. Guanabara Koogan. 4 ed. 2000.

PRADO, A.L.C.; FONSECA, P.H.S.; RODRIGUES, C.O.; VANZ, F. O Método Iso-stretching na otimização das aptidões para a prática do futebol de campo. Saúde. Santa Maria. v. 30, n. 1-2, p.57-64, 2004.

RAISTRICK, A. Nurses with back pain. Nursing Times. v.77, n.14, p.853-856, 1981.

RATHMELL, J.P. A 50-year-old man with chronic low back pain. JAMA. Massachusetts. v.299, n.17, p.2066-2077, 2008.

REIS, P.F.; MORO, A.R.P.; CONTIJO, L.A. A importância da manutenção de bons níveis de flexibilidade nos trabalhadores que executam suas atividades laborais sentados. 2003. Disponível em: <http:// www. ergonet.com.br/download/postura_sentada_flex.pdf>. Acessado em: abril, 2009.

RIO, R.P; PIRES, L. Ergonomia - Fundamentos da prática ergonômica. Belo Horizonte: Ed. Health, 1999.

RISSANEN, A.; KALIMO, H.; ALARANTA, H.; HAZARD, R.G. Effect of intensive trianing on the isokinetic strength and structure of lumbar muscles in patients with chronic low back pain. Spine. v. 20, n. 3, p. 333-340, 1995.

ROCHA, A.M. Fatores ergonômicos e traumáticos envolvidos na ocorrência de dor nas costas em trabalhadores de enfermagem. 1997. 151 p. Dissertação (Mestrado em Enfermagem) - Escola de Enfermagem da UFMG, Universidade Federal de Minas Gerais, Belo Horizonte, 1997.

ROSÁRIO, J.L.R.; MARQUES, A.P.; MALUF, S.A. Aspectos clínicos do alongamento: Uma revisão de Literatura. Revista Brasileira de Fisioterapia. São Carlos. v.8, n.1, p.83-88, 2004. 
ROSENTHAL, M. Agency for Health Care Policy \& Research. AHCPR Publication. n. 95-0642, 1994.

RUBINI, E.C; COSTA, A.L; GOMES, P.S. The effects of stretching on strength performance. Sports Medicine. Utah. v.37, n.3, p.213-224, 2007.

RYDEARD, R.; LEGER, A.; SMITH, D. Pilates-based therapeutic exercise: Effect on subjects with nonspecific chronic low back pain and functional disability: A randomized controlled trial. Journal of Orthopaedic \& Sports Physical Therapy. Ontário. v.36, n.7, p.472-482, 2006.

SACCO, I.C.N.; ANDRADE, M.S.; SOUZA, P.S; NISIYAMA, M., et al. Método Pilates em Revista: aspectos biomecânicos de movimentos específicos para reestruturação postural - Estudo de caso. Revista Brasil de Ciência e Movimento. Brasília. v.13, n.4, p.65-78, 2006.

SAFRAN, M.R.; SEABER, A.V.; GARRET, W.E. Warm-up and muscular injury prevention: an update. Sports Medicine. North Carolina. v.26, n.4, p.239-249, 1989.

SAHRMANN, S.A. Diagnosis and treatement of movement impairment syndromes. St. Louis: Mosby, 2002.

SALVETTI, M.G. Incapacidade em pessoas com dor lombar crônica: Prevalência e fatores preditores. 2010. 122p. Tese (Doutorado em Ciências)

- Escola de Enfermagem, Universidade de São Paulo, São Paulo, 2010.

SANTOS, P.R. Estudo do processo de trabalho da enfermagem em Hemodinâmica: cargas de trabalho e fatores de riscos à saúde do trabalhador. 2001. 145p. Dissertação (Mestrado em Ciências) - Escola Nacional de Saúde Pública, Fiocruz, Rio de Janeiro, 2001.

SCHALL, R. Estimation in generalized linear models with random effects. Biometrika. Oxoford. v. 78, n.4, p. 719-727, 1991.

SCHMIDT, D.R.C; DANTAS, R.A.S. Qualidade de vida no trabalho de profissionais de enfermagem, atuantes em unidades do bloco cirúrgico sob a ótica da satisfação. Revista Latino-Americana de Enfermagem. Ribeirão Preto. v.14, n.1, p.54-60, 2006.

SEBASTIÃO, B.A. Efeitos adversos na saúde de cirurgiões-dentistas e suas correlações com o uso de equipamentos motores. 2007. $72 \mathrm{f}$. Dissertação (Mestrado em Enfermagem) - Programa de Pós-Graduação em Enfermagem Fundamental do Departamento de Enfermagem Geral e Especializada da Escola de Enfermagem de Ribeirão Preto, Universidade de São Paulo, Ribeirão Preto, 2007.

SECCHI. K.,V., et al. Efeito do alongamento e do exercício contra-resistido no músculo esquelético de rato. Revista Brasileira de Fisioterapia. São Carlos. v.12, n.3, p.228-234,2008. 
SEGAL, N.A.; HEIN, J.; BASFORD, J.R. The effects of Pilates training on flexibility and body composition: An observational study. Archives of Physical Medicine and Rehabilitation. Lowa. v.85, n.12, p.1977-1981, 2004.

SEKENDIZ, B.; ALTUN, O.; KORKUSUZ,F.; AKIN,S. Effect of Pilates exercise on trunk strength, endurance and flexibility in sedentary adults females. Journal Bodywork Movement Therapy.Turkey. v.11, n.4, p.318-326, 2007.

SHERMAN, K.,J., et al. (Ed). Comparison of yoga versus stretching for chronic low back pain: protocol for the Yoga Exercise Self-care (YES) trial Sherman et al. Trials. Seattle. v.11, p.36-53, 2010.

SILVA, C.O.; BATTISTELLA, L.R.; KAVAMOTO, C.A.; LOPES, J.A.F., et al. Análise do ritmo lombar e pélvico durante a flexo-extensão da coluna vertebral em duas condições de simulação de levantamento de carga em policiais militares saudáveis. Acta Fisiátrica. São Paulo. v.11, n.3, p.117-124, 2004.

SILVA, D.M.P.P.; MARZIALE, M.H.P. Absenteísmo de trabalhadores de enfermagem em um hospital universitário. Revista Latino-Americana de Enfermagem. Ribeirão Preto. V. 8, n. 5, p. 44-51, 2000.

SISTO, S.A.; DYSON-HUDSON, T. Dynamometry testing in spinal cord injury. Journal of Rehabilitation Research and developemet. West Orange. v.44, n.1, p.123-136, 2007.

SMEDLEY, J; INSKIP, H; COOPER; COOPER, C., et al. Natural history of low back pain: a longitudinal study in nurses. Spine. New Hampshire. v.23, n.22, p.2422-2426,1998.

SMITH, L.K.; WEISS, E. L.; LEHMKUHL, L. D. Cinesiologia Clinica de Brunnstrom. São Paulo: Ed. Manole, 1997.

SMITH, L.K.; SMITH, E. Integrating Pilates-based core strengthening into older adult fitness programs - implications for practice. Topics in Geriatric Rehabilitation. Minneapolis. v.21, n.1, p.57-67,2005.

SOCIEDADE BRASILEIRA DE REUMATOLOGIA. Disponível em: < http://www.reumatologia.com.br> Acesso em out. 2010.

SOLOMONOW, M.; BARATTA, R.; ZHOU, B.; BURGER, E.; ZIESKE, A., et al.Muscular dysfunction elicited by creep of lumbar viscoelastic tissue. Journal of Electromyography and kinesiology, v. 13, p.381-396, 2003.

SÖLVEBORN, S. Guia completo de alongamento. 10 ed. Rio de Janeiro: Ed. Record, 2004.

SPALTEHOLZ, W.; SPANNER, R. Atlas de Anatomia Humana. Volume I Aparelho Locomotor, São Paulo: Ed Roca, 1988, p.42.

STUBBS, D.A.; BUCKLE, P.W.; HUDSON, M.P. Back pain in the nursing profession. Ergonomics. Oxon. v.26, n.8, p.767-769, 1983.

TEIXEIRA, M. J., et.al. Epidemiologia Clínica da Dor Músculo-Esquelética. Revista médica. São Paulo. v. 80, p.1-21. 2002. 
UENO, L.M., et al. Análise dos efeitos quantitativos e qualitativos de um programa de educação física sobre a flexibilidade do quadril em indivíduos com mais de 60 anos. Motriz. Revista de Educação Física. Rio Claro. v.6, n.1, p.916, 2000.

VERNIER, E.T.N.; DALL, 'AGNOLL, C.M. Reações de uma equipe de enfermagem diante a permanência conjunta pediátrica. Acta Paulista de Enfermagem. São Paulo. v.17, n.2, p.172-180, 2004.

VIGATTO, R.; ALEXANDRE, N.M.C.; CORREA FILHO, H.R.C. Development of a brazilian Portuguese version of the oswestry disability index. Spine. V. 32, n. 4, p. 481-486, 2007.

VIVEIROS, L., et al. Respostas agudas imediatas e tardias da flexibilidade na extensão do ombro em relação ao número de séries e duração do alongamento. Revista Brasileira de Medicina do Esporte. Niterói. v.10, n.6, p.459-463, 2004.

WALL, P.D.; MELZACK, R.; LONG, D.M. Chronic back pain. In: Textbook of pain. United Kingdom. Churchill Livingstone, 1999. Forth edition. 1999. p. 539558.

WALSH, I.A.P.; OISHI, J.; COURY, H.J.C.G. Clinical and functional aspects of work -related musculoskeletal disorders among active workers. Revista Saúde Pública. São Paulo. v.42, n.1, p.108-116, 2008.

WHO - WORLD HEALTH ORGANIZATION. Towards a common language for functioning, Disability and Health - ICF. (WHO/EIP/GPE/CAS/01.3) Genebra, 2002.

WITTINK, H. Functional capacity testing in patient chronic pain. Clinical Journal of pain. v.21, n.3, p.197-199, 2005.

WORRELL, T.W.; SMITH, T.L.; WINEGARDER, J. Effect of hamstring stretching on hamstring muscle desempenho. Journal of Orthopedic \& Sports Physical Therapy. v.20, n.3, p.154-159, 1994. 


$$
\mathcal{A P} \hat{\mathcal{E}} \mathcal{N D I C E S}
$$


APÊNDICE A

\section{TERMO DE CONSENTIMENTO LIVRE E ESCLARECIDO}

\section{ESCLARECIMENTO AOS SUJEITOS DA PESQUISA}

Prezado(a) $\operatorname{Sr}(a)$ :

Você está sendo convidado(a) a participar da pesquisa intitulada Exercícios físicos baseados no método Pilates: Uma proposta de tratamento para profissionais da enfermagem com lombalgia crônica idiopática. Este estudo tem por objetivo aplicar um protocolo de exercícios físicos baseado no método Pilates em profissionais da enfermagem com lombalgia crônica idiopática que lidam com pacientes com alto grau de dependência física (Neurocirurgia, Neuroclínica, CTI adulto e Ortopedia) e avaliar a melhora da função motora dos músculos extensores de tronco, dos abdominais e a flexibilidade de tronco e região lombar e com isso, promover a melhora da dor lombar em decorrência dos desajustes neuromusculares.

Os dados coletados serão destinados à elaboração de minha tese de doutorado a qual será apresentada ao Programa de Pós-Graduação na área de Enfermagem Fundamental do Departamento de Enfermagem Geral e Especializada da Escola de Enfermagem de Ribeirão Preto da Universidade de São Paulo - USP e posteriormente publicados.

Se você aceitar participar dessa pesquisa, você deverá preencher os dois questionários, um referente aos dados pessoais e o outro referente à incapacidade causada pela dor lombar (OSWESTRY), realizando o teste de flexibilidade de tronco e o teste de força muscular, bem como participando das sessões de exercícios físicos numa freqüência de duas vezes por semana com sessões de 45 minutos.

O estudo em questão não implica em nenhum ônus para o participante tendo o mesmo a liberdade de se recusar a participar da pesquisa ou retirar o seu consentimento em qualquer fase da mesma sem nenhuma penalização. $O$ voluntário também não sofrerá com nenhum desconforto durante o processo avaliatório nem com a realização dos exercícios e terá como benefício 
esperado a dor lombar amenizada ou até abolida ao final do tratamento. $O$ participante não terá gastos com materiais e acessórios utilizados durante as sessões, mas deverá participar das mesmas trajado adequadamente com roupas de ginástica e descalço.

Você deverá comunicar a pesquisadora da necessidade de ministração de medicação analgésica ou antiinflamatória para a dor lombar e a data de quando o fizer para que não haja interferência nos resultados da pesquisa.

Não haverá indenização com eventuais danos referentes à pesquisa por essa não oferecer nenhum risco à integridade física do participante.

Sendo assim, de acordo com o Projeto ora descrito, eu, ,RG

concordo em participar, voluntariamente, da pesquisa descrita acima desde que esta não implique em riscos ou desconforto a minha saúde física e/ou mental e que os dados obtidos serão mantidos em sigilo quanto a minha identificação.

Ribeirão Preto, de de 2009.

Assinatura do pesquisador responsável Assinatura do participante

Contato com Pesquisadora:

Barbara Aparecida Sebastião Franco

Departamento de Enfermagem Geral e Especializada

Av. Bandeirantes, 3900 - Campus da USP

CEP: $14048-900$

Ribeirão Preto/SP

Fone/Fax: (16) 36023430 / 91811461

e-mail: basfisio@usp.br 


\section{PRÉ-AVALIAÇÃo}

1. Iniciais do Nome:

2. Sexo: ( ) M; ( ) F

3. Você está grávida? ( ) S; （）N

4. Você já realizou cirurgias em coluna vertebral e/ou tem histórias de fraturas na coluna vertebral? ( ) S; ( ) N

5. Você tem diagnóstico de doenças reumáticas e/ou desordens metabólicas?

( )S; ( ) N

6. Possui lombalgia crônica com irradiação periférica de dor por, pelo menos, 3 meses, constatado através de prontuário médico? ( ) S; ( ) N

7. Pratica atividade física regular nos últimos cinco anos? ( )S; ( ) N

8. Realizou tratamento fisioterapeutico no último ano? ( )S; ( ) N

9. Possui evidência de comprometimento neurológico ou processo inflamatório agudo? ( )S; ( ) N 


\section{APÊNDICE C}

\section{FORMULÁRIO DE DADOS PESSOAIS}

1. Nome:

2. Sexo: ( ) Masculino; ( ) Feminino

3. Data de nascimento:

4. Peso: $\mathrm{Kg}$

5. Altura: $\mathrm{m}$

6. Fuma: ( ) Sim;

( ) Não

6.1 Se sim, quantos cigarros por dia:

7. Toma café: ( ) Sim; ( ) Não

7.1 Quantas xícaras por dia:

8. Consome bebida alcoólica freqüentemente: ( ) Sim;

( ) Não
8.1
Quantas vezes por semana:

9. Como você se locomove no trajeto casa-trabalho:
( ) à pé
( ) ônibus
( ) vã
( ) carro
( ) Moto
( ) outros

10. Qual a duração do trajeto: $\min$.

11. Qual sua profissão: ( ) Enfermeiro; ( ) auxiliar de enfermagem

12. Em que setor atua?

13. Quantas horas trabalha por dia:

14. Quantos dias por semana:

15. Trabalha em mais de um lugar? ( ) Sim; ( ) Não

16. Se sim, quantos?

17. Em qual turno trabalha: ( ) matutino; ( ) vespertino; ( ) noturno

18. Qual a postura física mais adotada em sua rotina de trabalho:

19. Qual a porcentagem do seu turno você permanece nessa postura: 
Para questões 18 e 19, ver figura no verso:

Posição das pernas

Posição do dorso

$\overline{\text { Em pé,parado }} \overline{\text { Em pé andando }} \overline{\text { Agachado }} \overline{\text { Sentado }}$

Ereto

Torcido


APÊNDICE D

PROTOCOLO 1: EXERCÍCIOS FíSICOS BASEADOS NO MÉTODO PILATES

\begin{tabular}{|c|c|c|c|}
\hline ORDEM & EXERCÍCIO & REPETIÇÕES & VARIAÇÃO DA 11a A 20ㄹ SESSÃO \\
\hline 1 & $\begin{array}{l}\text { Breathing } \\
\text { (Respiração) }\end{array}$ & 10 & $\begin{array}{l}\text { Os antebraços flexionados com uma mão } \\
\text { sobre o tórax e a outra sobre o abdômen } \\
\text { passa para a postura de braços alongados } \\
\text { e posicionados ao longo do tronco. }\end{array}$ \\
\hline 2 & $\begin{array}{l}\text { Articulating sholder } \\
\text { Bridge (Ponte) }\end{array}$ & 10 & Não há. \\
\hline 3 & $\begin{array}{l}\text { Single Leg Circles } \\
\text { (Círculo com uma } \\
\text { perna) }\end{array}$ & 10 & $\begin{array}{l}\text { A perna que não realiza o círculo passou de } \\
\text { flexionada com o pé apoiado no chão para a } \\
\text { posição de estendida com os dedos dos pés } \\
\text { alongados. }\end{array}$ \\
\hline 4 & Hundred (Cem) & 10 & $\begin{array}{l}\text { Elevação da cervical e elevação das pernas } \\
\text { a } 90^{\circ} \text { com as coxas. }\end{array}$ \\
\hline 5 & $\begin{array}{l}\text { Single leg stretch } \\
\text { (Alongamento de } \\
\text { uma perna) }\end{array}$ & 10 & $\begin{array}{l}\text { O exercício deveria ser realizado com } \\
\text { ambas pernas estendidas. }\end{array}$ \\
\hline 6 & $\begin{array}{l}\text { Swimming } \\
\text { (Nadando) }\end{array}$ & 10 & $\begin{array}{l}\text { Os braços foram elevados acima da } \\
\text { cabeça, estendidos, com as palmas das } \\
\text { mãos voltadas para baixo. }\end{array}$ \\
\hline
\end{tabular}

7

Cat (gato)

10

Elevação de braços e pernas alternados.

\begin{tabular}{|c|c|c|c|}
\hline 8 & $\begin{array}{l}\text { Push Up (Empurrar } \\
\text { para cima) }\end{array}$ & 10 & $\begin{array}{l}\text { Caminhar para frente até apoiar-se nos } \\
\text { cotovelos e retornar a posição inicial do } \\
\text { exercício. }\end{array}$ \\
\hline 9 & $\begin{array}{l}\text { Standing footwork } \\
\text { (Trabalhando com } \\
\text { os pés }\end{array}$ & 10 & $\begin{array}{l}\text { Elevação e abaixamento dos calcanhares } \\
\text { durante a manutenção da flexão dos } \\
\text { joelhos. }\end{array}$ \\
\hline 10 & Mermaid (Sereia) & 10 & Não há. \\
\hline
\end{tabular}




\section{PROTOCOLO 2: EXERCÍCIOS DE ALONGAMENTO E FORTALECIMENTO CONVENCIONAIS}

\begin{tabular}{|c|c|c|c|}
\hline ORDEM & EXERCÍCIO & REPETIÇÕES & VARIAÇÃO DA 11ª A 20ㄹ SESSÃO \\
\hline 1 & $\begin{array}{l}\text { Reeducação } \\
\text { Respiratória }\end{array}$ & 10 & $\begin{array}{l}\text { Os antebraços flexionados com uma mão } \\
\text { sobre o tórax e a outra sobre o abdômen } \\
\text { passa para a postura de braços alongados } \\
\text { e posicionados ao longo do tronco. }\end{array}$ \\
\hline 2 & $\begin{array}{l}\text { Articulating sholder } \\
\text { Bridge (Ponte) }\end{array}$ & 10 & Não há \\
\hline 3 & Abdominais & 10 & $\begin{array}{l}\text { Braços elevados atrás da cabeça com as } \\
\text { mãos apoiadas sob a nuca com uma palma } \\
\text { da mão sobre a outra de modo que os } \\
\text { cotovelos permaneçam abertos. }\end{array}$ \\
\hline 4 & $\begin{array}{l}\text { Alongamento de } \\
\text { Isquiotibais (IT) }\end{array}$ & 3 & Extensão das duas pernas. \\
\hline 5 & $\begin{array}{l}\text { Fortalecimento de } \\
\text { tronco }\end{array}$ & 10 & $\begin{array}{l}\text { Elevação de perna e braço contralateral } \\
\text { com manutenção do alinhamento do tronco. }\end{array}$ \\
\hline 6 & $\begin{array}{l}\text { Fortalecimento de } \\
\text { ombros }\end{array}$ & 10 & $\begin{array}{l}\text { Apoio nas mãos e nos antepés apenas } \\
\text { durante a execução do exercício. }\end{array}$ \\
\hline 7 & $\begin{array}{l}\text { Alongamento de } \\
\text { tronco anterior }\end{array}$ & 3 & Não há. \\
\hline 8 & $\begin{array}{l}\text { Fortalecimento de } \\
\text { quadríceps com } \\
\text { inclinação anterior } \\
\text { de tronco }\end{array}$ & 10 & Não há. \\
\hline 9 & $\begin{array}{l}\text { Alongamentos } \\
\text { cervicais (inclinação, } \\
\text { rotação, flexão e } \\
\text { extensão) em } \\
\text { posição ortostática }\end{array}$ & 3 & Não há. \\
\hline 10 & $\begin{array}{l}\text { Alongamento de } \\
\text { adutores de quadril }\end{array}$ & 3 & Elevação dos braços em posição de "V". \\
\hline
\end{tabular}


00000

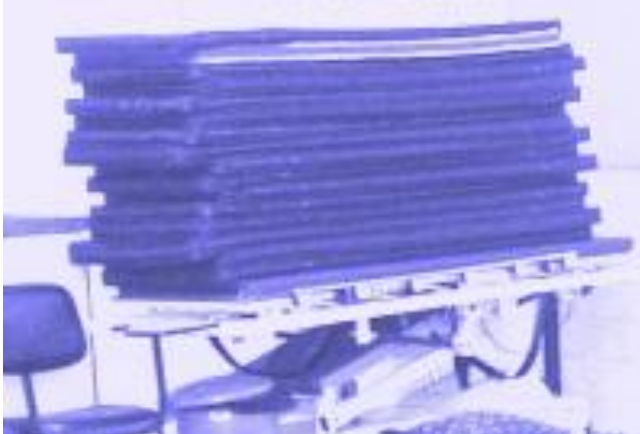

i 1

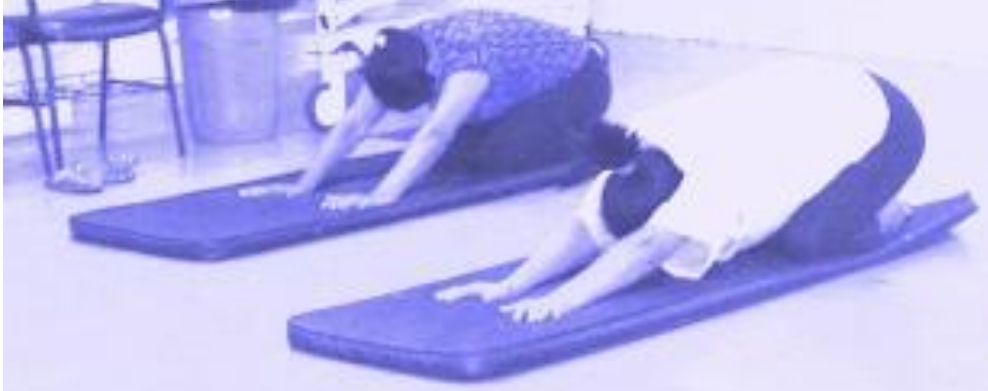

$\mathcal{A} \mathcal{N E X O S}$ 
ANEXO A

HOSPITAL DAS CLINICAS DA FACULDADE DE MEDICINA

DE RIBEIRAO PRETO DA UNIVERSIDADE DE SÄO PAULO

www.herp.fmrp.usp.br

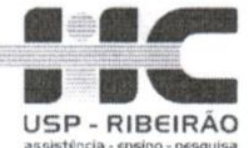

Ribeirão Preto, 15 de abril de 2009

Oficio $n^{\circ} 1164 / 2009$

$\mathrm{CEP} / \mathrm{MGV}$

Prezadas Senhoras,

O trabalho intitulado "EXERCícIos FísICOS

BASEADOS NO MÉTODO PILATES: UMA PROPOSTA DE TRATAMENTO PARA PROFISSIONAIS DA ENFERMAGEM COM LOMBALGIA CRÔNICA IDIOPÁTICA" foi analisado pelo Comitê de Ética em Pesquisa, em sua 284 ${ }^{\text {a }}$ Reunião Ordinária realizada em 13/04/2009 e enquadrado na categoria: APROVADO, bem como o Termo de Consentimento Livre e Esclarecido, de acordo com o Processo HCRP n $12957 / 2008$.

Este Comitê segue integralmente a Conferência Internacional de Harmonização de Boas Práticas Clinicas (IGH-GCP), bem como a Resolução $n^{\circ}$ 196/96 CNS/MS.

Lembramos que devem ser apresentados a este CEP, o

Relatório Parcial e o Relatório Final da pesquisa.

Atenciosamente.

$$
\begin{aligned}
& \text { tearenaw leamove } \\
& \text { DR MARCIA GUIMARÃES VILLANOVA } \\
& \text { Vice-Coordenadora do Comitê de Ética em } \\
& \text { Pesquisa do HCRP e da FMRP-USP }
\end{aligned}
$$

Ilustrissimas Senhoras

BÁRBARA APARECIDA SEBASTIÃO FRANCO PROF $^{\text {a }}$ DR $^{\text {a }}$ MARIA HELENA PALUCCI MARZIALE (Orientadora)

Escola de Enfermagem de Ribeirão Preto-USP 
ANEXO B

\section{QUESTIONÁRIO OSWESTRY PARA AVALIAÇÃO DA DOR LOMBAR}

Por favor, responda esse questionário. Ele foi desenvolvido para dar-nos informações sobre como seu problema nas costas ou pernas tem afetado a sua capacidade de realizar as atividades da vida diária. Por favor, responda a todas as seções. ASSINALE EM CADA UMA DELAS APENAS A RESPOSTA QUE MAIS CLARAMENTE DESCREVE A SUA CONDIÇÃO NO DIA DE HOJE.

\section{Seção 1 - Intensidade da Dor}

Não sinto dor no momento.

A dor é muito leve no momento.

A dor é moderada no momento.

A dor é razoavelmente intensa no momento.

A dor é muito intensa no momento.

A dor é a pior que se pode imaginar no momento.

\section{Seção 2 - Cuidados Pessoais (lavar-se, vestir-se, etc.)}

Posso cuidar de mim mesmo normalmente sem que isso aumente a dor.

Posso cuidar de mim mesmo normalmente, mas sinto muita dor.

Sinto dor ao cuidar de mim mesmo e faço isso lentamente e com cuidado.

Necessito de alguma ajuda, porém consigo fazer a maior parte dos meus cuidados pessoais.

Necessito de ajuda diária na maioria dos aspectos de meus cuidados pessoais.

$\square$ Não consigo me vestir, lavo-me com dificuldade e permaneço na cama.

\section{Seção 3 - Levantar Objetos}

Consigo levantar objetos pesados sem aumentar a dor.

Consigo levantar objetos pesados, mas isso aumenta a dor.

A dor me impede de levantar objetos pesados do chão, mas consigo levantá-los se estiverem convenientemente posicionados, por exemplo, sobre uma mesa.

A dor me impede de levantar objetos pesados, mas consigo levantar objetos leves a moderados, se estiverem convenientemente posicionados.

Consigo levantar apenas objetos muito leves. 
Não consigo levantar ou carregar absolutamente nada.

\section{Seção 4 - Caminhar}

A dor não me impede de caminhar qualquer distância.

$\square$ A dor me impede de caminhar mais de 1.600 metros (aproximadamente 16 quarteirões de 100 metros).

$\square$ A dor me impede de caminhar mais de 800 metros (aproximadamente 8 quarteirões de 100 metros).

$\square$ A dor me impede de caminhar mais de 400 metros (aproximadamente 4 quarteirões de 100 metros).

Só consigo andar usando uma bengala ou muletas.

Fico na cama a maior parte do tempo e preciso me arrastar para ir ao banheiro.

\section{Seção 5 - Sentar}

Consigo sentar em qualquer tipo de cadeira durante o tempo que quiser.

$\square$ Consigo sentar em uma cadeira confortável durante o tempo que quiser.

$\square$ A dor me impede de ficar sentado por mais de 1 hora.

A dor me impede de ficar sentado por mais de meia hora.

A dor me impede de ficar sentado por mais de 10 minutos.

A dor me impede de sentar.

\section{Seção 6 - Ficar em Pé}

Consigo ficar em pé o tempo que quiser sem aumentar a dor.

Consigo ficar em pé durante o tempo que quiser, mas isso aumenta a dor.

A dor me impede de ficar em pé por mais de 1 hora.

A dor me impede de ficar em pé por mais de meia hora.

$\square$ A dor me impede de ficar em pé por mais de 10 minutos.

A dor me impede de ficar em pé.

\section{Seção 7 - Dormir}

Meu sono nunca é perturbado pela dor.

Meu sono é ocasionalmente perturbado pela dor. 
Durmo menos de 6 horas por causa da dor.

Durmo menos de 4 horas por causa da dor.

Durmo menos de 2 horas por causa da dor.

A dor me impede totalmente de dormir.

\section{Seção 8 - Vida Sexual}

Minha vida sexual é normal e não aumenta minha dor.

Minha vida sexual é normal, mas causa um pouco mais de dor.

Minha vida sexual é quase normal, mas causa muita dor.

Minha vida sexual é severamente limitada pela dor.

Minha vida sexual é quase ausente por causa da dor.

A dor me impede de ter uma vida sexual.

\section{Seção 9 - Vida Social}

Minha vida social é normal e não aumenta a dor.

Minha vida social é normal, mas aumenta a dor.

A dor não tem nenhum efeito significativo na minha vida social, porém limita alguns interesses que demandam mais energia, como por exemplo, esporte, etc.

$\square$ A dor tem restringido minha vida social e não saio de casa com tanta freqüência.

$\square$ A dor tem restringido minha vida social ao meu lar.

Não tenho vida social por causa da dor.

\section{Seção 10 - Locomoção (ônibus/carro/táxi)}

Posso ir a qualquer lugar sem sentir dor.

Posso ir a qualquer lugar, mas isso aumenta a dor.

A dor é intensa, mas consigo me locomover durante 2 horas.

A dor restringe-me a locomoções de menos de 1 hora.

A dor restringe-me a pequenas locomoções necessárias de menos de 30 minutos.

A dor impede de locomover-me, exceto para receber tratamento.

"Development of a Brazilian Portuguese version of the Oswestry Disability Index. Cross-cultural adptation, reliability, and validity." 